\title{
Characterization of Carbonaceous Matter in Xenolithic Clasts from the Sharps (H3.4) Meteorite: Constraints on the Origin and Thermal Processing
}

Yoko Kebukawa $^{\mathrm{a} *}$, Michael E. Zolensky ${ }^{\mathrm{b}}$, Queenie H. S. Chan ${ }^{\mathrm{b}}$, Keisuke Nagao ${ }^{\text {c\#}}$, A. L. David Kilcoyne ${ }^{\mathrm{d}}$, Robert. J. Bodnar ${ }^{\mathrm{e}}$, Charles Farley ${ }^{\mathrm{e}}$, Zia Rahman ${ }^{\mathrm{f}}$, Loan Le ${ }^{\mathrm{f}}$, and George D. Cody ${ }^{\mathrm{g}}$

${ }^{a}$ Faculty of Engineering, Yokohama National University, 79-5 Tokiwadai, Hodogaya-ku, Yokohama 240-8501, Japan

${ }^{\mathrm{b}}$ ARES, NASA Johnson Space Center, 2101 NASA Parkway, Houston, TX 77058, USA

${ }^{\mathrm{c}}$ Geochemical Research Center, Graduate School of Science, University of Tokyo, Bunkyo-ku, Tokyo 113-0033, Japan

d Advanced Light Source, Lawrence Berkeley National Laboratory, 1 Cyclotron Road, Berkeley, CA 94720, USA

${ }^{\mathrm{e}}$ Department of Geosciences, Virginia Tech, Blacksburg, VA 24061, USA

f Jacobs - NASA Johnson Space Center, Houston, TX 77058, USA

${ }^{\mathrm{g}}$ Geophysical Laboratory, Carnegie Institution of Washington, 5251 Broad Branch Road, NW, Washington, DC 20015, USA

"Present address: Korea Polar Research Institute, 26 Songdomirae-ro, Yeonsu-gu, Incheon 21990, South Korea

* Corresponding author: kebukawa@ynu.ac.jp +81-45-339-3937 


\begin{abstract}
Primitive xenolithic clasts, often referred to as "dark clasts", are well known in many regolith breccias. The Sharps H3.4 ordinary chondrite contains unusually large dark clasts up to $\sim 1 \mathrm{~cm}$ across. Poorly-graphitized carbon (PGC), with Fe, Ni metal and described as "carbon-rich aggregates", has been reported in these clasts (Brearley, 1990). We report detailed analyses of carbonaceous matter in several identical Sharps clasts using FTIR, Raman, C-XANES, and TEM that provide insight on the extent of thermal processing and possible origin of such clasts. We also prepared acid residues of the clasts using the $\mathrm{HCl} / \mathrm{HF}$ method and conducted mass spectrometric analysis of the entrained noble gases.
\end{abstract}

Carbonaceous matter is often used to infer thermal history due to its sensitivity to thermal processes. The FTIR spectra of the acid residue from the Sharps clast suggest that carbonaceous matter in the clast contains less hydrogen and oxygen compared to acid residues from typical type 3.4 ordinary chondrites. The metamorphic temperatures obtained by Raman spectroscopy ranges between $\sim 380{ }^{\circ} \mathrm{C}$ to $\sim 490{ }^{\circ} \mathrm{C}$. TEM observations indicate that the clasts experienced a peak temperature of $300{ }^{\circ} \mathrm{C}$ to $400{ }^{\circ} \mathrm{C}$, based on the carbon $d_{002}$ layer lattice spacing of C-rich aggregates. These estimates are consistent with an earlier estimate of $330 \pm 50{ }^{\circ} \mathrm{C}$, that is also estimated by the $d_{002}$ layer lattice spacing (Brearley, 1990). It should be noted that the lattice spacing thermometer is based on terrestrial metamorphose rocks, and thus temperature was probably underestimated. Meanwhile, the C-XANES spectra of the C-rich aggregates show high exciton intensities, indicative of graphene structures that developed at around $700{ }^{\circ} \mathrm{C}$ to $800{ }^{\circ} \mathrm{C}$ following an extensive period of time (millions of years), however, the surrounding matrix areas experienced lower temperatures of less than $300{ }^{\circ} \mathrm{C}$ to $500{ }^{\circ} \mathrm{C}$. Noble gas analysis of the acid residue from the Sharps clasts shows that the residue is almost identical with some material 
reported in carbonaceous chondrites, i.e., heavily enriched in the Q-gas component as well as HL-gas from presolar diamonds and $\mathrm{Ne}-\mathrm{E}(\mathrm{H})$ from presolar $\mathrm{SiC}$.

These results indicate that the C-rich aggregates in the Sharps clasts formed under relatively high temperature conditions, up to $800{ }^{\circ} \mathrm{C}$, and were subsequently mixed with lower temperature matrix, probably in a different parent body, before they were incorporated into the final Sharps lithology by collision.

\section{INTRODUCTION}

The Sharps meteorite is an $\mathrm{H}$ group ordinary chondrite of petrologic type 3.4. The less altered type 3 ordinary chondrites, commonly referred to as unequilibrated ordinary chondrites (UOCs), are of considerable interest because they have been subjected to minimal hydrothermal alteration that could perturb their organic contents. UOCs generally contain more than $0.2 \mathrm{wt} \%$ of carbon (Moore and Lewis, 1967), which is composed of both organic and inorganic carbon (e.g., carbonate, diamond, graphite). Most of the carbon is present as organic material, a minor fraction of which is solvent-soluble organic matter (e.g., carboxylic acids, amino acids, nucleobases, aromatic hydrocarbons). The majority occurs as insoluble organic matter (IOM) or macromolecular carbon (MMC), which is not soluble in organic solvents, but can be isolated from the meteorite bulk by removing soluble organic matter and minerals through acid treatment (HF/HCl or CsF/HF) (e.g., Cronin and Chang, 1993; Cody et al., 2002; Pizzarello et al., 2006) or hydrous pyrolysis (Sephton, 2002; Sephton et al., 2003).

Primitive xenolithic clasts are often found in regolith breccias, especially carbonaceous chondrites, ordinary chondrites and howardites (e.g., Zolensky et al., 1992; Buchanan et al., 1993; Zolensky et al., 2009). These clasts show many similarities to type 1-2 carbonaceous 
chondrites, but significant differences also exist. Aggregates of carbonaceous material in the clasts were first identified in Allan Hills (ALH) A77011 (L3.5) (McKinley et al., 1981), and later were also found in some other ordinary chondrites, including Sharps (H3.4) (Scott et al., 1981a,b, 1988). The Sharps meteorite contains unusually abundant and large carbonaceous clasts up to $\sim 1$ cm across (e.g., Fredriksson, 1969). They were originally interpreted to be carbonaceous chondrites (Fredriksson, 1969), then reported to be an intergrowth of graphite and magnetite (Scott et al., 1981a,b), and finally, and more appropriately, as poorly-graphitized carbon (PGC) with $\mathrm{Fe}, \mathrm{Ni}$ metal, and described as "carbon-rich aggregates" that have only been identified in several ordinary chondrites, including Sharps, ALHA77011, ALHA78119, ALHA81024, Dimmitt, Plainview, and Weston (Brearley, 1990). The C-rich aggregates range in size from 5 to $1000 \mu \mathrm{m}$ and consist of a fine scale intergrowth of PGC, amorphous carbon, Fe, Ni metal, and minor Fe carbides and chromite, although well-crystallized graphite and magnetite are absent (Brearley, 1990). The empirical geothermometer of Rietmeijer and Mackinnon (1985) that is based on $d_{002}$ spacings of PGC and suggests formation temperatures on the order of $330 \pm 50{ }^{\circ} \mathrm{C}$, which is considerably lower than the proposed metamorphic temperatures $\left(\sim 450-500{ }^{\circ} \mathrm{C}\right.$; Dodd, 1981) for type 3.4 ordinary chondrites (Brearley, 1990).

The development of graphene (not graphite) domains in chondritic organic matter has been used as a thermometer, as it has been shown that such development is controlled by thermal processing (Cody et al., 2008b). Using scanning transmission X-ray microscopy (STXM) combined with carbon X-ray absorption near-edge structure (C-XANES) spectroscopy, the normalized intensity of the $1 \mathrm{~s}-\sigma^{*}$ exciton features provides a precise measurement of parent body metamorphism and, using a thermokinetic expression derived from the experimental data, enables the intensity of the $1 \mathrm{~s}-\sigma^{*}$ exciton to be used as an estimate of the effective temperature 
( $\left.T_{\mathrm{EFF}}\right)$ integrated over time (Cody et al., 2008b). A kinetic expression obtained by quantifying the intensity of the infrared primary vibrational mode spectral band of aliphatic $\mathrm{C}-\mathrm{H}$ upon heating can be also used to evaluate the thermal history of organic matter in carbonaceous chondrites (Kebukawa et al., 2010).

The metamorphic history of carbonaceous materials can also be inferred based on Raman spectral analysis that reveals the structural organization (order) of the polyaromatic organic phases. Carbonaceous materials exhibit Raman bands in the first- and second-order regions (Nemanich and Solin, 1979; Beyssac et al., 2002b). Typically, the most frequently examined peaks are the first-order defect (D) band at $\sim 1350 \mathrm{~cm}^{-1}$ and the graphite (G) band at $\sim 1580 \mathrm{~cm}^{-1}$ (Tuinstra and Koenig, 1970a, b). The peak parameters of the D and G bands for IOM, such as the peak center position, peak width, in terms of full width at half-maximum (FWHM), and peak intensity ratio have been correlated with independent (e.g. mineralogical) estimates of temperatures and the degree of thermal metamorphism (Busemann et al., 2007).

Carbonaceous residues which are obtained after acid demineralization of chondritic meteorites are known to contain high concentrations of primordial noble gases (e.g., Lewis et al., 1975). The carrier phase of these gases, a so-called "phase Q", is quite resistant to high temperatures and only releases these gases at $>1000{ }^{\circ} \mathrm{C}$, but is susceptible to oxidation. Phase Q is considered by many investigators to be carbonaceous (e.g., Lewis et al., 1975; Busemann et al., 2000), but the chemical structure of phase Q and the origin of the Q-gases are still subject to debate. It is not even known if this is a single phase, or rather a mixture of different phases. After decomposition of phase $\mathrm{Q}$ with oxidizing acid, presolar grains such as diamond, SiC, and graphite remain in the residue (e.g., Amari et al., 1994; Huss and Lewis, 1994, 1995; Lodders and Amari, 2005 and references therein). 
We present below results of a multi-pronged analyses of the carbonaceous matter in the Sharps clasts using Fourier transform infrared (FTIR) micro-spectroscopy, Raman spectroscopy, C-XANES, transmission electron microscopy (TEM), and noble gas analysis in order to better constrain the origin and thermal history of the Sharps carbonaceous clasts.

\section{SAMPLE AND ANALYTICAL METHODS}

\subsection{Sample preparation}

Samples of Sharps meteorite (USNM640) containing dark, mm-sized clasts were subsampled at the National Museum of Natural History; Smithsonian Institution (Washington DC) (Fig. 1). Sample preparation methods and analytical methods applied for each sample are summarized in Table 1.

For FTIR analysis, a small amount of clast material was crushed between two baked $\left(500^{\circ} \mathrm{C}, 3 \mathrm{~h}\right)$ glass slides, then pressed onto a $\mathrm{KBr}$ plate $(\sim 5 \times 5 \times 1 \mathrm{~mm})$ freshly cleaved from a $\sim 5 \times 5 \times 5 \mathrm{~mm}$ cube. STXM-XANES analysis requires a sample thickness on the order of 100$150 \mathrm{~nm}$, therefore, a 100 nm-thick section was subsampled from selected clast fragments using a Quanta 3d FEG focused ion beam (FIB) instrument at NASA/JSC. Some thin sections are also prepared using ultramicrotome (UMT). A small aliquot of the clast was embedded in supercooled high-purity molten sulfur, and attached to an epoxy stub. Ultra-thin sections of $\sim 100$ $\mathrm{nm}$ thickness were prepared with a LEICA ultramicrotome equipped with a diamond knife. These sections were then transferred to $\mathrm{SiO}$-coated TEM grids.

Acid residues were prepared using the $\mathrm{HCl} / \mathrm{HF}$ technique, in which the powdered clast samples were first leached with $2 \mathrm{~N} \mathrm{HCl}$ and $9 \mathrm{~N} \mathrm{HF}$ solution at room temperature for 12 days, followed by rinsing with milliQ water. The acid leaching procedure is similar to that applied to 
chondrites to recover residues enriched in Q-phase and other presolar grains (e.g., Lewis et al., 1975; Busemann et al., 2000 and references therein). For the FTIR analyses, the acid residue was deposited onto a $\mathrm{BaF}_{2}$ disk $(13 \times 1 \mathrm{~mm})$, and dried by mild heating $\left(<100{ }^{\circ} \mathrm{C},<15 \mathrm{~min}\right)$. After centrifugation of the residue-containing solution, the liquid was pipetted off before the solid residue was dried at $\sim 90{ }^{\circ} \mathrm{C}$ in air. For STXM-XANES analyses, the dried acid residue was mixed with high-purity sulfur powder and placed on a hot plate to melt the sulfur $\left(\sim 150{ }^{\circ} \mathrm{C}\right.$ for up to $\sim 30$ seconds). The molten sulfur droplet was subsequently cooled and attached to an epoxy stub using a dab of cyanoacrylate cement. Ultra-thin 100-150 nm thick sections were prepared with a LEICA ultramicrotome equipped with a diamond knife. These sections were then transferred to SiO-coated TEM grids and gently heated $\left(<100{ }^{\circ} \mathrm{C},<15 \mathrm{~min}\right)$ until the sulfur sublimed off the grid.

\subsection{FTIR spectroscopy}

Infrared absorption spectra were collected using a $\mu$-FTIR (Jasco FT/IR-6300 + IMV4000) at Carnegie Institution of Washington, with a ceramic infrared light source, a germanium-coated $\mathrm{KBr}$ beam splitter, a mercury-cadmium-telluride (MCT) detector, and $\times 16$ Cassegrainian mirrors. During analysis, the microscope and the FTIR were continuously purged with dry $\mathrm{N}_{2}$. A total of 1024 scans of infrared transmission spectra were accumulated with a wavenumber resolution of $4 \mathrm{~cm}^{-1}$, in the wavenumber range of $7000-600 \mathrm{~cm}^{-1}$, with a $50 \times 50$ or $80 \times 80 \mu \mathrm{m}^{2}$ aperture. Background spectra were acquired through the $\mathrm{KBr}$ or $\mathrm{BaF}_{2}$ plate adjacent to the samples.

\subsection{Raman spectroscopy}


Sulfur-mounted samples were analyzed using a Jobin-Yvon Horiba LabRam HR (800 mm) Raman microprobe at the Department of Geosciences, Virginia Tech. The operation parameters were as follows: Slit width $-150 \mu \mathrm{m}$; confocal hole $-400 \mu \mathrm{m}$; Gratings -600 grooves/mm; Excitation wavelength $-514.53 \mathrm{~nm}$ (green) (provided by Modu-Laser Stellar Pro-L $514 \mathrm{~nm}, 100 \mathrm{Mw}$ solid-state laser operated at $50 \mathrm{~mW}$ at the source); Objective - 40× (Numerical Aperture $=0.55$; the Raman probe spatial resolution at the analyzed spot was $1.1 \mu \mathrm{m}$ at this

magnification for the green laser); Spectral range $-100 \mathrm{~cm}^{-1}$ to $4000 \mathrm{~cm}^{-1}$, which includes the first- and second-order Raman bands of carbon; Number of accumulations - 3; three accumulated spectra were collected from each analytical spot to identify and discard spurious signals, such as those from cosmic rays. Wavelength calibration against a silicon wafer sample was checked daily prior to sample analyses.

Raman analysis of poorly-ordered polyaromatic organic materials is affected by the irradiation time and laser intensity, which should be carefully adjusted with reference to the size and optical characteristics of the samples in order to avoid irreversible thermal damage. Obvious thermal damage can be observed as laser-induced heating artifacts evidenced by a visibly burnt spot on the sample surface. In order to avoid laser damage, we set the exposure time to $10 \mathrm{~s}$ and used a D0.6 laser filter that reduced the laser intensity at the sample surface to $\sim 25 \%$ of its nominal value of $\sim 9 \mathrm{~mW}$, resulting in a laser intensity at the sample of $\sim 2.25 \mathrm{~mW}$. We also monitored the physical damage by taking images of the sample before and after laser scans. See the Appendix for more details.

\subsubsection{Curve-fitting and baseline correction}


Spectral parameters are obtained after appropriate baseline correction and peak decomposition. While some studies select a particular curve-fitting model to allow comparison with previous studies, there are also studies that used particular curve-fitting models that generated the best fit to their data, which makes quantitative comparison of data between different studies rather difficult. Weak fluorescence background was subtracted using a linear (Matrajt et al., 2004; Quirico et al., 2005a, 2009; Bonal et al., 2006, 2007; Busemann et al., 2007; Maslova et al., 2012; Kouketsu et al., 2014), spline (Muñoz Caro et al., 2006; Fries et al., 2011), and Lorentzian baseline (Nemanich and Solin, 1979).

The peak center positions $(\omega)$ and FWHM, $\Gamma$ of each Raman band were determined by simultaneous peak fitting to five Lorentzian profiles (one G and four D bands) and linear baseline correction was accomplished using custom software written in the Python programming language. We used a model that includes five Lorentzian profiles for the following reasons: (1) the Sharps clasts are composed of disordered graphitic carbon and the use of Voigt profiles increases the degrees of freedom which reduces the reproducibility for a given spectrum, (2) to facilitate comparison with previous studies (Bernard et al., 2010; Lahfid et al., 2010), (3) higher coefficient of determination $\left(r^{2}\right)$ values, indicating better fitting (see Fig. 2), and (4) further instrumental broadening effects can be solved by fixing an additional Gaussian width in the Voigt profile which is well represented by a pure Lorentzian profile (Meier, 2005). An example of peak decomposition is presented in Fig. 5. The fluorescence background in the Raman spectra is weak, therefore baseline removal was accomplished by subtracting a linear baseline defined by the two end points of the selected spectral range $\left(1000 \mathrm{~cm}^{-1}\right.$ to $1800 \mathrm{~cm}^{-1}$, which covers the overlapping carbon bands of interest). We disregarded spectra that showed a significant 
fluorescence contribution that results in a nonlinear baseline that could significantly affect the peak fitting results.

\subsection{STXM-XANES}

C-XANES micro-spectroscopy was performed using the STXM at beam line 5.3.2.2 of the Advanced Light Source, Lawrence Berkeley National Laboratory (Kilcoyne et al., 2003). The beam line is designed specifically for light elements, such as $\mathrm{C}, \mathrm{N}$, and $\mathrm{O} K$-edge energy regions. Soft X-rays generated by a bending magnet provided a useful photon range spanning from 250$780 \mathrm{eV}$ with a photon flux of $10^{7}$ photons $\mathrm{s}^{-1}$. Energy selection was performed with a lowdispersion spherical grating monochromator, affording an energy resolution $(E / \Delta E)$ of 5000; with most of our data at an energy resolution of $\sim 3000$, i.e., at $\sim 0.1 \mathrm{eV}$. Beam focusing utilized Fresnel zone plate optics for a theoretical spot size of $31 \mathrm{~nm}$. The C-XANES spectra were acquired using a multi-spectral imaging method ("Stacks" method; Jacobsen et al., 2000). The Stacks method relies on the acquisition of a series of pixelated X-ray absorption images over a range of energies that span a given XANES region. This generates an aligned hyperspectral data cube where every pixel contains a complete XANES spectrum. In the fine structure portions of the near-edge region (283-295.5 eV), the energy step size $(\triangle E)$ employed was $0.1 \mathrm{eV}$; in the less featured pre-edge (278-283 eV) and post-edge (295.5-301.0 eV) regions, energy steps of $0.5 \mathrm{eV}$ provided sufficient spectral resolution. The final span of extended X-ray absorption structure (EXAFS) oscillations decaying down to the slope of the atomic C absorption (301-340 eV) was adequately covered with energy steps of $2 \mathrm{eV}$. The acquisition time per energy step varied from 1 to $3 \mathrm{~ms}$. The C-XANES spectra were normalized to the intensity at $296 \mathrm{eV}$. 


\subsection{TEM}

We employed a JEOL 2000FX STEM with a Link EDX and image processing system, and a JEOL 2500SE field-emission scanning and transmission electron microscope (STEM), equipped with thin window Energy Dispersive X-Ray (EDX), Gatan imaging filter (GIF), highangle annular darkfield detector (HAADF) and $2 \mathrm{~K} \times 2 \mathrm{~K}$ slow scan $\mathrm{CCD}$ camera. Both instruments are located at the ARES Division, NASA Johnson Space Center.

\subsection{Noble gas mass spectrometry}

The Sharps carbonaceous clasts (Fig. 1) contain abundant $\sim \mu \mathrm{m}$ size carbon-rich grains. An aliquot of these was recovered from one clast by leaching silicates with $\mathrm{HCl} / \mathrm{HF}$ acid treatment as described above. The residue is mainly composed of PGC/glassy carbon with small amounts of organic carbon derived from the matrix of the clast.

The acid residue sample for noble gas analysis was prepared at the Carnegie Institution of Washington, and transferred to the University of Tokyo in a small plastic container filled with milliQ water $(<1 \mathrm{~mL})$. An aliquot of the sample was pipetted into an empty cup made of thin Alfoil (6 $\mu \mathrm{m}$-thick). The sample was then dried in air overnight at a temperature of $130{ }^{\circ} \mathrm{C}$. The weight of the sample used for noble gas analysis was $182.3 \mu \mathrm{g}$ and was determined precisely by subtracting the weight of empty cup $(4545.3 \mu \mathrm{g})$ from the weight of the cup with dried sample (4727.6 $\mu \mathrm{g})$, using an electric ultramicrobalance. A modified-VG5400/MS-III mass spectrometry system at the Geochemical Research Center, The University of Tokyo, was used for noble gas analyses. The sample was loaded in a side arm of a sample holder made of borosilicate glass attached to a newly-constructed extraction furnace designed for sub-mg sized samples. The furnace is connected to a noble gas purification line constructed in 2010 for noble gas analysis of 
the Hayabusa samples returned from asteroid Itokawa (Nagao et al., 2011). The sample was preheated in ultrahigh vacuum at $150{ }^{\circ} \mathrm{C}$ for about one day to remove atmospheric contamination. For noble gas extraction, the sample was dropped into a Mo-crucible placed in a Ta-tube, which could be heated from outside by radiation emitted from a W resistance heater. The temperature was recorded by a W-Re thermocouple set outside the Ta-tube and monitored and controlled by computer. Noble gas extraction from the sample was performed by stepwise heating at 300, 700, 1000,1500 , and $1750^{\circ} \mathrm{C}$, and the gases evolved at each temperature step were purified using two getter pumps (NP10 of SAES Getters S.p.A.). Among the purified noble gases, Ne, Ar, Kr, and Xe were adsorbed onto a cryogenically-cooled, sintered, stainless-steel trap (Cryo-trap) at $20 \mathrm{~K}$. Helium, which remains in the gas phase, was introduced into the mass spectrometer for isotope analysis. After He analysis, $\mathrm{Ne}, \mathrm{Ar}, \mathrm{Kr}$, and Xe were successively desorbed from the Cryo-trap at temperatures of 50,110, 150, and $230 \mathrm{~K}$, respectively, and analyzed with the mass spectrometer.

Sensitivities and mass discrimination correction factors of the mass spectrometer were determined by measuring known amounts of atmospheric noble gases and a ${ }^{3} \mathrm{He}-{ }^{4} \mathrm{He}$ mixture with ${ }^{3} \mathrm{He} /{ }^{4} \mathrm{He}=1.71 \times 10^{-4}$. Uncertainty in the ${ }^{3} \mathrm{He} /{ }^{4} \mathrm{He}$ ratio of the mixture is estimated to be $\approx$ 1\% (Nagao et al., 2010). Blank corrections were applied to noble gas data. Typical blank levels

for ${ }^{4} \mathrm{He},{ }^{20} \mathrm{Ne},{ }^{36} \mathrm{Ar},{ }^{40} \mathrm{Ar},{ }^{84} \mathrm{Kr}$, and ${ }^{132} \mathrm{Xe}$ at $1750{ }^{\circ} \mathrm{C}$ were $2.7 \times 10^{-11}, 5.6 \times 10^{-13}, 3.0 \times 10^{-12}, 8.6$ $\times 10^{-10}, 1.7 \times 10^{-14}, 4.3 \times 10^{-15} \mathrm{~cm}^{3} \mathrm{STP}$, respectively

\section{RESULTS}

Overall, most of the carbon in the clasts occurs in C-rich aggregates. There are some carbonaceous materials in the clast matrix but the concentration is very low compared to C-rich aggregates (see STXM C-map in Fig. 7). Therefore, one can consider that a majority of the acid 
residue from the clast to consist of C-rich aggregates, and the Raman D- and G-band signatures represent mostly C-rich aggregates. It should be noted that various analytical methods were applied to the different clasts and some methods were used on more than one clast (Table 1), and, in general, different clasts all show nearly identical compositional characteristics, e.g., CXANES of FIB\#1 (clast 2), FIB\#2 (clast 3), and UMT (clast 4) samples all show similar compositional characteristics, consistent with what was previously reported (Brearley, 1990).

\subsection{FTIR analyses}

The FTIR spectra (Fig. 3) of the Sharps clasts exhibit a broad $3400 \mathrm{~cm}^{-1}$ absorption band characteristic of $\mathrm{O}-\mathrm{H}$ stretching modes $(\mathrm{OH}$ in hydrous minerals with some contribution from terrestrial adsorbed water), a weak triplet absorption band near $2900 \mathrm{~cm}^{-1}$ characteristic of aliphatic $\mathrm{C}-\mathrm{H}$ stretching modes (including $2960 \mathrm{~cm}^{-1}$ assigned to $\mathrm{CH}_{3}$ asymmetric stretching, $2925 \mathrm{~cm}^{-1}$ assigned to $\mathrm{CH}_{2}$ asymmetric stretching, and $2855 \mathrm{~cm}^{-1}$ assigned to symmetric $\mathrm{CH}_{3}$ and $\mathrm{CH}_{2}$ stretching), a broad absorption band centered at $1585 \mathrm{~cm}^{-1}$ characteristic of aromatic $\mathrm{C}=\mathrm{C}$ stretching modes, and intense absorption bands in the range 1100 to $800 \mathrm{~cm}^{-1}$ assigned to $\mathrm{Si}-\mathrm{O}$ stretching of silicates. The FTIR spectra (Fig. 3) of the Sharps clast acid residue is essentially featureless, only a very weak, broad band around $1570 \mathrm{~cm}^{-1}$ is apparent and is likely due to aromatic $\mathrm{C}=\mathrm{C}$. The $1570 \mathrm{~cm}^{-1}$ band could be due to an absorption of $\mathrm{H}_{2} \mathrm{O}$, but it is not likely in this case because there should also be a band at $3400 \mathrm{~cm}^{-1}$. The very weak signal for the aromatic $\mathrm{C}=\mathrm{C}$ band indicates that the acid residue is mainly composed of a graphite-like structure that has

no infrared absorption in the range $4000-800 \mathrm{~cm}^{-1}$. The majority of aliphatics shown in the Sharps clast before acid treatment must therefore be in the form of soluble compounds and/or surface contamination associated with silicates. 
The Si-O band characteristic in the FTIR spectrum of the clast (Fig. 3, top) is similar to dehydrated carbonaceous chondrites $(\mathrm{CO}, \mathrm{CV}, \mathrm{CK}, \mathrm{CB}$ and $\mathrm{CH})$, but not to hydrated carbonaceous chondrites (CI, CM and CR) (Osawa et al., 2005; Beck et al., 2014). The positions of peaks at 1072,964 , and $883 \mathrm{~cm}^{-1}$ in the $\mathrm{Si}-\mathrm{O}$ band region are indicative of dominated in olivine and pyroxene rather than phyllosilicates (Beck et al., 2014).

\subsection{Raman analyses}

The structure of crystalline graphite belongs to the $\mathrm{D}_{6 \mathrm{~h}}{ }^{4}$ space group symmetry with vibration modes $2 \mathrm{E}_{2 \mathrm{~g}}+2 \mathrm{~B}_{2 \mathrm{~g}}+\mathrm{E}_{1 \mathrm{u}}+\mathrm{A}_{2 \mathrm{u}}$. Only the $2 \mathrm{E}_{2 \mathrm{~g}}$ double degenerate in-plane vibration modes are Raman active, and the $\mathrm{E}_{2 \mathrm{~g} 2}$ corresponds to the single sharp $\mathrm{G}$ band. In the case of a polycrystalline graphitic material, the strain fields in individual crystallites contribute to peak broadening of the overall $\mathrm{G}$ band. A single crystal of graphitic material, however, will feature a narrow peak width arising from a single crystal structure with a relatively equilibrated, uniform strain environment. Therefore, a sharp $\mathrm{G}$ band indicates the presence of well-crystalline graphitic materials. The Raman spectra of finite-sized microcrystallites (in-plane crystallites diameter, $L_{a}$ $<1000 \AA$ ) and materials with disrupted crystal symmetry (i.e., increasing the degree of disorder by introducing edges, defects) contain D bands (Wang et al., 1990) which are not present in perfectly stacked graphite. So far, four D bands have been observed in the first order region, including the D1 $\left(\sim 1350 \mathrm{~cm}^{-1}\right), \mathrm{D} 2\left(\right.$ or D') $\left(\sim 1620 \mathrm{~cm}^{-1}\right), \mathrm{D} 3\left(\sim 1510 \mathrm{~cm}^{-1}\right)$ and $\mathrm{D} 4\left(\sim 1200 \mathrm{~cm}^{-1}\right)$ bands (Beyssac et al., 2002b; Bernard et al., 2010; Kouketsu et al., 2014). The D1 band is considered to be the result of in-plane defects resulting from the presence of heteroatoms such as hydrogen, nitrogen and oxygen (Beny-Bassez and Rouzaud, 1985), but the specific origin and corresponding vibration modes of the other D-bands are still unresolved. 
Numerous studies have documented variations in the Raman spectral characteristics of carbon as a function of the structural state of the material, that, in turn, reflects the thermal history. In the most general case, the "G" band is characteristic of well-ordered (graphitic) carbon and the "D" band characterizes disordered or amorphous carbon. Busemann et al. (2007) note that the D and G bands both show a systematic decrease in the peak width (FWHM) with increasing meteorite petrologic types as determined through mineralogical indicators, as does the intensity ratio $\left(I_{\mathrm{D}} / I_{\mathrm{G}}\right)$ of the two bands, while other authors reported the lack of clear correlations between G band width and metamorphic degree (Quirico et al., 2003, 2011). Moreover, Kouketsu et al. (2014) examined carbonaceous matter in low grade terrestrial regionally metamorphosed rocks and concluded that the FWHM values of D1- and D2-bands show almost linear relations with temperature in the range of approximately $150-400{ }^{\circ} \mathrm{C}$. However, because the D2 band overlaps with the G band (Fig. 5) and peak deconvolution is required to quantify the FWHM of the D2 band, this correlation is not commonly used. The center position of the G band is a function of the energy of vibrational modes in the crystalline domains where larger, more equilibrated domains exhibit less overall edge-induced strain, and thus represents the mean size of those domains. FWHM is a function of the distribution of the sizes of crystalline domains (Bower et al., 2013). The combination of these peak parameters describes the overall size distribution of the crystalline domains. In general, crystalline domains are larger for materials processed at higher temperatures; therefore the peak parameters may be used to interpret the metamorphic history of the host. The relative intensity between the D1 and G bands $\left(I_{D} / I_{G}\right)$ is one common method used to determine $L_{a}$ and quantify the defects in carbonaceous matter, and another is the relationship between peak position and FWHM for the G band alone (e.g., Fries et al., 2011). 
$I_{D} / I_{G}$ can be used to estimate $L_{a}$; however, it strongly depends on (1) the wavelength of the incident laser source and (2) the graphitization ability of the material (Wang et al., 1990; Sood et al., 2001). Therefore, without some initial understanding of the chemical composition and alteration history of a sample, it is rather difficult to characterize the organic composition and metamorphic grade of the sample based on the peak parameters of the D and G bands alone. Thus, interpretation and comparison of the structural order or metamorphic grade of IOM is only valid for samples with similar organic compositions.

While the $\mathrm{G}$ band corresponds to stretching in both carbon rings and chains, the $\mathrm{D}$ band is caused by the breathing modes in rings and thus corresponds only to aromatic structures (Castiglioni et al., 2004; Ferrari and Robertson, 2004). The Raman spectra of the Sharps clast show a significant $\mathrm{D}$ band contribution, which indicates the presence of highly disordered aromatic materials. The second-order region is useful for studying highly graphitic materials, and since the Sharps clast is composed of disordered graphitic carbon, we will not discuss the second-order region in further detail.

\subsubsection{Metamorphic grade and peak metamorphic temperatures (PMT)}

The metamorphism of carbon ("Graphitization") is an irreversible process (unaffected by retrograde metamorphic events) that alters the structure of carbonaceous matter in response to the increase in metamorphic grade (time, temperature and/or pressure). Therefore, carbonaceous materials offer a reliable geothermometer for the study of the peak metamorphic temperature (PMT) a sample has experienced. It has been shown that Raman spectra of carbonaceous matter in terrestrial rocks change systematically with increasing metamorphic grade (Beyssac et al., 2002a; Kouketsu et al., 2014). Raman spectroscopic analysis of carbonaceous material has also 
been extensively used to investigate the thermal history of meteorites (e.g., Bonal et al., 2007; Busemann et al., 2007). A typical raw Raman spectrum of the Sharps clast is shown in Fig. 4 and the peak parameters of all analyzed spots are listed in Table A1 (Appendix). Raman spectra with low fitting coefficients $\left(r^{2}<0.99\right)$ or high fluorescence background were not considered in this study. As shown in Fig. 4, the Raman spectrum of the Sharps clast consists of distinctive carbon bands in the first- $\left(1100 \mathrm{~cm}^{-1}\right.$ to $\left.1800 \mathrm{~cm}^{-1}\right)$ and second-order $\left(2200 \mathrm{~cm}^{-1}\right.$ to $\left.3400 \mathrm{~cm}^{-1}\right)$ regions. The first-order region is composed of two major peaks that correspond to the G and D1 to D4 bands. The spectrum is characterized by a broad $\mathrm{D}$ band $\left(\Gamma_{\mathrm{D}}=146 \pm 6 \mathrm{~cm}^{-1}\right)$ and a $\mathrm{G}_{\mathrm{L}}$ band (composed of the $\mathrm{G}$ and $\mathrm{D} 2$ bands) at around $1610 \mathrm{~cm}^{-1}$. While the D4 band is a small saddle on the D1 band and D3 occurs between the two major bands, the D2 band is only observable after peak deconvolution (fitting) (Fig. 5), of which the uncertainties can be represented by the standard error of each band.

A gradual change in the shape of Raman spectra of graphitic carbon has been shown for terrestrial metamorphic rocks with different PMT (Buseck and Beyssac, 2014). A visual comparison of the overall shape of the Raman spectrum (Fig. 5) suggests that the Sharps clast has been metamorphosed to the terrestrial equivalent of greenschist grade (with $T=300{ }^{\circ} \mathrm{C}$ to $360^{\circ} \mathrm{C}$ ). With increasing metamorphic grade, the intensity of the D1 band decreases relative to the $\mathrm{G}$ band. While the $\mathrm{G}$ band becomes narrower, the $\mathrm{D} 1$ band disappears above $700{ }^{\circ} \mathrm{C}$. The $\mathrm{D}$ and $\mathrm{G}$ band widths also decrease with increasing metamorphism (Busemann et al., 2007). The broad $\mathrm{G}\left(\Gamma_{\mathrm{G}} \sim 60 \mathrm{~cm}^{-1}\right)$ and $\mathrm{D} 1\left(\Gamma_{\mathrm{D} 1} \sim 140 \mathrm{~cm}^{-1}\right)$ bands of the Sharps clast indicate that the meteorite has experienced only low temperature. Meteorites that have experienced high temperatures show higher second-order band intensity at $2700 \mathrm{~cm}^{-1}$ (S1 band) with respect to $2900 \mathrm{~cm}^{-1}$ (S2 band) (Beyssac et al., 2002a; Bonal et al., 2007). Thus, the presence of the D3 
band in the first-order region and the two broad S1 and S2 bands in the second-order region indicate that Sharps was not heated above $400{ }^{\circ} \mathrm{C}$ after incorporation of the carbonaceous clasts into the present structure.

Empirically derived Raman geothermometers have been formulated to relate the changes in Raman spectral parameters with the degree of thermal metamorphism. These Raman thermometers are generally calibrated by independent estimates of temperature (e.g., mineral equilibria and other temperature-dependent inorganic processes); this is true in the case of both terrestrial and extraterrestrial Raman based thermometers, i.e., laboratory based thermokinetic experiments have not been used to calibrate Raman based estimates of thermal transformation.

Extraterrestrial material is affected transformational processes other than heating (e.g., impact, radiolysis [e.g., gamma ray irradiation], parent body and terrestrial weathering) that can alter the IOM structure and thus the Raman parameters, as described above. Whereas metamorphic heating in terrestrial rocks occurs gradually over long periods of time $\left(10^{5}-10^{7}\right.$ years), graphitic materials in meteorites can be influenced by both short (shock metamorphism) and long term (radiogenic) heating. In the case of shock heating, heating rates are fast and very high temperatures can be reached in a very short period of time. Under these circumstances, kinetics can exert a dominant role in modifying the structural characteristics of IOM, which can complicate the interpretation of Raman spectra. For example, if the IOM were heated to high temperatures but for a short period of time, the D and $\mathrm{G}$ band parameters might indicate a lower temperature than the actual PMT. It should be noted that all Raman thermometers used here are based on long duration processes, and the temperature estimations are based on an assumption that the $\mathrm{C}$-rich aggregates are subjected by a long term heating. 
One particular issue arises using Raman based thermal models, this is the complex issue related in part to choice of optimum curve fitting models (e.g., Beyssac et al., 2002a; Rahl et al., 2005; Busemann et al., 2007; Aoya et al., 2010; Lahfid et al., 2010; Kouketsu et al., 2014). We start with a reference estimate of PMT of $330 \pm 50{ }^{\circ} \mathrm{C}$ that was suggested for the Sharps clast (Brearley, 1990). We, therefore, compare our results to the PMT predicted by the Raman geothermometers proposed by Beyssac et al. (2002a), Busemann et al. (2007) and Rahl et al. (2005) for the organic solids in the Sharps clasts.

The correlation between $\Gamma_{\mathrm{D}}$ and PMT of IOM in less primitive chondrites has been addressed with the use of a two-peak curve fitting model and an empirical 2nd order polynomial fit of the correlation of measured Raman parameters with independent (mineralogical and compositional) estimates of parent body thermal history (Busemann et al., 2007):

$$
\text { PMT }\left({ }^{\circ} \mathrm{C}\right)=931-5.10 \times \Gamma_{\mathrm{D}} \mathrm{cm}+9.1 \times 10^{-3} \times \Gamma_{\mathrm{D}}^{2} \mathrm{~cm}^{2} .
$$

Given a D-band width of $146 \mathrm{~cm}^{-1}$ obtained using the two-peak Lorentzian and BreitWigner-Fano (LBWF) model (Fig. 6), the Busemann et al. (2007) model (equation 1) predicts a PMT of $\sim 380{ }^{\circ} \mathrm{C}$ for the Sharps clast. Because $\Gamma_{\mathrm{D}}$ is indicative of the PMT and thus the bulk metamorphic grade of a meteorite, it can provide a rough estimate of the petrologic subclassification of type 3 chondrites (Quirico et al., 2003). Following Busemann et al. (2007), Cody et al. (2008b) derived an alternative equation based on the Raman data of Busemann et al. (2007), using temperatures obtained from an experimentally derived C-XANES thermometer (see details below). Following Busemann et al. (2007), a second order polynomial fit was also applied, acknowledging that this fit is entirely empirical, i.e., there is no physical reason to presume a second order polynomial is the necessary functional form to fit such data. In Cody et al. (2008b) it was argued that the term "PMT" was not accurate as the temperature-time path is 
not known and continued reaction during the cooling path will occur; thus, an accurate PMT can only be determined through detailed thermal modeling. Rather, one can only infer an effective equivalent isothermal temperature, defined as $T_{\mathrm{EFF}}$ in Cody et al. (2008b).

$$
T_{\mathrm{EFF}}\left({ }^{\circ} \mathrm{C}\right)=899.9-3.0 \times \Gamma_{\mathrm{D}} \mathrm{cm}+1.4 \times 10^{-3} \times \Gamma_{\mathrm{D}}{ }^{2} \mathrm{~cm}^{2}
$$

Using the equation reported in Cody et al. (2008b), the estimated effective temperature ( $\left.T_{\mathrm{EFF}}\right)$ for the Sharps clast is $\sim 490( \pm 120){ }^{\circ} \mathrm{C}-$ this temperature is significantly higher than that derived from Raman based thermometers, although effective temperature must be lower than PMT.

We have also calculated the peak intensity $I_{\mathrm{D}}$ and $I_{\mathrm{G}}$, integrated intensity $\mathrm{A}_{\mathrm{D}, \mathrm{G}}, \mathrm{D} 1 / \mathrm{G}$ peak intensity $\left(I_{\mathrm{D} 1} / I_{\mathrm{G}}\right.$, i.e. peak height) ratio $\left(\mathbf{R} 1\right.$ ratio), and $A_{D 1} /\left(A_{G}+A_{D 1}+A_{D 2}\right)$ (i.e. peak area) ratio ( $\mathbf{R 2}$ ratio), using the five-Lorentzian model (Fig. 5). The $\mathrm{R} 1$ ratio of Sharps (1.65) is comparable to the value (1.3-2.1) obtained for low metamorphic grade metasediments in the chlorite zone $\left(330^{\circ} \mathrm{C}\right)$ (Beyssac et al., 2002a). Generally, with initial heating of organic matter, $I_{\mathrm{D}} / I_{\mathrm{G}}$ increases and then begins to decrease when graphite domains start to appear, while $\Gamma_{\mathrm{D}}$ decreases with increasing metamorphic temperature (Busemann et al., 2007). For instance, the $\mathrm{R} 1$ ratio and $\Gamma_{\mathrm{D}}$ of CO3.4/3.6 Lancé meteorite are $\sim 1.4$ and $\sim 80 \mathrm{~cm}^{-1}$, respectively (Bonal et al., 2007). In order to compare our results to the literature, we have also estimated the R1 ratio and $\Gamma_{\mathrm{D}}$ using a LBWF model, which gave values of 0.97 and $146 \mathrm{~cm}^{-1}$, respectively, and indicates that the Sharps clast exhibits a lower metamorphic grade than Lancé. The R2 ratio of the Sharps clast is determined to be 0.68. Equation 3 of Beyssac et al. (2002a) shows a linear correlation between PMT and R2 ratio over the range 330 to $600{ }^{\circ} \mathrm{C}$ for regionally metamorphosed terrestrial rocks. Equation 3 applied here reveals a PMT of $\sim 340{ }^{\circ} \mathrm{C}$ for the Sharps clast.

$$
\operatorname{PMT}\left({ }^{\circ} \mathrm{C}\right)=-445 \times \mathrm{R} 2+641
$$


Rahl et al. (2005) proposed a geothermometer based on regionally metamorphosed terrestrial rocks that spans the temperature range from 100 to $700{ }^{\circ} \mathrm{C}$ which is applicable for IOM with low metamorphic grade:

$$
\operatorname{PMT}\left({ }^{\circ} \mathrm{C}\right)=737.3+320.9 \times \mathrm{R} 1-1067 \times \mathrm{R} 2-80.638 \times \mathrm{R} 1^{2} .
$$

Using this geothermometer, the calculated PMT of the Sharps clast is $\sim 320{ }^{\circ} \mathrm{C}$.

It is noted that the estimated temperatures derived by Busemann et al. (2007) and Cody et al. (2008b) (i.e., $380-490{ }^{\circ} \mathrm{C}$, Equation 1 and 2) are higher than those of Beyssac et al. (2002a) and Rahl et al. (2005) (i.e., $320-340{ }^{\circ} \mathrm{C}$, Equation 3 and 4), which may represent variations in the graphitization mechanisms of organic matter on small asteroidal bodies and Earth. Therefore, the former estimations $\left(380-490{ }^{\circ} \mathrm{C}\right)$ are more plausible. Raman based graphitization thermometers calibrated by terrestrial metamorphic rocks suggest PMT values that are lower than that those derived from chondrites. The reasons for such differences most likely reside in the fact that organic matter transformation on a small planetesimal must differ significantly from organic matter transformation in regionally metamorphosed sedimentary rocks on Earth. It is well known that shear deformation affects the transformation of organic matter to graphite, as documented in Ross et al. (1991) and Mählmann et al. (2002), although at least some pressure required for graphitization of non-graphitizing precursors (Beyssac et al., 2003). Cody et al. (2008b) noted that the transformation of terrestrial carbonaceous matter during regional metamorphism is due to both heating and shear deformation, whereas transformation of organic matter in planetesimals occurs (in the absence of impacts) due to heating alone and possibly aided by decay of short-lived radionuclides. It is expected that these differences (with or without shear strain) are significant and will modify the thermokinetic response considerably. Thus, any thermometer that is calibrated against terrestrial metamorphic rocks subjected to both heat and 
shear deformation may be expected to report lower temperatures than a thermometer derived from carbonaceous matter in chondrites.

The $\Gamma_{\mathrm{D}}$ and $I_{\mathrm{D} 1} / I_{\mathrm{G}}$ ratio of the Sharps non-clast matrix were $210 \pm 57 \mathrm{~cm}^{-1}$ and $0.88 \pm 0.08$, respectively. These values are roughly in the ranges of type 3.1 to 3.4 chondrites (Bonal et al., 2006), and consistent with the fact that the Sharps meteorite is petrologic type 3.4.

\subsection{C-XANES}

STXM carbon maps of the FIB and UMT sections from Sharps clasts were obtained by acquiring pairs of images below and on the carbon $K$-edge, at 283 and $289 \mathrm{eV}$, respectively, taking the $-\log \left(I_{290} / I_{280}\right)$ for each pixel (Fig. 7b, d, f). C-rich aggregates are observed in these sections, although C-rich aggregates are not so clearly distinguished in C maps of the UMT section. The C-XANES spectra of these aggregates (Fig. 8) reveal absorption features at $285 \mathrm{eV}$ that are assigned to the $1 \mathrm{~s}-\pi^{*}$ of aromatic carbon $(\mathrm{C}=\mathrm{C})$ and a distinct absorption feature at 291.7 $\mathrm{eV}$ that is assigned to the $1 \mathrm{~s}-\sigma^{*}$ exciton of graphene structures. The identities and the photon energies of these characteristic C-XANES absorptions are summarized in Table 2 (Cody et al., 2008a, b).

The C-XANES spectra of the matrix areas surrounding these C-rich aggregates (Fig. 8) reveal absorption features at $285 \mathrm{eV}$ assigned to the $1 \mathrm{~s}-\pi^{*}$ of aromatic carbon $(\mathrm{C}=\mathrm{C}), 287.5 \mathrm{eV}$ assigned to the $1 \mathrm{~s}-3 \mathrm{p} / \mathrm{s}$ of aliphatic carbon $(\mathrm{C}-\mathrm{C}), 288.5 \mathrm{eV}$ assigned to the $1 \mathrm{~s}-\pi^{*}$ of carboxyl groups $(\mathrm{O}-\mathrm{C}=\mathrm{O})$, and $290.5 \mathrm{eV}$ assigned to the $1 \mathrm{~s}-\pi^{*}$ of carbonate $\left(\mathrm{CO}_{3}\right)$. A graphene $1 \mathrm{~s}-\sigma^{*}$ exciton feature at $291.7 \mathrm{eV}$ of the matrix areas is much weaker (if present at all) than that observed for carbon in the C-rich aggregates, indicating that the matrix has experienced lower temperatures than the C-rich aggregates have (Cody et al., 2008b). C-XANES spectra of the 
surrounding matrix contain less carbon as shown in Fig. 7, but the carbonaceous matter is primitive, similar to that found in CM, CI and CR carbonaceous chondrites (Le Guillou et al., 2014). There is no significant difference between C-XANES obtained from FIB and UMT methods, indicating that there is no sample damage during FIB processes. Small differences in the intensity of fine peaks in C-XANES of the matrix organic matter are likely due to sample heterogeneity, and similar heterogeneity is observed with C-XANES of the acid residues (all prepared with UMT).

The $1 \mathrm{~s}-\sigma^{*}$ exciton of graphene at $291.7 \mathrm{eV}$ allows us to estimate the effective metamorphic temperature, $T_{\mathrm{EFF}}$ (Cody et al., 2008b). The effective temperatures of C-rich aggregates and matrix were obtained by following the method of Cody et al. (2008b) and the online supplemental materials. The exciton intensity was obtained by taking the first derivative of the normalized C-XANES spectrum and applying a 5-point smoothing process (Fig. 9). Then, the intensity was normalized using the values of EET 92042 (lowest intensity; $H_{E}=0.09$ ) and graphite $\left(H_{G}=1.48\right)$, therefore the exciton intensity, $E(\%)$, is given by:

$$
E=\left[\left(H_{A}-H_{E}\right) /\left(H_{G}-H_{E}\right)\right] \times 100
$$

The effective temperature, $T_{E F F}$, was calculated using the kinetic expression (Eq. 6), assuming isothermal heating for $10^{7}$ years (i.e., the effective temperature was kept for $10^{7}$ years).

$$
\ln E=\ln (\ln t / 0.0002)+A+B / T
$$

where $T$ is temperature (K), $t$ is heating duration (sec), $A=2.26$, and $B=-2177.1 \mathrm{~K}$ (which implies an apparent activation energy, $\left.E_{A}=18 \mathrm{~kJ}\right)$.

The exciton intensities and effective temperatures of C-rich aggregates and matrix are summarized in Table 3. The C-rich aggregates have significant exciton intensities, with E\% ranging from $47 \%$ to $58 \%$ (Table 3). In the original study of Cody et al. (2008b), the CO 
chondrite Isna (petrologic type 3.8) was shown to have a maximum equilibration temperature of $700{ }^{\circ} \mathrm{C}$ based on olivine/spinel thermometry (Wlotzka, 2005) and has an exciton intensity (E\%) $=43.2$. The enstatite chondrite, Indarch (petrologic type 4.0) has an exciton intensity $(E \%)=68$. Assuming that growth of the exciton is purely an effect of thermal processing, this would indicate that the sharps clasts were subjected to higher temperature than Isna (CO3.8) and slightly lower temperature than Indarch (E4.0). Using equation 6, one determines that the graphene structures in the Sharps clasts developed at temperatures $\left(T_{\mathrm{EFF}}\right)$ between $750{ }^{\circ} \mathrm{C}$ and $850{ }^{\circ} \mathrm{C}$. The surrounding matrix shows much weaker (if at all) graphene exciton intensities and estimated effective temperatures are approximately $300{ }^{\circ} \mathrm{C}$ to $500{ }^{\circ} \mathrm{C}$. These latter temperatures should be considered as upper limits since the matrix might contain small fractions of C-rich aggregates that would increase the matrix exciton intensity and estimated temperature.

\subsection{TEM observations}

We prepared a focused ion beam (FIB) slice of one of the Sharps clasts, as shown in Fig. 10a, using techniques described above. The clast consists mainly of very fine-grained silicates, as described earlier by Brearley (1990) and Zolensky et al. (1996). Contained within the silicates are carbon-rich masses measuring up to $\sim 4 \mu \mathrm{m}$ in size (Fig. 10a), which are the focus of this paper. TEM imaging reveals that the carbon in the masses has a wide range of morphologies, as previously described by Brearley (1990) but now imaged with better resolution using a field emission gun (FEG) TEM. Fig. 10b and c are close-up images of a portion of one of these carbon-rich masses. "Books" of graphitic carbon are scattered about (indicated in Fig. 10c), and areas of poorly-organized to irregularly-oriented carbon domains occur between these books, as shown in Fig. 10e and f. Within the books the 002 layer lattice fringes are very apparent (Fig. 10 
d,e,f) and persist under TEM imaging conditions sufficiently long to permit accurate measurements of the interlayer spacings. These measured spacings are 0.34 to $0.35 \mathrm{~nm}$. Existing thermometers based on the interlayer spacings of graphitized carbon (e.g., Rietmeijer and Mackinnon, 1985) have $\sim 50{ }^{\circ} \mathrm{C}$ uncertainties because of the sluggishness of the graphitization process, and the fact that some carbons have structures that lock in and cannot be graphitized further. Subject to these caveats, using interlayer (002) spacing as a criteria, the carbon in this particular Sharps clast has been heated to a maximum of $300-400{ }^{\circ} \mathrm{C}$. This temperature range is in good agreement with the results for Sharps clasts $\left(330 \pm 50{ }^{\circ} \mathrm{C}\right)$ reported by Brearley (1990), that is obtained using Rietmeijer and Mackinnon (1985) interlayer spacing thermometer. It is noted, however, that like many of the Raman based thermometers, the interlayer spacing thermometer was calibrated with regionally metamorphosed terrestrial rocks that were subjected to both heating and shear deformation and as noted above, shear deformation greatly enhances graphitization (Ross et al., 1991; Mählmann et al., 2002), therefore, thermometers calibrated with terrestrial metamorphic rocks would be expected to yield lower estimated temperatures.

The textures of carbonaceous matter in the high resolution TEM images are somewhat similar to IOM from petrologic type $\geq 3.6$ carbonaceous chondrites (Tieschitz, Kainsaz, Mokoia, Ornans, and Allende), but do not resemble to IOM from pristine carbonaceous chondrites, e.g., Tagish Lake (C2 ungrouped), Orgueil (CI1), Murchison (CM2), and Semarkona (LL3.0) (Le Guillou et al., 2012), and are consistent with well-ordered graphene structures. In some regions of the C-rich aggregates, the graphitic carbon is more well-ordered (based on lattice fringes), but only in very small randomly oriented domains, as shown in Fig. 11a and b. The more wellcrystalline domains achieve a maximum size of between 5 and $10 \mathrm{~nm}$, and this texture is, therefore, also suggestive of low degrees of thermal processing. This conclusion is further 
supported by the ubiquitous presence of discontinuous carbon sheets (discontinuous 002 lattice fringes) (see Buseck et al., 1988), as shown in Fig. 11d.

As described by Brearley (1990), carbonaceous masses in the Sharps clast are often associated with grains of Fe-Ni metal, Fe-Ni carbides, and magnetite. Fig. 11c shows an example of graphite flakes surrounding a Fe-Ni grain. An inference from this association and texture is that the metal grains serve as a catalyst for the nucleation of graphite.

\subsection{Noble gases}

Concentrations of $\mathrm{He}, \mathrm{Ne}, \mathrm{Ar},{ }^{84} \mathrm{Kr}$, and ${ }^{132} \mathrm{Xe}$, and isotopic ratios of $\mathrm{He}, \mathrm{Ne}$, and $\mathrm{Ar}$ in the Sharps clast acid residue are presented in Table A2 (Appendix). Isotopic ratios of $\mathrm{Kr}$ and $\mathrm{Xe}$ are listed in Table A3 and Table A4 (Appendix), respectively. Experimental errors for isotopic ratios are $1 \sigma$, including statistical errors and uncertainties in blank corrections. Errors for noble gas concentrations include experimental uncertainties related to the stability of sensitivity and blank corrections. The concentration of ${ }^{3} \mathrm{He}$ and the ${ }^{3} \mathrm{He} /{ }^{4} \mathrm{He}$ ratio at $1750{ }^{\circ} \mathrm{C}$ are not presented because the amount of ${ }^{3} \mathrm{He}$ released at that tempearture was too small to be analyzed.

The noble gas compositions for the acid residue are largely different from the reported values for bulk samples from the Sharps meteorite (Zadnik, 1985). Trapped noble gas concentrations in bulk samples are much lower than those in our PGC sample, and the $\mathrm{Ne}$ isotopic composition in the bulk samples is almost totally cosmogenic, showing cosmic ray exposure ages up to $25 \mathrm{Ma}$ (Zadnik, 1985). This difference clearly indicates that the carbonaceous chondrite-like clasts containing the C-rich aggregates studied in this work are exotic materials that were incorporated into the Sharps meteorite parent body (i.e., xenoliths). 
As shown in Table A2, the largest release of ${ }^{4} \mathrm{He},{ }^{20} \mathrm{Ne},{ }^{36} \mathrm{Ar}$, and ${ }^{84} \mathrm{Kr}$ was at $1000{ }^{\circ} \mathrm{C}$. On the other hand, ${ }^{40} \mathrm{Ar}$ and ${ }^{132} \mathrm{Xe}$ released at the lowest temperature of $300{ }^{\circ} \mathrm{C}$ are significantly modified by atmospheric contamination, as explained below.

\subsubsection{He}

${ }^{3} \mathrm{He} /{ }^{4} \mathrm{He}$ ratios are plotted against concentrations of ${ }^{4} \mathrm{He}$ released at each temperature step in Fig. 12, in which isotopic ratios for typical reservoirs in the solar system and in meteorites are shown for comparison. A small amount of ${ }^{4} \mathrm{He}\left(1.6 \times 10^{-7} \mathrm{~cm}^{3} \mathrm{STP} / \mathrm{g}\right)$ with relatively high ${ }^{3} \mathrm{He} /{ }^{4} \mathrm{He}$ ratio of $14.9 \times 10^{-4}$ released at the lowest temperature of $300{ }^{\circ} \mathrm{C}$ is affected by cosmogenic He produced by spallation reactions on carbon, which is a main target element in the acid residue sample. Larger amounts of He were released at $1000{ }^{\circ} \mathrm{C}$ and $1500{ }^{\circ} \mathrm{C}$ and their ${ }^{3} \mathrm{He} /{ }^{4} \mathrm{He}$ ratios are similar to that of He-HL $\left(1.70 \pm 0.10 \times 10^{-4}\right.$ in presolar diamonds; Huss and Lewis, 1994). A portion of the noble gas component trapped in presolar diamond is referred to as "HL" because it is enriched in both heavy $(\mathrm{H})$ and light $(\mathrm{L})$ isotopes of Xe. Moreover, the ratio is substantially higher than the value of $1.23 \times 10^{-4}$ for He-Q (Busemann et al., 2000; Ott, 2002). Although the ${ }^{3} \mathrm{He} /{ }^{4} \mathrm{He}$ ratio is similar to that in Jupter's atmosphere $\left(1.66 \pm 0.05 \times 10^{-4}\right.$; Mahaffy et al., 1998), such an origin is unlikely because the ${ }^{20} \mathrm{Ne} /{ }^{22} \mathrm{Ne}$ ratio in Jupiter's atmosphere is 13 \pm 2 (Mahaffy et al., 2000). This value is distinctly different from the ratios of our sample dominated by $\mathrm{Ne}-\mathrm{HL}\left({ }^{20} \mathrm{Ne} /{ }^{22} \mathrm{Ne}=8.5\right)$, but does agree with the composition of solar wind (13.78 \pm 0.03 ; Heber et al., 2009). The ${ }^{3} \mathrm{He} /{ }^{4} \mathrm{He}$ ratio of $4.8 \times 10^{-4}$ at $700{ }^{\circ} \mathrm{C}$, which is similar to SW-He $\left((4.64 \pm 0.09) \times 10^{-4}\right.$; Heber et al., 2009) , is likely a mixture of He-HL and cosmogenic He. The cumulative concentration of ${ }^{4} \mathrm{He}$ for all temperature steps is as high as $2.6 \times 10^{-4}$ $\mathrm{cm}^{3} \mathrm{STP} / \mathrm{g}$, indicating abundant presolar diamonds in the acid residue sample. 


\subsection{2. $\mathrm{Ne}$}

Isotope ratios of $\mathrm{Ne}$ are shown in Fig. 13. Data for the 300 and $700{ }^{\circ} \mathrm{C}$ fractions plot on a mixing line between cosmogenic $\mathrm{Ne}$ and $\mathrm{Ne}-\mathrm{HL}$, indicating release of cosmogenic $\mathrm{Ne}$ at low temperatures. The main target element for the cosmogenic Ne released at low temperature may be sulfur, because free sulfur remains in $\mathrm{HCl} / \mathrm{HF}$ etched residue and can be removed by $\mathrm{CS}_{2}$ (Lewis et al., 1975). Sulfur can not be a target element for cosmogenic Ar production by spallation reaction due to its smaller mass than Ar.

The largest release of ${ }^{20} \mathrm{Ne}\left(8.4 \times 10^{-7} \mathrm{~cm}^{3} \mathrm{STP} / \mathrm{g}\right.$ in Table A2) occurs at $1000{ }^{\circ} \mathrm{C}$ and the isotopic ratios agree with those of $\mathrm{Ne}-\mathrm{HL}$, which is known to be present in presolar diamonds (Huss and Lewis, 1994). At 1500 and $1750{ }^{\circ} \mathrm{C}$ the data plot on a line between Ne-HL and Ne-E, suggesting the presence of $\mathrm{Ne}-\mathrm{E}(\mathrm{H})$ trapped in presolar SiC (Lewis et al., 1994; Ott, 2002) that is released at high temperatures. Ne-E(L), a low temperature component trapped in presolar graphite (Ott, 2002), was not observed at low temperatures. This indicates the absence of presolar graphite in the acid residue sample, or that the presolar graphite had lost $\mathrm{Ne}-\mathrm{E}(\mathrm{L})$ during heating $\left(\leq 700^{\circ} \mathrm{C}\right)$. Thus, a stepwise heating experiment could resolve three different components, i.e., cosmogenic, $\mathrm{HL}$ and $\mathrm{E}(\mathrm{H})$, for this sample. The presence of atmospheric Ne and/or Ne-Q is not clearly indicated, suggesting their absence or near absence compared with the other three components. The He and $\mathrm{Ne}$ data indicate that the major trapped $\mathrm{He}$ and $\mathrm{Ne}$ component is not $\mathrm{Q}$ but, rather, is HL.

\subsubsection{Ar}


Isotope ratios of Ar are plotted in Fig. 14. The largest amount of ${ }^{40} \mathrm{Ar}$ with relatively high ${ }^{40} \mathrm{Ar} /{ }^{36} \mathrm{Ar} \approx 50$ was released at the lowest temperature $\left(300{ }^{\circ} \mathrm{C}\right)$. Similarly, high ${ }^{40} \mathrm{Ar} /{ }^{36} \mathrm{Ar} \approx 32$ was also observed for the highest temperature of $1750{ }^{\circ} \mathrm{C}$. Because ${ }^{38} \mathrm{Ar} /{ }^{36} \mathrm{Ar}$ ratios for these fractions agree within experimental error with the atmospheric value of 0.1880 (Nier, 1950), this Ar must be affected by atmospheric contamination or from blank Ar. Although the ${ }^{40} \mathrm{Ar}{ }^{36} \mathrm{Ar}$ ratio of the $700{ }^{\circ} \mathrm{C}$ fraction is still high, it might be elevated by radiogenic ${ }^{40} \mathrm{Ar}$ produced in-situ from ${ }^{40} \mathrm{~K}$, which may have been incorporated into the sample as an impurity. This interpretation is supported by the fact that its ${ }^{38} \mathrm{Ar} /{ }^{36} \mathrm{Ar}$ ratio is higher than the atmospheric value and agrees with those of the $1000{ }^{\circ} \mathrm{C}$ and $1500{ }^{\circ} \mathrm{C}$ fractions with very low ${ }^{40} \mathrm{Ar} /{ }^{36} \mathrm{Ar}$ ratios $(0.20$ and 0.44 , respectively), indicating insignificant contamination by atmospheric $\mathrm{Ar}$. The ${ }^{38} \mathrm{Ar} /{ }^{36} \mathrm{Ar}$ ratios for the 700,1000 and $1500{ }^{\circ} \mathrm{C}$ fractions, which are slightly higher than the atmospheric value, resulted from admixing of a small amount of Ar-HL $\left({ }^{38} \mathrm{Ar} /{ }^{36} \mathrm{Ar}=0.2270\right.$ : Huss and Lewis, 1994) to $\mathrm{Ar}-\mathrm{Q}\left({ }^{38} \mathrm{Ar}{ }^{36} \mathrm{Ar}=0.1873\right.$ : Busemann et al., 2000) as will be discussed later.

\subsection{4. $\mathrm{Kr}$ and $\mathrm{Xe}$}

Fig. 15 is a plot of ${ }^{130} \mathrm{Xe} /{ }^{132} \mathrm{Xe}$ versus ${ }^{136} \mathrm{Xe} /{ }^{132} \mathrm{Xe}$, showing contributions of different endmembers to the measured Xe isotopic compositions. Most data points plot on or close to the mixing line between $\mathrm{Xe}$-air and $\mathrm{Xe}-\mathrm{Q}$, which shows that the dominant component of $\mathrm{Xe}$ in the sample was Xe-Q and was affected afterwards by terrestrial atmospheric Xe. Xe in the $300{ }^{\circ} \mathrm{C}$ fraction plots just on Xe-air, and that in the $700{ }^{\circ} \mathrm{C}$ fraction shows a small shift along the mixing line from Xe-air to Xe-Q. $68 \%$ of the total ${ }^{132} \mathrm{Xe}$ was released in the two low temperature fractions, which indicates significant contamination from atmospheric Xe. At higher temperatures almost pure Xe-Q was released. The abundance of Xe-HL, if any, must be much 
smaller than that of Xe-Q. A trace of Xe-HL is observed at $1500{ }^{\circ} \mathrm{C}$ (Fig. 15 and Table 4), representing only $1.4 \%$ of the total ${ }^{132} \mathrm{Xe}$ at this temperature, while $70.5 \%$ and $28.1 \%$ are $\mathrm{Q}$ and air, respectively. Because of a small variation of $\mathrm{Kr}$ isotopic ratios among different components, it is difficult to evaluate contributions from each $\mathrm{Kr}$ component to the measured isotopic ratios. However, the results are consistent with the interpretation that $\mathrm{Kr}$ in the sample is a mixture of Q, HL and air as indicated by the Ar and Xe results.

\subsection{5. ${ }^{36} \mathrm{Ar} /{ }^{132} \mathrm{Xe}$ versus ${ }^{84} \mathrm{Kr} /{ }^{132} \mathrm{Xe}$ (Elemental composition)}

${ }^{36} \mathrm{Ar} /{ }^{132} \mathrm{Xe}$ versus ${ }^{84} \mathrm{Kr} /{ }^{132} \mathrm{Xe}$ are plotted in Fig. 16, where the ratios for both measured concentrations of ${ }^{36} \mathrm{Ar},{ }^{84} \mathrm{Kr}$ and ${ }^{132} \mathrm{Xe}$ and those of the $\mathrm{Q}$ component (Table 4) are plotted. The method used to calculate of the Q component concentration is described below. All measured data (filled circles) plot to the lower left of the Q composition, which is inconsistent with the observation that the $\mathrm{Xe}$ at 1000,1500 , and $1750{ }^{\circ} \mathrm{C}$ is mostly of Xe-Q (Fig. 15). This reflects the large amount of contamination by atmospheric Xe as noted above and shown in Table 4. If we plot the ${ }^{36} \mathrm{Ar},{ }^{84} \mathrm{Kr}$ and ${ }^{132} \mathrm{Xe}$ data only for the Q component (Table 4), the array shown in Fig. 16 is obtained, which may indicate a fractionation trend of Q gas during stepwise heating.

\subsubsection{Trapped noble gases}

The overall isotopic data indicate that most noble gases are trapped components and their concentrations are very high, e.g., ${ }^{36} \mathrm{Ar}$ concentration is comparable to or higher than that of ureilites, and the concentration of ${ }^{132} \mathrm{Xe}-\mathrm{Q}\left(95 \times 10^{-9} \mathrm{~cm}^{3} \mathrm{STP} / \mathrm{g}\right.$ in Table 4$)$ is similar to the high values reported for ureilites, e.g., $(0.8-79) \times 10^{-9} \mathrm{~cm}^{3} \mathrm{STP} / \mathrm{g}$ for 13 ureilites (Nagao et al., 2014). 


\subsubsection{Partitioning of noble gases betweencomponents}

We calculated the partitioning of each noble gas to several components (cosmogenic, HL, Q, E, and air) based on the considerations noted below. The number of components to be partitioned is restricted by simultaneous equations with independent variables (number of isotopic ratios of different components). Mixing of HL and cosmogenic noble gas components was assumed for ${ }^{3,4} \mathrm{He}$, and that of HL and Q for ${ }^{36,38} \mathrm{Ar}$. Three component mixing was applied for ${ }^{20,21,22} \mathrm{Ne}$ (HL, E, cosmogenic), ${ }^{78,84,86} \mathrm{Kr}$ (Q, HL, air), and ${ }^{124,132,136} \mathrm{Xe}$ (Q, HL, air). Results are summarized in Table 4, where isotopic ratios of the endmembers used in the calculation are shown in the table caption.

${ }^{38} \mathrm{Ar} /{ }^{36} \mathrm{Ar}$ ratios (Fig. 14) at heating temperatures of 700,1000 and $1500{ }^{\circ} \mathrm{C}$ are $\sim 0.189$, slightly but clearly higher than those of Ar-Q (0.1873; Busemann et al., 2000; Ott, 2002) and Arair $\left(0.1880\right.$; Nier, 1950). Because the ${ }^{38} \mathrm{Ar} /{ }^{36} \mathrm{Ar}$ ratio of cosmogenic Ar is much higher $(\approx 1.5)$ than the observed value, it might be a candidate to elevate the ${ }^{38} \mathrm{Ar} /{ }^{36} \mathrm{Ar}$ ratio originally trapped in the sample. However, the concentrations of cosmogenic ${ }^{3} \mathrm{He}$ and ${ }^{21} \mathrm{Ne}$ are as low as $9 \times 10^{-9}$ $\mathrm{cm}^{3} \mathrm{STP} / \mathrm{g}$ and $7 \times 10^{-9} \mathrm{~cm}^{3} \mathrm{STP} / \mathrm{g}$, respectively (Table 4). As noted above their low temperature release suggests that material(s) producing cosmogenic He and Ne may be sulfur/sulfides, that are susceptible to heating. Because sulfur is not a target element for Ar production by cosmic rays, the cosmogenic ${ }^{38} \mathrm{Ar}$ concentration seems to be lower than those due to the absence of target elements (e.g., elements with masses heavier than Ar, such as $\mathrm{K}, \mathrm{Ca}, \mathrm{Fe}, \mathrm{Ni}, \mathrm{Ti}, \mathrm{Cr}, \mathrm{Mn}$ ) for production of cosmogenic Ar in the acid residue sample, which is mostly composed of PGC containing carbon-rich material (probable carrier of Q), diamonds (carrier of HL), and SiC (carrier of $\mathrm{Ne}-\mathrm{E}(\mathrm{H})$ ). The cosmogenic ${ }^{38} \mathrm{Ar}$ concentration should be lower than that of cosmogenic ${ }^{21} \mathrm{Ne}\left(7 \times 10^{-9} \mathrm{~cm}^{3} \mathrm{STP} / \mathrm{g}\right)$, which is $0.4 \%$ of the total ${ }^{38} \mathrm{Ar}$ concentration of $1660 \times$ 
$10^{-9} \mathrm{~cm}^{3} \mathrm{STP} / \mathrm{g}$ (Table A2) in the sample. Hence, the cosmogenic Ar may not be a candidate to elevate the ${ }^{38} \mathrm{Ar} /{ }^{36} \mathrm{Ar}$ ratio from 0.1873 of Q-Ar (Busemann et al., 2000) to the observed value of 0.189. Because the HL component is dominated by light noble gases $\mathrm{He}$ and $\mathrm{Ne}$, and the $\mathrm{Q}$ component is dominated by heavy noble gases $\mathrm{Kr}$ and $\mathrm{Xe}$, the slightly elevated ${ }^{38} \mathrm{Ar} /{ }^{36} \mathrm{Ar}$ is reasonably explained by addition of Ar-HL with $\left({ }^{38} \mathrm{Ar}{ }^{36} \mathrm{Ar}\right)_{\mathrm{HL}}=0.2270$ (Huss and Lewis, 1994; Ott, 2002) to Ar-Q (0.1873; Busemann et al., 2000; Ott, 2002).

Concerning atmospheric contamination, the concentration of atmospheric ${ }^{36} \mathrm{Ar}$ in the $300{ }^{\circ} \mathrm{C}$ fraction is estimated from the elemental ratio of $\left[{ }^{84} \mathrm{Kr}\right]_{\text {air }} /\left[{ }^{132} \mathrm{Xe}\right]_{\text {air }}=0.175$ (Table 4) and the Earth's atmospheric fractionation trend line shown in Fig. 16, obtaining $\left.\left[{ }^{36} \mathrm{Ar}\right]\right]_{\mathrm{air}} /\left[{ }^{132} \mathrm{Xe}\right]_{\mathrm{air}} \sim 1$ and $\left[{ }^{36} \mathrm{Ar}\right]_{\text {air }}=80 \times 10^{-9} \mathrm{~cm}^{3} \mathrm{STP} / \mathrm{g}$. This represents $15 \%$ of the measured ${ }^{36} \mathrm{Ar}$ concentration of $518 \times 10^{-9} \mathrm{~cm}^{3} \mathrm{STP} / \mathrm{g}$ at $300{ }^{\circ} \mathrm{C}$ (Table A2) and is neglected in the later calculation for partitioning to HL and Q components.

The high concentration of ${ }^{36} \mathrm{Ar}\left(8770 \times 10^{-9} \mathrm{~cm}^{3} \mathrm{STP} / \mathrm{g}\right)$ is mostly composed of ${ }^{36} \mathrm{Ar}-\mathrm{Q}$ (96\%) and only $4 \%$ is ${ }^{36} \mathrm{Ar}-\mathrm{HL}$. No meaningful value of the HL component was obtained for $\mathrm{Kr}$ and $\mathrm{Xe}$, indicating negligible contribution of $\mathrm{HL}$ to the measured $\mathrm{Kr}$ and $\mathrm{Xe}$. Also, no ${ }^{84} \mathrm{Kr}$-air was obtained except for the $300{ }^{\circ} \mathrm{C}$ fraction (54\% and $46 \%$ are air and $\mathrm{Q}$, respectively) which means that $\mathrm{Kr}$ is almost pure $\mathrm{Kr}-\mathrm{Q}$. In contrast to $\mathrm{He}-\mathrm{Kr}$, high contamination of Xe-air (65\% of total ${ }^{132} \mathrm{Xe}$ concentration) is obtained only for $\mathrm{Xe}$, and the remaining component is Q. These results show that $\mathrm{Ar}, \mathrm{Kr}$ and $\mathrm{Xe}$ originally trapped in the acid residue sample were mostly Qcomponent, but trapped $\mathrm{He}$ and $\mathrm{Ne}$ are $\mathrm{HL}$ with a small amount of $\mathrm{Ne}-\mathrm{E}(\mathrm{H})\left(11 \times 10^{-9} \mathrm{~cm}^{3} \mathrm{STP} / \mathrm{g}\right)$.

The release profiles of representative noble gas isotopes of different components (Table 4) are plotted in Fig. 17. Both $\mathrm{HL}(\mathrm{He}$ and $\mathrm{Ne}$ ) and Q ( $\mathrm{Ar}$ and $\mathrm{Kr}$ ) show similar profiles with a peak release at $1000{ }^{\circ} \mathrm{C}$, indicating similar retention of noble gases for both HL in presolar 
diamonds and Q-gas in phase Q. Small amounts of cosmogenic $\mathrm{He}$ and $\mathrm{Ne}$ are released at low temperatures. $\mathrm{Ne}-\mathrm{E}(\mathrm{H})$ in presolar $\mathrm{SiC}$ grains (e.g., Lewis et al., 1994; Ott, 2002) appeared at 1500 and $1750{ }^{\circ} \mathrm{C}$. A small release peak of cosmogenic $\mathrm{Ne}$ at $1500{ }^{\circ} \mathrm{C}$ is likely from the $\mathrm{SiC}$, because $\mathrm{Si}$ can be a target element producing Ne isotopes through a spallation reaction by cosmic rays. Xe from atmospheric contamination is mostly released at low temperatures (300 and $\left.700{ }^{\circ} \mathrm{C}\right)$, decreasing at higher temperatures $\left(1000\right.$ and $\left.1500{ }^{\circ} \mathrm{C}\right)$. The release profile of $\mathrm{Xe}-\mathrm{Q}$ is similar to those of $\mathrm{Ar}-\mathrm{Q}$ and $\mathrm{Kr}-\mathrm{Q}$, though it is more strongly retained at low temperatures.

Measured noble gas elemental compositions of HL and Q components are compared with literature values for HL and Q in Table 4 and Fig. 18. Concentrations of ${ }^{4} \mathrm{He},{ }^{20} \mathrm{Ne},{ }^{84} \mathrm{Kr}$ and ${ }^{132} \mathrm{Xe}$ for HL and Q in the sample were calculated by normalizing the elemental ratios to ${ }^{36} \mathrm{Ar}$ concentrations of $366 \times 10^{-9} \mathrm{~cm}^{3} \mathrm{STP} / \mathrm{g}(\mathrm{HL})$ and $8404 \times 10^{-9} \mathrm{~cm}^{3} \mathrm{STP} / \mathrm{g}(\mathrm{Q})$, respectively. Gray rectangles in Fig. 18 indicate concentration ranges of Q-gases reported for acid residues enriched in Q-phase (Table 8 in Buseman et al., 2000). Concentrations of $\left({ }^{4} \mathrm{He}\right.$ and $\left.{ }^{20} \mathrm{Ne}\right){ }_{\mathrm{Q}}$ and $\left({ }^{84} \mathrm{Kr}\right.$ and $\left.{ }^{132} \mathrm{Xe}\right)_{\mathrm{HL}}$ for the acid residue sample could not be determined for reasons described above. Measured ${ }^{4} \mathrm{He}-\mathrm{HL}$ and ${ }^{20} \mathrm{Ne}-\mathrm{HL}$ concentrations (Total in Table 4) are $12 \%$ and $43 \%$, respectively, of estimated concentrations normalized to the ${ }^{36} \mathrm{Ar}-\mathrm{HL}$ concentration. Both He-HL and Ne-HL must have experienced selective partial loss from presolar diamonds in the acid residue sample. The partial loss of He-HL and Ne-HL from presolar diamonds in the acid residue sample is reasonably explained by the estimation of effective temperatures of $\sim 550-850{ }^{\circ} \mathrm{C}$ (Table 3 ) for C-rich aggregates and acid residue. The noble gas release profiles obtained by stepwise heating experiments on high purity presolar diamonds by Huss and Lewis (1994) showed a high temperature $\left(\geq 1000^{\circ} \mathrm{C}\right)$ for the release of the HL noble gas component, which also supports the estimated high-heating temperature. On the other hand, total concentrations of measured ${ }^{36} \mathrm{Ar}$, 
${ }^{84} \mathrm{Kr}$ and ${ }^{132} \mathrm{Xe}$ of the Q-component plotted in Fig. 18 are in the range of concentrations reported for acid residues of carbonaceous chondrites (Busemann et al., 2000). If Q (He and Ne) and HL ( $\mathrm{Kr}$ and $\mathrm{Xe}$ ) are contained in the acid residue sample, it is difficult to resolve them clearly from other dominant components observed in this experiment.

Our results indicate that the Sharps clast acid resdue, which could be observed as $\mu \mathrm{m}$-size C-rich aggregates, are identical to the acid-leached residues enriched in Q-phase, presolar diamonds and presolar SiC reported in many studies (e.g., Lewis et al., 1994; Busemann et al., 2000). The fractionation effect for elemental composition of heavy noble gases (Ar, $\mathrm{Kr}$ and $\mathrm{Xe}$ ) of Q-component is not significant. On the other hand, selective partial loss of $\mathrm{He}, \mathrm{Ne}$ and $\mathrm{Ar}$ from presolar diamonds in the C-rich aggregates has occurred, probably caused by a thermal event.

\section{DISCUSSION}

\subsection{Comparison of metamorphic temperatures obtained from various thermometers}

The estimated temperatures of the C-rich aggregates in the Sharps clast vary according to the analytical methods and the nature of the thermometer applied. In general, thermometers that are calibrated with terrestrial metamorphic rocks yield temperatures that are lower than thermometers that are calibrated by mineralogical thermometers derived from chondrites. The temperature estimation based on C-XANES shows the highest value $\left(\sim 750-850{ }^{\circ} \mathrm{C}\right)$; that of Raman shows $\sim 380-490{ }^{\circ} \mathrm{C}$, and that of the TEM is in the range $300-400^{\circ} \mathrm{C}$. This illustrates that metamorphic temperatures of carbonaceous matter obtained by different methods depend on different characteristics and reflect change in molecular structure as a result of heating or heterogeneity in the structure and thermal history of the Sharps clasts. It should be noted that C- 
XANES kinetic thermometer indicates effective temperature $\left(T_{\mathrm{EFF}}\right)$ and Raman and TEM thermometers indicate PMT.

Considering the noble gas release profiles upon heating, carbonaceous chondrites were known to have "CCF (carbonaceous chondrite fission) - Xe" which is released at relatively low heating temperatures, in the range $700-1000{ }^{\circ} \mathrm{C}$, during stepwise heating experiments on bulk meteorite samples (e.g., Reynolds and Turner, 1964; Manuel et al., 1972). The CCF-Xe came to be known as a portion of the noble gas component (Manuel et al., 1972) trapped in presolar diamond and was named "HL" because of an enrichment in both heavy $(\mathrm{H})$ and light $(\mathrm{L})$ isotopes of Xe (Lewis et al., 1987; Huss and Lewis, 1994 and references therein). The release temperature of HL noble gases, however, is much higher $\left(>1000{ }^{\circ} \mathrm{C}\right)$ when high-purity presolar diamonds are heated stepwise (Huss and Lewis, 1994). The estimated loss of He-HL (88\%) and Ne-HL (57\%) described above (in section 3.5.7) might have been caused by partial diffusive loss of $\mathrm{He}$ and $\mathrm{Ne}$ from diamonds and/or partial decomposition of diamonds.

If the observed loss of the HL component of $\mathrm{He}$ and $\mathrm{Ne}$ occurs by diffusion during $800{ }^{\circ} \mathrm{C}$ heating for $0.5 \mathrm{~h}$ in the laboratory, the equivalent temperature for prolonged heating $(1 \mathrm{ky}$ $-10 \mathrm{My}$ ) in a planetesimal is estimated to be $450-650{ }^{\circ} \mathrm{C}$, assuming an activation energy $E_{\mathrm{a}}$ of 50-100 times larger than the heating energy $R T$, where $R$ is gas constant and $T=1073 \mathrm{~K}\left(E_{\mathrm{a}}\right.$ in Ozima and Podosek, 2002). The noble gas data indicate that the metamorphic temperature experienced by the PGC was higher than $300-400{ }^{\circ} \mathrm{C}$ as proposed by based on Raman and TEM thermometers, and may support higher temperatures estimated from C-XANES $\left(\sim 750-850{ }^{\circ} \mathrm{C}\right)$.

It should be noted that while Raman has relatively good spatial resolution $(\sim 1.1 \mu \mathrm{m})$, it is difficult to obtain spectra of C-rich aggregates without some contribution from the matrix since C-rich aggregates represent only $\sim 10 \%$ of the area of the clasts (Fig. 19). However, most of the 
$\mathrm{G}$ and $\mathrm{D}$ band features consist of C-rich aggregates since matrix carbon contents are very low compared to the C-rich aggregates, as shown in the STXM C-map (Fig. 7).

The $1 \mathrm{~s}-\sigma^{*}$ exciton from C-XANES spectra reflects the development of the graphene structure in the macromolecular carbon due to heat-induced decomposition of labile functional groups and aromatization (Cody et al., 2008b). The thermometer proposed by Cody et al. (2008b) is based on the kinetics obtained from heating experiments of the Murchison CM2 meteorite assuming a metamorphism time scale of $10^{7}$ years, that the excitation response is a function of temperature and follows the Arrhenius behavior, and adjusted with pure graphite as $100 \%$ exciton intensity and the least-altered (among the meteorites they analyzed) chondrite EET 92042 (CR2) as 0\% exciton intensity. The Raman $\mathrm{G}$ band is the result of in-plane vibration of the graphite crystalline structure, and a sharp G band indicates the presence of well-crystalline graphitic materials. The Raman D1 band is the result of in-plane defects resulting from the presence of heteroatoms - indeed the origin of the D bands is ambiguous. The geothermometers based on Raman spectra have been well studied and originally used to obtain the PMT of geological carbonaceous samples (Beyssac et al., 2002a; Kouketsu et al., 2014). This technique has also been used to investigate the metamorphic history of meteorites (e.g., Bonal et al., 2007; Busemann et al., 2007). Cody et al. (2008b) pointed out that there is a good correlation between the intensity of the $1 \mathrm{~s}^{-} \sigma^{*}$ exciton and Raman spectral data in these studies. The TEM observations reveal the $d_{002}$ layer lattice fringes of graphite, which is $0.345 \mathrm{~nm}$ for perfectly crystalline graphite. The thermometers based on the interlayer spacings of graphitized carbon have been used for extraterrestrial samples (e.g., Rietmeijer and Mackinnon, 1985), based on the observation of naturally occurring PGC in terrestrial metamorphic rocks. 
The parameters that are used for the thermometers from C-XANES and Raman are obtained from the features that are generated from planar structures of graphene sheets, and the parameter from TEM is based on the vertical structure of stacked graphene sheets. To illustrate, the Raman spectra of perfectly-crystalline graphene and graphite (stacks of graphene sheets) are very similar in the first-order region (Ferreira et al., 2010). That potentially causes the difference between the calculated metamorphic temperatures. However, the metamorphic temperature obtained from Raman is rather more similar with that from TEM than it is from C-XANES. This may be due to the analytical spot size of Raman $(\sim 1.1 \mu \mathrm{m})$ that includes not only C-rich aggregates but also low temperature matrix carbon, and the PMT of the C-rich aggregates may be underestimated (Fig. 19). In fact that $T_{\mathrm{EFF}}$ of acid residue estimated by C-XANES thermometer is $\sim 550 \pm \sim 150{ }^{\circ} \mathrm{C}$ that is lower than $T_{\mathrm{EFF}}$ of C-rich aggregates (Table 3 ).

Considering the methods for developing the thermometer, only the exciton intensity thermometer was experimentally obtained using genuine extraterrestrial carbons, although even this thermometer required a calibration with an established chondritic mineralogical thermometer, i.e., the olivine-spinel thermometer (Wlotzka, 2005). Other thermometers rely on kerogen in regional metamorphic terrestrial rocks that were subjected to both heat and shear deformation. The origin and composition of extraterrestrial and terrestrial carbonaceous matter are significantly different, although the products are somewhat similar in molecular structures, i.e., "kerogen-like". Therefore, it is not clear that terrestrial carbon (kerogen) is the best model for extraterrestrial IOM and may be inappropriate for the application of these thermometers to extraterrestrial samples. The exciton intensity thermometer is based on kinetics, and as a consequence the metamorphic time scale has to be fixed, in this case the time is fixed at $10^{7}$ years, which is in reality there is not such time constraint for the C-rich aggregates, although the 
temperature dependence of the exciton intensity is much larger than the time dependence (Cody et al., 2008b). It should be noted that the effective temperatures estimated from C-XANES is based on the assumptions that the starting material was similar to CM-CI-CR like IOM with long term heating (not shock metamorphism), and it might not be the case of the C-rich aggregates.

The variation in temperatures obtained from different methods (from $300{ }^{\circ} \mathrm{C}$ up to $850^{\circ} \mathrm{C}$ ) may also indicate that the C-rich aggregates did not originate from typical carbonaceous materials as observed in chondrites, i.e., IOM. Because if C-rich aggregates originated from IOM-like precursor, one might expect that even use of different thermometer ends up similar temperature range as long as the thermometers are based on IOM (not for some Raman estimations based on terrestrial rock).

\subsection{Cosmogenic $\mathrm{He}$ and $\mathrm{Ne}$}

A small contribution of cosmogenic $\mathrm{He}$ and $\mathrm{Ne}$ is observed at low temperatures, $300^{\circ} \mathrm{C}$ and $700{ }^{\circ} \mathrm{C}$, as shown in Fig. 12 and Fig. 13. These concentrations are much smaller than those reported for the bulk sample of the Sharps meteorite (Zadnik, 1985). The low concentrations for our acid residue sample possibly reflect a loss of cosmogenic He from poorly-crystalized carbon materials. Production of Ne by cosmic ray bombardment is difficult in almost target-free PGC material. Thermally fragile sulfur-bearing material that might remain in the residue as an impurity could be a target for He and Ne production by cosmic rays as already noted above.

The cosmogenic ${ }^{21} \mathrm{Ne}\left(0.47 \times 10^{-9} \mathrm{~cm}^{3} \mathrm{STP} / \mathrm{g}\right)$ at $1500{ }^{\circ} \mathrm{C}$ was probably produced in presolar $\mathrm{SiC}$ as noted above. Based on the discussion of $\mathrm{SiC}$ grains from the Murchison meteorite in Lewis et al. (1994) (i.e., ${ }^{21} \mathrm{Ne}$ production rate is $4.21 \times 10^{-9} \mathrm{~cm}^{3} \mathrm{STP} / \mathrm{gSiC} / \mathrm{Ma}$; recoil loss is 10-50\%; possible exposure ages preceeding solar system formation are $>100 \mathrm{Ma}$ ), the 
weight fraction of $\mathrm{SiC}$ in the acid residue sample was less than 600-1000 ppm. If the yield of acid residue from the Sharps carbonaceous clast is $1 \%$, the weight fraction of $\mathrm{SiC}$ in the bulk clast is less than 6-10 ppm. This value is consistent with the estimation of $7 \pm 2 \mathrm{ppm} \mathrm{SiC} \mathrm{for}$ bulk Murchison meteorite (Lewis et al., 1994). The measured ${ }^{22} \mathrm{Ne}-\mathrm{E}(\mathrm{H})$ concentration of $11 \times$ $10^{-9} \mathrm{~cm}^{3} \mathrm{STP} / \mathrm{g}$ is converted to less than $(1.8-1.1) \times 10^{-5} \mathrm{~cm}^{3} \mathrm{STP} / \mathrm{gSiC}$ using the above weight fraction of $\mathrm{SiC}$ in the acid residue. Although the estimate seems to be slightly lower than the ${ }^{22} \mathrm{Ne}-\mathrm{E}(\mathrm{H})$ concentrations of $(5-36) \times 10^{-5} \mathrm{~cm}^{3} \mathrm{STP} / \mathrm{gSiC}$ reported for $\mathrm{SiC}$ grains separated from the Murchison chondrite by Lewis et al. (1994), it would be in the range for presolar SiC grains in various classes of carbonaceous chondrites.

\subsection{Origins of the $\mathrm{C}$-rich aggregates}

Overall, the carbonaceous matter in C-rich aggregates is characterized by a welldeveloped graphene-like planar structure with loose layer structure with little or no H, N, and O. The FTIR spectra of the acid residue (mostly consist of C-rich aggregates) from the Sharps clast show almost no features, suggesting lower hydrogen and oxygen contents than acid residues from typical type 3.4 ordinary chondrites. Using the kinetics of aliphatic $\mathrm{C}-\mathrm{H}$ peak decomposition (Kebukawa et al., 2010), assuming that the C-rich aggregate has primitive IOMlike precursor, minimum heating duration that is required for complete loss of aliphatic $\mathrm{C}-\mathrm{H}$ peak is $10 \mathrm{~h}$ if $T_{\mathrm{EFF}}$ is $300{ }^{\circ} \mathrm{C}$, and is $1 \mathrm{~s}$ if $T_{\mathrm{EFF}}$ is $800{ }^{\circ} \mathrm{C}$. The C-XANES thermometer intensities indicate a peak temperature around $750{ }^{\circ} \mathrm{C}$ to $850{ }^{\circ} \mathrm{C}$ for the C-rich aggregates, and less than $300-500{ }^{\circ} \mathrm{C}$ for the surrounding matrix. The actual temperatures that the $\mathrm{C}$-rich aggregates and clast matrix were metamorphosed at are very much subject to the thermometer used to determine, 
e.g., carbon $d_{002}$ layer lattice fringes of the C-rich aggregates indicate a low temperature range of $300-400{ }^{\circ} \mathrm{C}$; Raman thermometer suggests a temperature range of $380-490{ }^{\circ} \mathrm{C}$.

The C-XANES spectra show unambiguous differences between the C-rich aggregates and the clast matrix carbon, suggesting that the C-rich aggregates did not originate from the clast parent body. Moreover, the C-XANES spectra of clast matrix carbon are similar to those of CR, CI and CM chondrites reported in Le Guillou et al. (2014), indicating that the clasts originated from a primitive, likely small, parent body somewhat similar to the those of CR, CI and CM chondrites.

The noble gas-rich nature of the C-rich aggregates indicates that these gases had already been trapped in the $\mathrm{C}$-rich aggregates, or at least the precursors of the C-rich aggregates, before accretion into planetesimals. Once the carbonaceous matter has accreted into planetesimals, the probability of noble gases being incorporated into the carbonaceous matter is reduced, although the timing and mechanism of the noble gas trapping are controversial. By some unknown process, the C-rich aggregates were mixed with the clast parent body, and later the clast parent body impacted into the Sharps parent body (H chondrite parent body). The angular shape of the clasts (Fig. 1) indicates that the clasts were incorporated into the Sharps parent body relatively soon after the shock event without any gardening process that would have rounded the edges. The timing of the shock event is ambiguous because the clast matrix carbon indicates a temperature of $\sim 300$ to $500{ }^{\circ} \mathrm{C}$, which is comparable with the metamorphic temperature of the Sharps parent body (350 to $400{ }^{\circ} \mathrm{C}$; Huss et al., 2006). It should be noted that if the $\mathrm{C}$-rich aggregates represent thermally metamorphosed IOM, then the thermometers used here (C-XANES, Raman and TEM) are valid, but if the carbon in the C-rich aggregates has a completely different origin than primitive IOM, then the thermometric methods applied to the C-rich clasts may not be justified. 
In either case, it is clear that the $\mathrm{C}$-rich aggregates experienced different processing than the clast matrix organic matter and are not indigenous to the Sharps clast parent body.

In the following sections, we discuss the possible origins for the C-rich aggregates. There are multiple "point of origin" hypotheses regarding where and how organic solids are formed. These include Pre-solar origin, meaning formation in the interstellar medium, preaccretionary synthesis in the disk, and post planetesimal accretion within planetesimal interiors.

\subsubsection{Presolar origin?}

Carbonaceous particles are observed in the diffuse interstellar medium (ISM) (e.g., Ehrenfreund and Charnley, 2000). Interstellar infrared observations commonly detect an aromatic band, and one of the most plausible candidates for the band is polycyclic aromatic hydrocarbons (PAHs) (Allamandola et al., 1989; Puget and Léger, 1989; Sellgren, 2001). The aggregates of large PAHs may form glassy carbon that would be similar to the C-rich aggregates in the Sharps clasts. Sandford et al. (1998) attempted to constrain the carriers of noble gases by simulating the ISM environment by deposition of multiple layers of ices of different compositions. Each layer was composed of mixed-molecular ice containing $\mathrm{H}_{2} \mathrm{O}, \mathrm{CH}_{3} \mathrm{OH}, \mathrm{CO}$, $\mathrm{NH}_{3}$, noble gases ( $\mathrm{He}, \mathrm{Ne}, \mathrm{Ar}, \mathrm{Kr}, \mathrm{Xe}$ ), and a PAH. This multilayer assemblage was then irradiated by UV at a low temperature $(10 \mathrm{~K})$. These workers succeeded in trapping high concentrations of elementally fractionated $\mathrm{Kr}$ and $\mathrm{Xe}$, but $\mathrm{He}$ and $\mathrm{Ne}$ were not trapped. Noble gasses were extracted from the samples at $1000{ }^{\circ} \mathrm{C}$ after preheating at $130-150{ }^{\circ} \mathrm{C}$ in a vacuum. Their results indicate that heavy noble gases $\mathrm{Kr}$ and $\mathrm{Xe}$ can be trapped in the mixed-molecular ice and retained to temperatures between 150 to $1000{ }^{\circ} \mathrm{C}$. Similar experiments may illuminate the formation and trapping mechanism of Q-gas in phase Q. 
Hydrogenated aromatic carbon (HAC; a-C:H) have been proposed by some to be a potentially significant component of interstellar dust (e.g., Jones, 1990; Dartois et al., 2004, 2007; Dartois and Muñoz-Caro, 2007; Pino et al., 2008). UV irradiation of HAC materials (produced by pulsed-laser ablation of a rotating graphite target in a quenching gas atmosphere which consists of a mixture of $\mathrm{He}$ and $\mathrm{H}_{2}$ gas at a pressure of 4.5 mbar) revealed that the amorphous structure of the carbonaceous grains can be transformed into more graphitic structures (Gadallah et al., 2011). TEM observation of the UV-irradiated HAC showed ordered graphitic structures that are similar to the C-rich aggregates in Sharps clasts (Fig. 10). It has also been shown that UV irradiation induces loss of $\mathrm{sp}^{3}$ carbon as observed in IR spectra of irradiated HAC (Gadallah et al., 2011), which is also consistent with our IR observations of the acid residue (Fig. 3), suggesting the possibility that the apparent maturity of the C-rich aggregates is not due to heating, but rather having been photolytically processed prior to accretion. On the other hand, $\mathrm{H}^{+}, \mathrm{He}^{+}$and $\mathrm{Ar}^{++}$ion irradiation of "soot" samples induces amorphization not graphitization, as indicated by Raman spectra (Brunetto et al., 2009). Therefore, the argument is that if the C-rich aggregates in the Sharps clasts originated from interstellar carbonaceous matter, then one would have to argue that their carbon had been processed by UV irradiation, but not by ion irradiation.

\subsubsection{Solar nebula process?}

One of our TEM images (Fig. 11c) shows graphitic flakes growing on a Fe-Ni grain, and the graphite likely nucleated on the metal surface. Such a texture could be indicative of FischerTropsch type (FTT) synthesis, as Brearley (1990) suggested. The basic FTT synthesis produces hydrocarbons from carbon monoxide and hydrogen over metal catalysts at $200-350{ }^{\circ} \mathrm{C}$ (e.g., Dry, 
2002). The potential of such catalytic gas-solid reactions occurring in moderately high temperature regions of the solar nebula has been proposed by some as a potential source for IOM (Anders et al., 1973; Llorca and Casanova, 2000; Kress and Tielens, 2001; Nuth et al., 2008). When FTT synthesis is prolonged or carried out at higher temperatures, polyaromatic hydrocarbons with up to seven rings are formed. Products similar to meteoritic macromolecular carbon were produced in an FTT synthesis that extended over 6 months (Studier et al., 1968; Studier et al., 1972; Anders et al., 1973). During a grain surface FTT reaction, unreactive graphitic carbon forms from carbidic (reactive) carbon at higher temperatures (which usually "poisons" the catalytic surface and lowers the reaction rate) (Kress and Tielens, 2001).

Not all carbon in the C-rich aggregates appears to have been synthesized on the Fe-Ni grain surface. Because carbonaceous materials can also catalyze FTT reactions (Nuth et al., 2008), carbon-rich thin layers could be synthesized on preexisting presolar grains such as nanodiamonds, graphite, and SiC. The large abundance of presolar diamonds ( $500 \mathrm{ppm})$ and their small size $(\sim 2-3 \mathrm{~nm})$ in primitive meteorites (e.g., Zinner, 1998) could have provided large surface areas for FTT reactions to produce carbonaceous coatings. Q-gas could have been trapped during this synthesis. The surface coating of presolar nanodiamonds might be one of the plausible candidates for the phase Q (Lewis et al., 1987; Busemann et al., 2000), although trapping mechanisms for high concentrations of elementally fractionated noble gases and high retentivity are still enigmatic.

\subsubsection{Parent body origin?}

Cody et al. (2011) proposed the formation of IOM-like organic solids from simple molecules (formaldehyde) in the presence of liquid water in the interiors of planetesimals. 
Further investigations of this hypothesis revealed that ammonia accelerated the formation of the organic solids and resulted in significant incorporation of N-bearing functional groups into the organic solids (Kebukawa et al., 2013; Kebukawa and Cody, 2015). Subsequent parent body thermal processing decreased the $\mathrm{H}, \mathrm{N}$, and $\mathrm{O}$ contents in IOM (Alexander et al., 2007; Alexander et al., 2010), and induced graphitization. If this is the case then molecular evolution is entirely based on environmental heating and the C-rich aggregates had to form somewhere else before becoming incorporated with the Sharps clasts parent body later

Carbonaceous precursors can be divided into two classes based on their ability to graphitize; graphitizing and non-graphitizing carbon. In the non-graphitizing carbons, a strong system of cross-linking uniting the crystallites leads to a random orientation of the crystallites in a rigid structure, which enables the rearrangement of the layer-planes (Franklin, 1951; Buseck and Beyssac, 2014). Crystallite growth is impeded both by the strong cross-linking between neighboring crystallites and by their random orientation (Buseck and Beyssac, 2014).

The C-rich aggregates in this study appear mostly to consist of non-graphitizing carbon. TEM images show randomly oriented carbonaceous sheet domains that are characteristic of glassy carbon. These randomly oriented carbonaceous sheet domains do not readily reform into large coherent domains and thence to well-crystalline graphite when subjected to elevated temperature and pressure, instead forming turbostratic graphitic carbon.

\subsection{Origins of the Sharps clasts}

In contrast to the C-rich aggregates, the Sharps clast matrix contains primitive organic matter similar to that of CR, CI and CM chondrites as seen in C-XANES. Therefore, the clasts originated from a primitive, likely small, parent body somewhat similar to those of CR, CI and 
CM chondrites. The temperature estimated from C-XANES is higher than temperatures for these primitive chondrites, but it is likely due to some contributions from fine grained C-rich aggregates in the matrix. The clast parent body acquired C-rich aggregates by a process that we cannot yet constrain (as discussed in the previous sections). In any case, an impact event may have scattered the angular carbonaceous clasts off of its parent body for delivery to the Sharps $\mathrm{H}$ chondrite parent body, and/or impact events may have been repeated during incorporation into that final parent body. It is also possible that the parent body of the clasts was destroyed after the sharps parent asteroid accreted, with the clast pieces being incorporated into the regolith of the sharps asteroid in time to be later released for its voyage to earth.

It is possible to propose specific asteroids as the parent bodies of the carbonaceous clasts, and the Sharps meteorite. Based upon the similarity of the reflectance spectrum with $\mathrm{H}$ chondrites and dynamical arguments, the proposed source of the $\mathrm{H}$ chondrites is asteroid 6 Hebe (Gaffey and Gilbert, 1998). As pointed out by Fries et al. (2013), Hebe currently has an orbit that essentially intersects that of the largest C-class asteroid, 1 Ceres. As C-class asteroids are probably carbonaceous, it is entirely possible that Ceres is the source of the carbonaceous clasts, and Hebe the source of Sharps. The modern orbits of Ceres and Hebe are reasonably similar, with aphelion/perihelion of Ceres and Hebe of 2.99/2.55 and 2.91/1.94 AU, respectively (Fries et al., 2013). Initial calculations by those authors indicate an approximate mean material transfer infall velocity of 1.20 to $1.38 \mathrm{~km} / \mathrm{s}$, which means that material from Ceres would, on average, be lightly shocked during incorporation onto Hebe, accounting for at least some of the heating experienced by the carbonaceous clasts in Sharps, but not being sufficiently severe to amorphize the glassy carbon. 


\section{CONCLUSIONS}

The carbonaceous matter in the dark clasts in the Sharps meteorite was investigated using various microscopic methods including FTIR, Raman, C-XANES and TEM. Acid residue was obtained from the clast, and noble gas concentrations and isotopic compositions of this material were analyzed using mass spectrometry.

We found that the C-rich aggregates are similar to the ones described earlier by Brearley (1990). C-XANES spectra of the C-rich aggregates show highly-developed graphene structures while surrounding matrix consists of primitive organic matter similar to that found in $\mathrm{CR}, \mathrm{CM}$ and CI carbonaceous chondrites. The C-XANES thermometer shows clear differences between the C-rich aggregates $\left(750\right.$ to $850{ }^{\circ} \mathrm{C}$ ) and matrix carbon (less than 300 to $500{ }^{\circ} \mathrm{C}$ ), suggesting that the C-rich aggregates did not originate from the clast parent body. Based on other organic thermometric methods, peak metamorphic temperatures for the C-rich aggregates were $\sim 380$ $490{ }^{\circ} \mathrm{C}$ (based on Raman), and $\sim 300-400{ }^{\circ} \mathrm{C}$ (based on TEM) indicating that the thermal processes associated with the C-rich aggregates are complex. The most plausible temperature estimation is likely using C-XANES thermometer, although it is based on the assumptions that the starting material was similar to CM-CI-CR like IOM with long term heating (not shock metamorphism).

Noble gases released from the $\mathrm{HF} / \mathrm{HCl}$ acid residue are mostly composed of $\mathrm{HL}$ and $\mathrm{Ne}-$ $\mathrm{E}(\mathrm{H})$, in addition to $\mathrm{Q}$ components. Low concentrations of cosmogenic ${ }^{3} \mathrm{He}$ and ${ }^{21} \mathrm{Ne}$ as well as terrestrial atmospheric heavy noble gases were also detected in this sample. The noble gas data clearly show the presence of both presolar diamonds and presolar $\mathrm{SiC}$ grains in addition to abundant Q-gas. The concentrations of Q-gas and $\mathrm{Ne}-\mathrm{E}(\mathrm{H})$ agree with the range reported for $\mathrm{HF} / \mathrm{HCl}$ residues of carbonaceous chondrites. These results may show that the "visible" $\mu \mathrm{m}$-size 
C-rich aggregates in the dark clasts in the Sharps meteorite were originally the same as the previously reported acid residues. The observed partial loss of He-HL and Ne-HL compared with Ar-HL from presolar diamonds would be a result of heating event(s) that occurred on the carbonaceous parent asteroid of the clasts, or on the H-chondrite parent body after incorporation of the clasts. Although the heating temperatures estimated by different methods range from 300 to $850{ }^{\circ} \mathrm{C}, \sim 700{ }^{\circ} \mathrm{C}$ could be preferable because HL-gas is released in the temperature range 700-1000 ${ }^{\circ} \mathrm{C}$ during stepwise heating experiments on bulk carbonaceous chondrites.

Several different scenarios can be considered for the origin of the C-rich aggregates and the clasts. One possibility is that the C-rich aggregates were incorporated into a clast parent body, probably primitive carbonaceous chondrite-like (possibly asteroid 1 Ceres, or some other $\mathrm{C}, \mathrm{P}$ or D asteroid), subsequently, the clast parent body crashed into the Sharps parent body (the $\mathrm{H}$ chondrite parent body, possibly asteroid 6 Hebe).

\section{ACKNOWLEDGMENTS}

We are very grateful to three anonymous reviewers and Associate Editor, Dr. Eric Quirico for their fruitful comments for this manuscript. We thank Marc Fries for valuable comments and discussion. We thank Dr. Bjørn O. Mysen for providing access to the FTIR. This research was supported by the NASA Astrobiology Institute. YK acknowledges supports through the Japan Society for the Promotion of Science (JSPS) Postdoctoral Fellowships and KAKENHI grant (No. 15K17794), and the Astrobiology Program of National Institutes of Natural Sciences (NINS). The FTIR facility at the Geophysical Laboratory was supported by the W. M. Keck Foundation. STXM-XANES data were acquired at beamline 5.3.2.2 at the ALS, which is supported by the Director of the Office of Science, Department of Energy, under Contract No. 
DE-AC02-05CH11231. MEZ was supported by the NASA Cosmochemistry and LARS Programs. QHSC acknowledges support from the NASA Postdoctoral Program at the Johnson Space Center, administered by Oak Ridge Associated Universities. KN acknowledges the Ministry of Science, ICT and Planning (MSIP) of Korea, for support to prepare the paper.

\section{APPENDIX}

\section{Sample damage as a result of laser interaction during Raman spectroscopy}

Laser irradiation of carbon-bearing materials often causes not only physical damage, but also photo-oxidation effects (Quirico et al., 2005b). Such alteration is difficult to recognize by visual observation, and in many cases the Raman spectra of damaged samples can be misleading because the Raman feature only represents the oxidized materials. To illustrate this, we show the changes in the carbon structure as a result of varying the laser intensity on the sample surface. The laser intensity on the sample with no filter is $\sim 9 \mathrm{~mW}$; the laser intensities on the sample with the D 0.3 , D 0.6 and D 1 filters are $\sim 4.5 \mathrm{~mW}, \sim 2.25 \mathrm{~mW}$ and $\sim 0.9 \mathrm{~mW}$, respectively (Fig. A1, Table A1). 


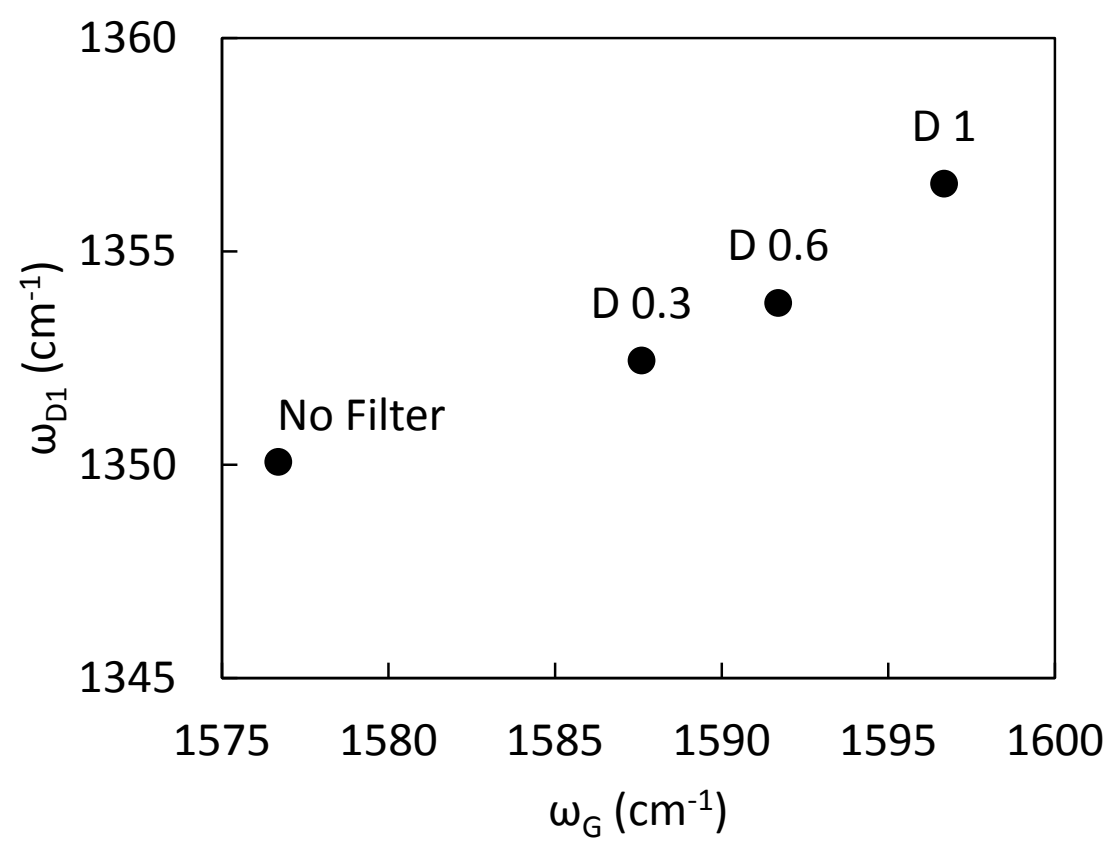

Fig. A1. Changes in peak center locations $\left(\omega_{\mathrm{D} 1}\right.$ and $\left.\omega_{\mathrm{G}}\right)$ with the use of different laser filters. The laser intensity on the sample with no filter is $\sim 9 \mathrm{~mW}$; the laser intensities on the sample with the D 0.3, D 0.6 and D 1 filters are $\sim 4.5 \mathrm{~mW}, \sim 2.25 \mathrm{~mW}$ and $\sim 0.9 \mathrm{~mW}$, respectively.

Table A1. Raman spectral parameters of the Sharps clast. 


\begin{tabular}{|c|c|c|c|c|c|c|c|c|c|c|c|c|c|}
\hline & Filter & $\begin{array}{c}\text { Laser } \\
\text { Intensity }\end{array}$ & $\omega_{\mathrm{G}}$ & $\omega_{\mathrm{D} 1}$ & $\Gamma_{\mathrm{G}}$ & $\Gamma_{\mathrm{Dl}}$ & $\mathbf{I}_{\mathrm{G}}$ & $\mathbf{I}_{\mathrm{Dl}}$ & $\begin{array}{c}\text { Rl } \\
\text { Ratio }\end{array}$ & ADl & AD2 & AG & $\begin{array}{r}\text { R2 } \\
\text { Ratio }\end{array}$ \\
\hline Sharps Pt 1 & D 0.6 & $25 \%$ & 1592 & 1334 & 56 & 165 & 29 & 56 & 1.91 & 12565 & 1142 & 2426 & 0.78 \\
\hline Sharps Pt 2 & D 0.6 & $25 \%$ & 1592 & 1354 & 57 & 124 & 57 & 77 & 1.35 & 13453 & 2449 & 4800 & 0.65 \\
\hline Sharps Pt 3 & D 0.6 & $25 \%$ & 1583 & 1351 & 66 & 151 & 33 & 63 & 1.91 & 13070 & 2983 & 3156 & 0.68 \\
\hline Sharps Pt 4 & D 0.6 & $25 \%$ & 1586 & 1352 & 62 & 146 & 38 & 73 & 1.92 & 14774 & 3212 & 3492 & 0.69 \\
\hline Sharps Pt 5 & D 0.6 & $25 \%$ & 1585 & 1353 & 63 & 123 & 47 & 71 & 1.49 & 12274 & 2755 & 4368 & 0.63 \\
\hline Sharps Pt 6 & D 0.6 & $25 \%$ & 1591 & 1351 & 61 & 134 & 49 & 66 & 1.34 & 12422 & 1726 & 4424 & 0.67 \\
\hline Mean & & & 1588 & 1349 & 61 & 140 & 42 & 68 & 1.65 & 13093 & 2378 & 3778 & 0.68 \\
\hline \multicolumn{3}{|c|}{ Standard deviation ( $\sigma$ ) } & 4 & 7 & 4 & 16 & 11 & 8 & 0.29 & 933 & 795 & 906 & 0.05 \\
\hline \multicolumn{3}{|c|}{ Standard error of the mean } & 2 & 3 & 1 & 7 & 4 & 3 & 0.12 & 381 & 325 & 370 & 0.02 \\
\hline \multicolumn{3}{|c|}{ Propagation of error $(\delta)$} & & & & & & & 0.45 & & & & 0.04 \\
\hline \multirow[t]{4}{*}{ Sharps Pt 2} & D 1 & $10 \%$ & 1597 & 1357 & 57 & 124 & 61 & 75 & 1.23 & 13156 & 1872 & 5172 & 0.65 \\
\hline & D 0.6 & $25 \%$ & 1592 & 1354 & 57 & 124 & 57 & 77 & 1.35 & 13453 & 2449 & 4800 & 0.65 \\
\hline & D 0.3 & $50 \%$ & 1588 & 1352 & 61 & 140 & 52 & 66 & 1.28 & 15098 & 2207 & 4472 & 0.66 \\
\hline & -- & $100 \%$ & 1577 & 1350 & 52 & 131 & 53 & 59 & 1.11 & 10863 & 2213 & 4130 & 0.63 \\
\hline \multicolumn{3}{|l|}{ Mean } & 1588 & 1353 & 57 & 130 & 56 & 69 & 1.24 & 13143 & 2185 & 4644 & 0.65 \\
\hline \multicolumn{3}{|c|}{ Standard deviation $(\sigma)$} & 9 & 3 & 4 & 8 & 4 & 8 & 0.10 & 1743 & 237 & 446 & 0.01 \\
\hline \multicolumn{3}{|c|}{ Standard error of the mean } & 4 & 1 & 2 & 4 & 2 & 4 & 0.05 & 872 & 119 & 223 & 0.01 \\
\hline \multicolumn{3}{|c|}{ Propagation of error $(\delta)$} & & & & & & & 0.17 & & & & 0.02 \\
\hline
\end{tabular}

Area ratio (integrated area) $R 2$ ratio $=A D 1 /(A D 1+A D 2+A G)$

$\delta \mathrm{R} 2=\left[(\mathrm{R} 2)^{2} /(\mathrm{AD} 1)^{2}\right] \cdot\left[(\delta \mathrm{AD} 1)^{2}+\left((\mathrm{AD} 1)^{2} \cdot(\delta \mathrm{AD} 2)^{2}+\left((\mathrm{AD} 1)^{2} \cdot(\delta \mathrm{AG})^{2}\right]^{1 / 2}\right.\right.$

$\delta \mathrm{IDIG}=\left[\mathrm{IDIG} \cdot\left[(\delta \mathrm{ID} / \mathrm{ID})^{2}+(\delta \mathrm{IG} / \mathrm{IG})^{2}\right]^{1 / 2}\right.$ 
Tables for noble gas concentrations and isotopic ratios in the Sharps clast acid residue

Table A2. He, Ne and Ar isotopic ratios, and concentrations of noble gases in the Sharps clast acid residue.

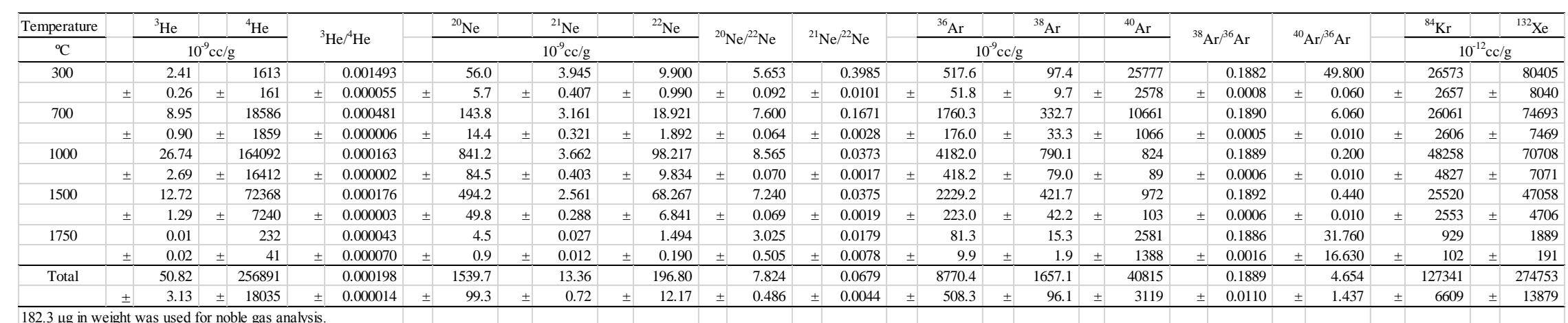


Table A3. Kr concentrations and isotopic ratios in the Sharps clast acid residue.

\begin{tabular}{|c|c|c|c|c|c|c|c|c|c|c|c|c|}
\hline Temperature & \multicolumn{2}{|c|}{${ }^{84} \mathrm{Kr}\left[10^{-12} \mathrm{cc} / \mathrm{g}\right]$} & \multicolumn{2}{|c|}{${ }^{78} \mathrm{Kr} /{ }^{84} \mathrm{Kr}$} & \multicolumn{2}{|c|}{${ }^{80} \mathrm{Kr} /{ }^{84} \mathrm{Kr}$} & \multicolumn{2}{|c|}{${ }^{82} \mathrm{Kr} /{ }^{84} \mathrm{Kr}$} & \multicolumn{2}{|c|}{${ }^{83} \mathrm{Kr} /{ }^{84} \mathrm{Kr}$} & \multicolumn{2}{|c|}{${ }^{86} \mathrm{Kr} /{ }^{84} \mathrm{Kr}$} \\
\hline \multirow[t]{2}{*}{300} & & 26573 & & 0.00622 & & 0.0410 & & 0.2051 & & 0.2011 & & 0.3025 \\
\hline & \pm & 2657 & \pm & 0.00022 & \pm & 0.0007 & \pm & 0.0031 & \pm & 0.0015 & \pm & 0.0038 \\
\hline \multirow[t]{2}{*}{700} & & 26061 & & 0.00616 & & 0.0415 & & 0.2019 & & 0.2029 & & 0.3078 \\
\hline & \pm & 2606 & \pm & 0.00037 & \pm & 0.0005 & \pm & 0.0021 & \pm & 0.0026 & \pm & 0.0041 \\
\hline \multirow[t]{2}{*}{1000} & & 48258 & & 0.00621 & & 0.0396 & & 0.1995 & & 0.2025 & & 0.3061 \\
\hline & \pm & 4827 & \pm & 0.00016 & \pm & 0.0009 & \pm & 0.0013 & \pm & 0.0012 & \pm & 0.0019 \\
\hline \multirow[t]{2}{*}{1500} & & 25520 & & 0.00623 & & 0.0389 & & 0.2001 & & 0.2022 & & 0.3056 \\
\hline & \pm & 2553 & \pm & 0.00030 & \pm & 0.0008 & \pm & 0.0022 & \pm & 0.0016 & \pm & 0.0023 \\
\hline \multirow[t]{2}{*}{1750} & & 929 & & 0.00618 & & 0.0427 & & 0.2075 & & 0.2065 & & 0.3102 \\
\hline & \pm & 102 & \pm & 0.00129 & \pm & 0.0044 & \pm & 0.0090 & \pm & 0.0118 & \pm & 0.0155 \\
\hline \multirow[t]{2}{*}{ Total } & & 127341 & & 0.00621 & & 0.0402 & & 0.2013 & & 0.2023 & & 0.3056 \\
\hline & \pm & 6609 & \pm & 0.00034 & \pm & 0.0021 & \pm & 0.0105 & \pm & 0.0105 & \pm & 0.0159 \\
\hline
\end{tabular}

$182.3 \mu \mathrm{g}$ in weight was used for noble gas analysis.

Table A4. Xe concentrations and isotopic ratios in the Sharps clast acid residue.

\begin{tabular}{|c|c|c|c|c|c|c|c|c|c|c|c|c|c|c|c|c|c|c|}
\hline \multirow{2}{*}{$\frac{\text { Temperature }}{300}$} & \multicolumn{2}{|c|}{${ }^{132} \mathrm{Xe}\left[10^{-12} \mathrm{cc} / \mathrm{g}\right]$} & \multicolumn{2}{|c|}{${ }^{124} \mathrm{Xe} /{ }^{132} \mathrm{Xe}$} & \multicolumn{2}{|c|}{${ }^{126} \mathrm{Xe} /{ }^{132} \mathrm{Xe}$} & \multicolumn{2}{|c|}{${ }^{128} \mathrm{Xe} /{ }^{132} \mathrm{Xe}$} & \multicolumn{2}{|c|}{${ }^{129} \mathrm{Xe} /{ }^{132} \mathrm{Xe}$} & \multicolumn{2}{|c|}{${ }^{130} \mathrm{Xe} /{ }^{132} \mathrm{Xe}$} & \multicolumn{2}{|c|}{${ }^{131} \mathrm{Xe} /{ }^{132} \mathrm{Xe}$} & \multicolumn{2}{|c|}{${ }^{134} \mathrm{Xe} /{ }^{132} \mathrm{Xe}$} & \multicolumn{2}{|c|}{${ }^{136} \mathrm{Xe} /{ }^{132} \mathrm{Xe}$} \\
\hline & & 80405 & & 0.00338 & & 0.00327 & & 0.0709 & & 0.993 & & 0.1515 & & 0.794 & & 0.3899 & & 0.3296 \\
\hline & \pm & 8040 & \pm & 0.00018 & \pm & 0.00009 & \pm & 0.0006 & \pm & 0.003 & \pm & 0009 & \pm & 0.003 & \pm & .0014 & \pm & .0022 \\
\hline \multirow[t]{2}{*}{700} & & 74693 & & 0.00362 & & 0.00356 & & 0.0738 & & 1.004 & & 0.1538 & & 0.797 & & 0.3845 & & 0.3243 \\
\hline & \pm & 7469 & \pm & 0.00010 & \pm & 0.00008 & \pm & 0.0003 & \pm & 0.003 & \pm & 0.0015 & \pm & 0.003 & \pm & 0.0020 & \pm & 0.0013 \\
\hline \multirow[t]{2}{*}{1000} & & 70708 & & 0.00422 & & 0.00405 & & 0.0806 & & 1.029 & & 0.1612 & & 0.822 & & 0.3830 & & 0.3212 \\
\hline & \pm & 7071 & \pm & 0.0001 & \pm & 0.0001 & \pm & 0.0008 & \pm & 0.006 & \pm & 0.0009 & \pm & 04 & \pm & 26 & \pm & 0.0024 \\
\hline \multirow[t]{2}{*}{1500} & & 47058 & & 0.004 & & 0.00392 & & 0.0802 & & 1.029 & & 0.1591 & & 0.817 & & 0.3846 & & .3255 \\
\hline & \pm & 4706 & \pm & 0.00 & \pm & 0.00009 & \pm & 0.0004 & \pm & 0.003 & \pm & 0010 & \pm & 06 & \pm & .0021 & \pm & 0.0023 \\
\hline \multirow[t]{2}{*}{1750} & & 1889 & & 0.00 & & 0.00 & & 0.0779 & & 1.021 & & 1611 & & 20 & & 0.3921 & & 0.3379 \\
\hline & \pm & 191 & \pm & 0.00 & \pm & & \pm & 0.0069 & \pm & 0.023 & \pm & 0.0050 & \pm & 0.026 & \pm & & \pm & 0.0127 \\
\hline \multirow[t]{2}{*}{ Total } & & 274753 & & & & & & 0.0758 & & 1.012 & & 560 & & 0.806 & & & & 0.3253 \\
\hline & \pm & 13879 & \pm & 0.00021 & \pm & 0.00019 & \pm & 0.0038 & \pm & 0.051 & \pm & 0.0079 & \pm & 0.041 & \pm & 0.0195 & \pm & 0.0165 \\
\hline
\end{tabular}

$182.3 \mu \mathrm{g}$ in weight was used for noble gas analysis.

\section{REFERENCES}

Alexander, C. M. O. D., Fogel, M., Yabuta, H. and Cody, G. D. (2007) The origin and evolution of chondrites recorded in the elemental and isotopic compositions of their macromolecular organic matter. Geochimica et Cosmochimica Acta 71, 4380-4403.

Alexander, C. M. O. D., Newsome, S. D., Fogel, M. L., Nittler, L. R., Busemann, H. and Cody, G. D. (2010) Deuterium enrichments in chondritic macromolecular material- 
Implications for the origin and evolution of organics, water and asteroids. Geochimica et Cosmochimica Acta 74, 4417-4437.

Allamandola, L., Tielens, A. and Barker, J. (1989) Interstellar polycyclic aromatic hydrocarbonsThe infrared emission bands, the excitation/emission mechanism, and the astrophysical implications. The Astrophysical Journal Supplement Series 71, 733-775.

Amari, S., Lewis, R. S. and Anders, E. (1994) Interstellar grains in meteorites: I. Isolation of SiC, graphite, and diamond; size distributions of $\mathrm{SiC}$ and graphite. Geochimica et Cosmochimica Acta 58, 459-470.

Anders, E., Hayatsu, R. and Studier, M. H. (1973) Organic compounds in meteorites. Science 182, 781-790.

Aoya, M., Kouketsu, Y., Endo, S., Shimizu, H., Mizukami, T., Nakamura, D. and Wallis, S. (2010) Extending the applicability of the Raman carbonaceous-material geothermometer using data from contact metamorphic rocks. Journal of Metamorphic Geology 28, 895914.

Beck, P., Garenne, A., Quirico, E., Bonal, L., Montes-Hernandez, G., Moynier, F. and Schmitt, B. (2014) Transmission infrared spectra $(2-25 \mu \mathrm{m})$ of carbonaceous chondrites (CI, CM, CV-CK, CR, C2 ungrouped): Mineralogy, water, and asteroidal processes. Icarus 229, 263-277.

Beny-Bassez, C. and Rouzaud, J. (1985) Characterization of carbonaceous materials by correlated electron and optical microscopy and Raman microspectroscopy. Scanning electron microscopy 1, 119-132.

Bernard, S., Beyssac, O., Benzerara, K., Findling, N., Tzvetkov, G. and Brown Jr, G. E. (2010) XANES, Raman and XRD study of anthracene-based cokes and saccharose-based chars submitted to high-temperature pyrolysis. Carbon 48, 2506-2516.

Beyssac, O., Goffé, B., Chopin, C. and Rouzaud, J. N. (2002a) Raman spectra of carbonaceous material in metasediments: a new geothermometer. Journal of Metamorphic Geology 20, 859-871.

Beyssac, O., Rouzaud, J.-N., Goffé, B., Brunet, F. and Chopin, C. (2002b) Graphitization in a high-pressure, low-temperature metamorphic gradient: a Raman microspectroscopy and HRTEM study. Contributions to Mineralogy and Petrology 143, 19-31.

Bonal, L., Quirico, E., Bourot-Denise, M. and Montagnac, G. (2006) Determination of the petrologic type of CV3 chondrites by Raman spectroscopy of included organic matter. Geochimica et Cosmochimica Acta 70, 1849-1863.

Bonal, L., Bourot-Denise, M., Quirico, E., Montagnac, G. and Lewin, E. (2007) Organic matter and metamorphic history of CO chondrites. Geochimica et Cosmochimica Acta 71, 16051623.

Bower, D. M., Steele, A., Fries, M. D. and Kater, L. (2013) Micro Raman spectroscopy of carbonaceous material in microfossils and meteorites: Improving a method for life detection. Astrobiology 13, 103-113.

Brearley, A. J. (1990) Carbon-rich aggregates in type 3 ordinary chondrites: Characterization, origins, and thermal history. Geochimica et Cosmochimica Acta 54, 831-850.

Brunetto, R., Pino, T., Dartois, E., Cao, A. T., d'Hendecourt, L., Strazzulla, G. and Brechignac, P. (2009) Comparison of the Raman spectra of ion irradiated soot and collected extraterrestrial carbon. Icarus 200, 323-337.

Buchanan, P., Zolensky, M. and Reid, A. (1993) Carbonaceous chondrite clasts in the howardites Bholghati and EET87513. Meteoritics 28, 659-669. 
Buseck, P. R., Bo-Jun, H. and Miner, B. (1988) Structural order and disorder in Precambrian kerogens. Organic Geochemistry 12, 221-234.

Buseck, P. R. and Beyssac, O. (2014) From organic matter to graphite: Graphitization. Elements 10, 421-426.

Busemann, H., Baur, H. and Wieler, R. (2000) Primordial noble gases in "phase Q" in carbonaceous and ordinary chondrites studied by closed-system stepped etching. Meteoritics \& Planetary Science 35, 949-973.

Busemann, H., Alexander, M. O. D. and Nittler, L. R. (2007) Characterization of insoluble organic matter in primitive meteorites by microRaman spectroscopy. Meteoritics \& Planetary Science 42, 1387-1416.

Castiglioni, C., Tommasini, M. and Zerbi, G. (2004) Raman spectroscopy of polyconjugated molecules and materials: confinement effect in one and two dimensions. Philosophical Transactions of the Royal Society of London A: Mathematical, Physical and Engineering Sciences 362, 2425-2459.

Cody, G. D., Alexander, C. M. O. and Tera, F. (2002) Solid-state (H-1 and C-13) nuclear magnetic resonance spectroscopy of insoluble organic residue in the Murchison meteorite: A self-consistent quantitative analysis. Geochimica et Cosmochimica Acta 66, 1851-1865.

Cody, G. D., Ade, H., Alexander, C. M. O., Araki, T., Butterworth, A., Fleckenstein, H., Flynn, G., Gilles, M. K., Jacobsen, C., Kilcoyne, A. L. D., Messenger, K., Sandford, S. A., Tyliszczak, T., Westphal, A. J., Wirick, S. and Yabuta, H. (2008a) Quantitative organic and light-element analysis of comet 81P/Wild 2 particles using $\mathrm{C}-, \mathrm{N}-$, and $\mathrm{O}-\mu$-XANES. Meteoritics \& Planetary Science 43, 353-365.

Cody, G. D., Alexander, C. M. O., Yabuta, H., Kilcoyne, A. L. D., Araki, T., Ade, H., Dera, R., Fogel, M., Militzer, B. and Mysen, B. O. (2008b) Organic thermometry for chondritic parent bodies. Earth and Planetary Science Letters 272, 446-455.

Cody, G. D., Heying, E., Alexander, C. M. O., Nittler, L. R., Kilcoyne, A. L. D., Sandford, S. A. and Stroud, R. M. (2011) Establishing a molecular relationship between chondritic and cometary organic solids. Proceedings of the National Academy of Sciences of the United States of America 108, 19171-19176.

Cronin, J. R. and Chang, S. (1993) Organic matter in meteorites: Molecular and isotopic analyses of the Murchison meteorite. In The Chemistry of Life's Origins (eds. J. M. Greenberg, C. X. Mendoza-Gómez, V. Pirronello). Kluwer Academic, Dordrecht, pp. 209-258.

Dartois, E., Muñoz Caro, G. M., Deboffle, D. and d'Hendecourt, L. (2004) Diffuse interstellar medium organic polymers. Astronomy and Astrophysics 423, L33-L36.

Dartois, E., Geballe, T. R., Pino, T., Cao, A. T., Jones, A., Deboffle, D., Guerrini, V., Bréchignac, P. and d'Hendecourt, L. (2007) IRAS 08572+3915: constraining the aromatic versus aliphatic content of interstellar HACs. Astronomy and Astrophysics 463, 635-640.

Dartois, E. and Muñoz-Caro, G. M. (2007) Carbonaceous dust grains in luminous infrared galaxies-Spitzer/IRS reveals $\mathrm{aC}: \mathrm{H}$ as an abundant and ubiquitous ISM component. Astronomy \& Astrophysics 476, 1235-1242.

Dodd, R. T. (1981) Meteorites: A Petrologic-Chemical Synthesis. Cambridge University Press.

Dry, M. E. (2002) The Fischer-Tropsch process: 1950-2000. Catalysis today 71, 227-241.

Eberhardt, P., Eugster, O. and Marti, K. (1965) A Redetermination of the Isotopic Composition of Atmospheric Neon. Zeitschrift für Naturforschung A 20, 623-624. 
Ehrenfreund, P. and Charnley, S. B. (2000) Organic molecules in the interstellar medium, comets, and meteorites: A voyage from dark clouds to the early earth. Annual Review of Astronomy and Astrophysics 38, 427-483.

Ferrari, A. C. and Robertson, J. (2004) Raman spectroscopy of amorphous, nanostructured, diamond-like carbon, and nanodiamond. Philosophical Transactions A 362, 2477-2512.

Ferreira, E. H. M., Moutinho, M. V. O., Stavale, F., Lucchese, M. M., Capaz, R. B., Achete, C. A. and Jorio, A. (2010) Evolution of the Raman spectra from single-, few-, and manylayer graphene with increasing disorder. Physical Review B 82, 125429.

Franklin, R. E. (1951) Crystallite growth in graphitizing and non-graphitizing carbons. Proceedings of the Royal Society of London A: Mathematical, Physical and Engineering Sciences 209, \#196-218 (abstr.).

Fredriksson, K. (1969) The Sharps chondrite - new evidence on the origin of chondrules and chondrites. In Meteorite Research (ed. P. M. Millman). Springer-Verlag, pp. 155-165.

Fries, M., Bhartia, R. and Steele, A. (2011) Carbonaceous chondrite groups discerned using Raman spectral parameters. Lunar and Planetary Science Conference 42, \#1860 (abstr.).

Fries, M., Messenger, S., Steele, A. and Zolensky, M. (2013) Do We Already have Samples of Ceres? H Chondrite Halites and the Ceres-Hebe Link. 76th Annual Meeting of the Meteoritical Society, \#5266 (abstr.).

Gadallah, K. A. K., Mutschke, H. and Jaeger, C. (2011) UV irradiated hydrogenated amorphous carbon (HAC) materials as a carrier candidate of the interstellar UV bump at $217.5 \mathrm{~nm}$. Astronomy and Astrophysics 528, A56.

Gaffey, M. J. and Gilbert, S. L. (1998) Asteroid 6 Hebe: The probable parent body of the H-type ordinary chondrites and the IIE iron meteorites. Meteoritics \& Planetary Science 33, 1281-1295.

Heber, V. S., Wieler, R., Baur, H., Olinger, C., Friedmann, T. A. and Burnett, D. S. (2009) Noble gas composition of the solar wind as collected by the Genesis mission. Geochimica et Cosmochimica Acta 73, 7414-7432.

Huss, G. R. and Lewis, R. S. (1994) Noble gases in presolar diamonds I: Three distinct components and their implications for diamond origins. Meteoritics 29, 791-810.

Huss, G. R. and Lewis, R. S. (1995) Presolar diamond, SiC, and graphite in primitive chondrites: Abundances as a function of meteorite class and petrologic type. Geochimica et Cosmochimica Acta 59, 115-160.

Huss, G. R., Rubin, A. E. and Grossman, J. N. (2006) Thermal metamorphism in chondrites. In Meteorites and the Early Solar System II (eds. D. S. Lauretta, J. H. Y. McSween). University of Arizona Press, Tucson, pp. 567-586.

Jacobsen, C., Wirick, S., Flynn, G. and Zimba, C. (2000) Soft X-ray spectroscopy from image sequences with sub-100 nm spatial resolution. Journal of Microscopy 197, 173-184.

Jones, A. (1990) Carbon atom clusters in random covalent networks: PAHs as an integral component of interstellar HAC. Monthly Notices of the Royal Astronomical Society 247, 305-310.

Kebukawa, Y., Nakashima, S. and Zolensky, M. E. (2010) Kinetics of organic matter degradation in the Murchison meteorite for the evaluation of parent-body temperature history. Meteoritics \& Planetary Science 45, 99-113.

Kebukawa, Y., Alexander, C. M. O. D. and Cody, G. D. (2011) Compositional diversity in insoluble organic matter in type 1, 2 and 3 chondrites as detected by infrared spectroscopy. Geochimica et Cosmochimica Acta 75, nakamu. 
Kebukawa, Y., Kilcoyne, A. L. D. and Cody, G. D. (2013) Exploring the potential formation of organic solids in chondrites and comets through polymerization of interstellar formaldehyde. The Astrophysical Journal 771, 19.

Kebukawa, Y. and Cody, G. D. (2015) A kinetic study of the formation of organic solids from formaldehyde: Implications for the origin of extraterrestrial organic solids in primitive Solar System objects. Icarus 248, 412-423.

Kilcoyne, A., Tyliszczak, T., Steele, W., Fakra, S., Hitchcock, P., Franck, K., Anderson, E., Harteneck, B., Rightor, E. and Mitchell, G. (2003) Interferometer-controlled scanning transmission X-ray microscopes at the Advanced Light Source. Journal of Synchrotron Radiation 10, 125-136.

Kouketsu, Y., Mizukami, T., Mori, H., Endo, S., Aoya, M., Hara, H., Nakamura, D. and Wallis, S. (2014) A new approach to develop the Raman carbonaceous material geothermometer for low-grade metamorphism using peak width. Island Arc 23, 33-50.

Kress, M. E. and Tielens, A. (2001) The role of Fischer-Tropsch catalysis in solar nebula chemistry. Meteoritics \& Planetary Science 36, 75-91.

Lahfid, A., Beyssac, O., Deville, E., Negro, F., Chopin, C. and Goffé, B. (2010) Evolution of the Raman spectrum of carbonaceous material in low-grade metasediments of the Glarus Alps (Switzerland). Terra Nova 22, 354-360.

Le Guillou, C., Bernard, S., Brearley, A. J. and Remusat, L. (2014) Evolution of organic matter in Orgueil, Murchison and Renazzo during parent body aqueous alteration: In situ investigations. Geochimica et Cosmochimica Acta 131, 368-392.

Lewis, R., Srinivasan, B. and Anders, E. (1975) Host phase of a strange xenon component in Allende. Science 190, 1251-1262.

Lewis, R. S., Ming, T., Wacker, J. F., Anders, E. and Steel, E. (1987) Interstellar diamonds in meteorites. Nature 326, 160-162.

Lewis, R. S., Amari, S. and Anders, E. (1994) Interstellar grains in meteorites: II. SiC and its noble gases. Geochimica et Cosmochimica Acta 58, 471-494.

Llorca, J. and Casanova, I. (2000) Reaction between H(2), CO, and H(2)S over Fe,Ni metal in the solar nebula: Experimental evidence for the formation of sulfur-bearing organic molecules and sulfides. Meteoritics \& Planetary Science 35, 841-848.

Lodders, K. and Amari, S. (2005) Presolar grains from meteorites: Remnants from the early times of the solar system. Chemie der Erde-Geochemistry 65, 93-166.

Mählmann, R. F., Petrova, T. V., Pironon, J., Stern, W. B., Ghanbaja, J., Dubessy, J. and Frey, M. (2002) Transmission electron microscopy study of carbonaceous material in a metamorphic profile from diagenesis to amphibolite facies. Schweizerische Mineralogische und Petrographische Mitteilungen 82, 253-272.

Mahaffy, P., Donahue, T. M., Atreya, S., Owen, T. and Niemann, H. (1998) Galileo probe measurements of $\mathrm{D} / \mathrm{H}$ and $3 \mathrm{He} / 4 \mathrm{He}$ in Jupiter's atmosphere. Space Science Reviews 84, 251-263.

Mahaffy, P., Niemann, H., Alpert, A., Atreya, S., Demick, J., Donahue, T., Harpold, D. and Owen, T. (2000) Noble gas abundance and isotope ratios in the atmosphere of Jupiter from the Galileo Probe Mass Spectrometer. Journal of Geophysical Research: Planets 105, 15061-15071.

Manuel, O., Hennecke, E. and Sabu, D. (1972) Xenon in carbonaceous chondrites. Nature 240, 99-101. 
Maslova, O. A., Ammar, M. R., Guimbretière, G., Rouzaud, J. N. and Simon, P. (2012) Determination of crystallite size in polished graphitized carbon by Raman spectroscopy. Physical Review B 86, 134205.

Matrajt, G., Borg, J., Raynal, P. I., Djouadi, Z., d'Hendecourt, L., Flynn, G. and Deboffle, D. (2004) FTIR and Raman analyses of the Tagish Lake meteorite: Relationship with the aliphatic hydrocarbons observed in the Diffuse Interstellar Medium. $A \& A$ 416, 983-990.

McKinley, S. G., Scott, E., Taylor, G. and Keil, K. (1981) A unique type 3 ordinary chondrite containing graphite-magnetite aggregates-Allan Hills A77011. Lunar and Planetary Science Conference Proceedings 12, 1039-1048.

Meier, R. J. (2005) On art and science in curve-fitting vibrational spectra. Vibrational Spectroscopy 39, 266-269.

Moore, C. B. and Lewis, C. F. (1967) Total carbon content of ordinary chondrites. Journal of Geophysical Research 72, 6289-6292.

Muñoz Caro, G. M., Matrajt, G., Dartois, E., Nuevo, M., d'Hendecourt, L., Deboffle, D., Montagnac, G., Chauvin, N., Boukari, C. and Du, D. L. (2006) Nature and evolution of the dominant carbonaceous matter in interplanetary dust particles: effects of irradiation and identification with a type of amorphous carbon. Astronomy and Astrophysics 459, 147-159.

Nagao, K. (1994) Noble gases in hosts and inclusions from Yamato-75097 (L6),-793241 (L6) and-794046 (H5). Antarctic Meteorite Research 7, 197-216.

Nagao, K., Kusakabe, M., Yoshida, Y. and Tanyileke, G. (2010) Noble gases in Lakes Nyos and Monoun, Cameroon. Geochemical Journal 44, 519-543.

Nagao, K., Okazaki, R., Nakamura, T., Miura, Y. N., Osawa, T., Bajo, K., Matsuda, S., Ebihara, M., Ireland, T. R., Kitajima, F., Naraoka, H., Noguchi, T., Tsuchiyama, A., Yurimoto, H., Zolensky, M. E., Uesugi, M., Shirai, K., Abe, M., Yada, T., Ishibashi, Y., Fujimura, A., Mukai, T., Ueno, M., Okada, T., Yoshikawa, M. and Kawaguchi, J. (2011) Irradiation history of Itokawa regolith material deduced from noble gases in the Hayabusa samples. Science 333, 1128-1131.

Nagao, K., Haba, M. K., Park, J. and Herzog, G. F. (2014) Trapped noble gases in thirteen ureilites from Antarctica. Lunar and Planetary Science Conference 45, \#2016 (abstr.).

Nemanich, R. J. and Solin, S. A. (1979) First- and second-order Raman scattering from finitesize crystals of graphite. Physical Review B 20, 392-401.

Nier, A. O. (1950) A redetermination of the relative abundances of the isotopes of carbon, nitrogen, oxygen, argon, and potassium. Physical Review 77, 789-793.

Nuth, J. A., III, Johnson, N. M. and Manning, S. (2008) A self-perpetuating catalyst for the production of complex organic molecules in protostellar nebulae. Astrophysical Journal Letters 673, L225-L228.

Osawa, T., Kagi, H., Nakamura, T. and Noguchi, T. (2005) Infrared spectroscopic taxonomy for carbonaceous chondrites from speciation of hydrous components. Meteoritics \& Planetary Science 40, 71-86.

Ott, U. (2002) Noble gases in meteorites-Trapped components. In Noble Gases in Geochemistry and Cosmochemistry (eds. D. Porcelli, C. J. Ballentine, R. Wieler). Mineralogical Society of America, pp. 71-100.

Ozima, M. and Podosek, F. A. (2002) Noble Gas Geochemistry 2nd edition. Cambridge University Press. 
Pino, T., Dartois, E., Cao, A. T., Carpentier, Y., Chamaille, T., Vasquez, R., Jones, A. P., d'Hendecourt, L. and Brechignac, P. (2008) The $6.2 \mathrm{mu} \mathrm{m}$ band position in laboratory and astrophysical spectra: a tracer of the aliphatic to aromatic evolution of interstellar carbonaceous dust. Astronomy and Astrophysics 490, 665-672.

Pizzarello, S., Cooper, G. W. and Flynn, G. J. (2006) The nature and distribution of the organic material in carbonaceous chondrites and interplanetary dust particles. In Meteorites and the Early Solar System II (eds. D. S. Lauretta, J. H. Y. McSween). University of Arizona Press, Tucson, pp. 625-651.

Puget, J. and Léger, A. (1989) A new component of the interstellar matter-Small grains and large aromatic molecules. Annual review of astronomy and astrophysics 27, 161-198.

Quirico, E., Raynal, P.-I. and Bourot-Denise, M. (2003) Metamorphic grade of organic matter in six unequilibrated ordinary chondrites. Meteoritics \& Planetary Science 38, 795-811.

Quirico, E., Borg, J., Raynal, P.-I., Montagnac, G. and d'Hendecourt, L. (2005a) A micro-Raman survey of 10 IDPs and 6 carbonaceous chondrites. Planetary and Space Science 53, 1443-1448.

Quirico, E., Rouzaud, J.-N., Bonal, L. and Montagnac, G. (2005b) Maturation grade of coals as revealed by Raman spectroscopy: Progress and problems. Spectrochimica Acta Part A: Molecular and Biomolecular Spectroscopy 61, 2368-2377.

Quirico, E., Montagnac, G., Rouzaud, J. N., Bonal, L., Bourot-Denise, M., Duber, S. and Reynard, B. (2009) Precursor and metamorphic condition effects on Raman spectra of poorly ordered carbonaceous matter in chondrites and coals. Earth and Planetary Science Letters 287, 185-193.

Rahl, J. M., Anderson, K. M., Brandon, M. T. and Fassoulas, C. (2005) Raman spectroscopic carbonaceous material thermometry of low-grade metamorphic rocks: Calibration and application to tectonic exhumation in Crete, Greece. Earth and Planetary Science Letters 240, 339-354.

Reynolds, J. and Turner, G. (1964) Rare gases in the chondrite Renazzo. Journal of Geophysical Research 69, 3263-3281.

Rietmeijer, F. J. and Mackinnon, I. D. (1985) Poorly graphitized carbon as a new cosmothermometer for primitive extraterrestrial materials. Nature 315, 733-736.

Ross, J., Bustin, R. M. and Rouzaud, J. (1991) Graphitization of high rank coals - the role of shear strain: experimental considerations. Organic Geochemistry 17, 585-596.

Sandford, S. A., Bernstein, M. P. and Allamandola, L. J. (1998) Laboratory Studies of Interstellar/Cometary Ice Analogs. Laboratory Space Science Workshop 1, \#229 (abstr.).

Scott, E., Brearley, A., Keil, K., Grady, M., Pillinger, C., Clayton, R., Mayeda, T., Wieler, R. and Signer, P. (1988) Nature and origin of C-rich ordinary chondrites and chondritic clasts. Lunar and Planetary Science Conference Proceedings 18, 513-523.

Scott, E. R., Rubin, A. E., Taylor, G. J. and Keil, K. (1981a) New kind of type 3 chondrite with a graphite-magnetite matrix. Earth and Planetary Science Letters 56, 19-31.

Scott, E. R., Taylor, G. J., Rubin, A. E., Okada, A. and Keil, K. (1981b) Graphite-magnetite aggregates in ordinary chondritic meteorites. Nature 291, 544-546.

Sellgren, K. (2001) Aromatic hydrocarbons, diamonds, and fullerenes in interstellar space: puzzles to be solved by laboratory and theoretical astrochemistry. Spectrochimica Acta Part A: Molecular and Biomolecular Spectroscopy 57, 627-642.

Sephton, M. A. (2002) Organic compounds in carbonaceous meteorites. Natural Product Reports 19, 292-311. 
Sephton, M. A., Verchovsky, A. B., Bland, P. A., Gilmour, I., Grady, M. M. and Wright, I. P. (2003) Investigating the variations in carbon and nitrogen isotopes in carbonaceous chondrites. Geochimica et Cosmochimica Acta 67, 2093-2108.

Sood, A. K., Gupta, R. and Asher, S. A. (2001) Origin of the unusual dependence of Raman D band on excitation wavelength in graphite-like materials. Journal of Applied Physics $\mathbf{9 0}$, 4494-4497.

Steele, A., McCubbin, F. M., Fries, M., Glamoclija, M., Kater, L. and Nekvasil, H. (2010) Graphite in an Apollo 17 impact melt breccia. Science 329, 51-51.

Studier, M. H., Hayatsu, R. and Anders, E. (1968) Origin of organic matter in early solar system-I. Hydrocarbons. Geochimica et Cosmochimica Acta 32, 151-173.

Studier, M. H., Hayatsu, R. and Anders, E. (1972) Origin of organic matter in early solar system-V. Further studies of meteoritic hydrocarbons and a discussion of their origin. Geochimica et Cosmochimica Acta 36, 189-215.

Tuinstra, F. and Koenig, J. L. (1970a) Characterization of Graphite Fiber Surfaces with Raman Spectroscopy. Journal of Composite Materials 4, 492-499.

Tuinstra, F. and Koenig, J. L. (1970b) Raman spectrum of graphite. The Journal of Chemical Physics 53, 1126-1130.

Wang, Y., Alsmeyer, D. C. and McCreery, R. L. (1990) Raman spectroscopy of carbon materials: structural basis of observed spectra. Chemistry of Materials 2, 557-563.

Wlotzka, F. (2005) Cr spinel and chromite as petrogenetic indicators in ordinary chondrites: Equilibration temperatures of petrologic types 3.7 to 6. Meteoritics \& Planetary Science 40, 1673-1702.

Zadnik, M. (1985) Noble gases in the Bells (C2) and Sharps (H3) chondrites. Meteoritics 20, 245-257.

Zinner, E. (1998) Stellar nucleosynthesis and the isotopic composition of presolar grains from primitive meteorites. Annual Review of Earth and Planetary Sciences 26, 147-188.

Zolensky, M., Hewins, R., Mittlefehldt, D., Lindstrom, M., Xiao, X. and Lipschutz, M. (1992) Mineralogy, petrology and geochemistry of carbonaceous chondritic clasts in the LEW 85300 polymict eucrite. Meteoritics 27, 596-604.

Zolensky, M., Krot, A., Weisberg, M., Buchanan, P. and Prinz, M. (1996) Fine-grained inclusions in type 3 ordinary and carbonaceous chondrites. Lunar and Planetary Science Conference 27, \#1507 (abstr.).

Zolensky, M., Briani, G., Gounelle, M., Mikouchi, T., Ohsumi, K., Weisberg, M., Le, L., Satake, W. and Kurihara, T. (2009) Searching for chips of Kuiper Belt objects in meteorites. Lunar and Planetary Science Conference 40, \#2162 (abstr.). 


\section{Figures and tables}

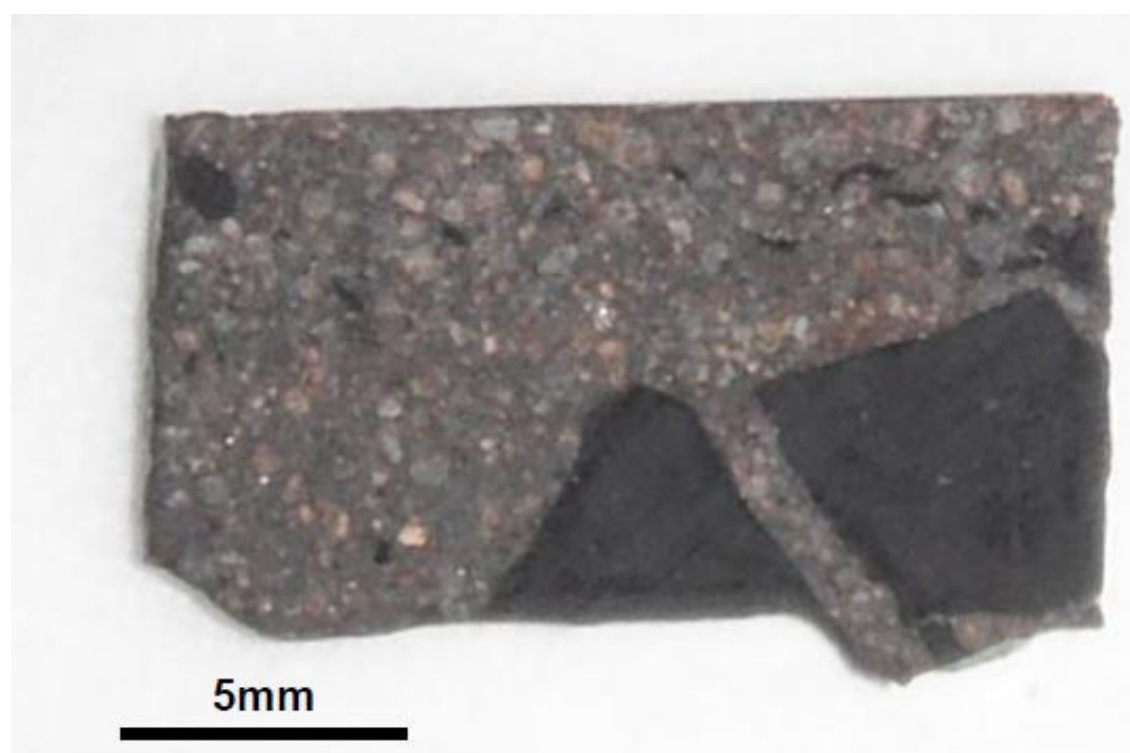

Fig. 1. A slice of the Sharps chondrite (USNM640) containing two angular carbonaceous clasts ( $5 \mathrm{~mm}$ long) at the lower right.

Table 1. List of Sharps clasts and the sample preparation and analytical methods used.

\begin{tabular}{cll}
\hline Sharps USNM640 & Sample preparation & Analytical methods \\
\hline Clast 1 & Acid residue & Noble gasses \\
Clast 2 & Grain & IR \\
& FIB\#1 & STXM \\
& Acid residue & IR, STXM \\
Clast 3 & FIB\#2 & STXM, TEM \\
Clast 4 & Ultramicrotome & STXM \\
& Potted butt & Raman \\
\hline
\end{tabular}




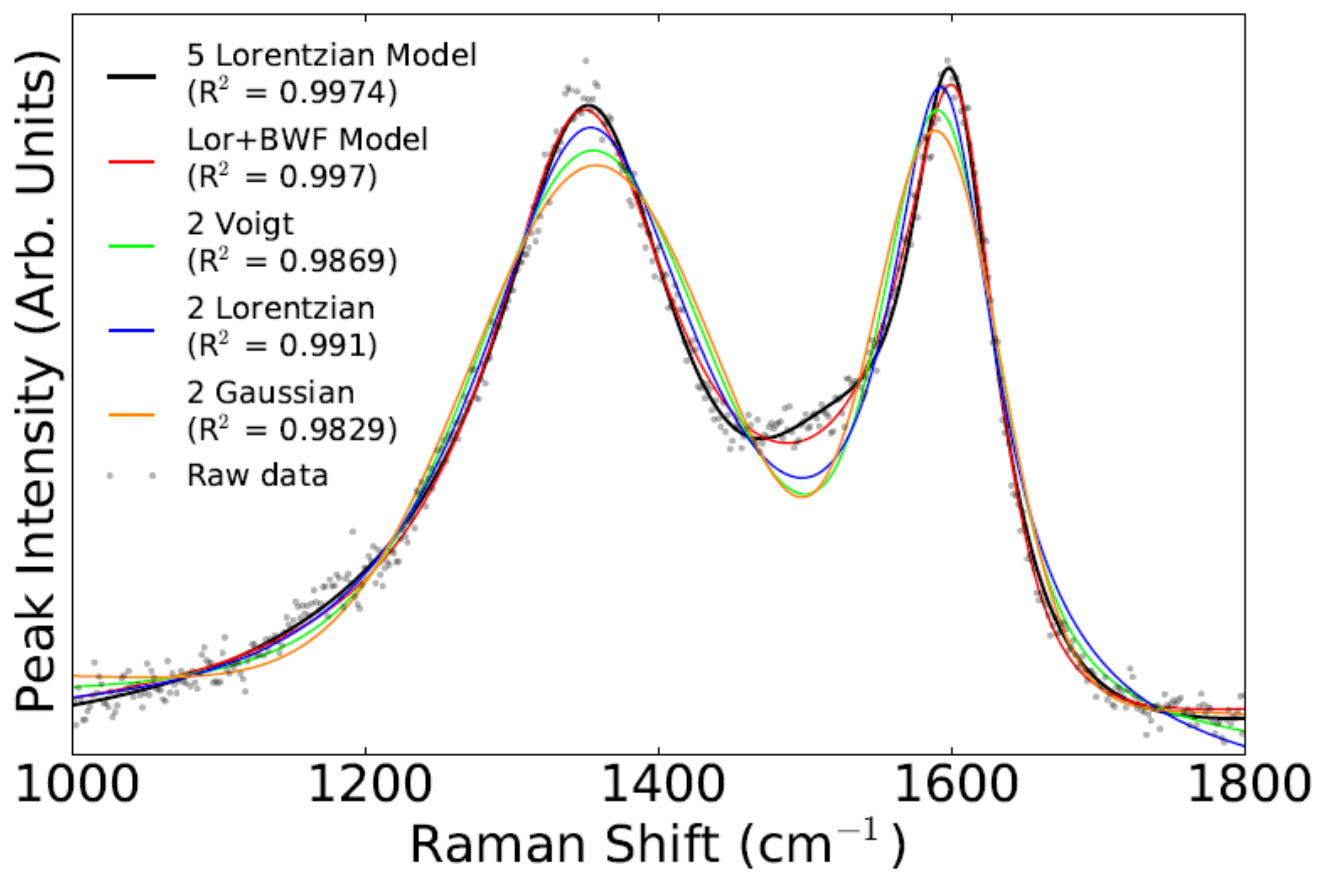

Fig. 2. Comparison between the fitting results of different curve fitting models. 


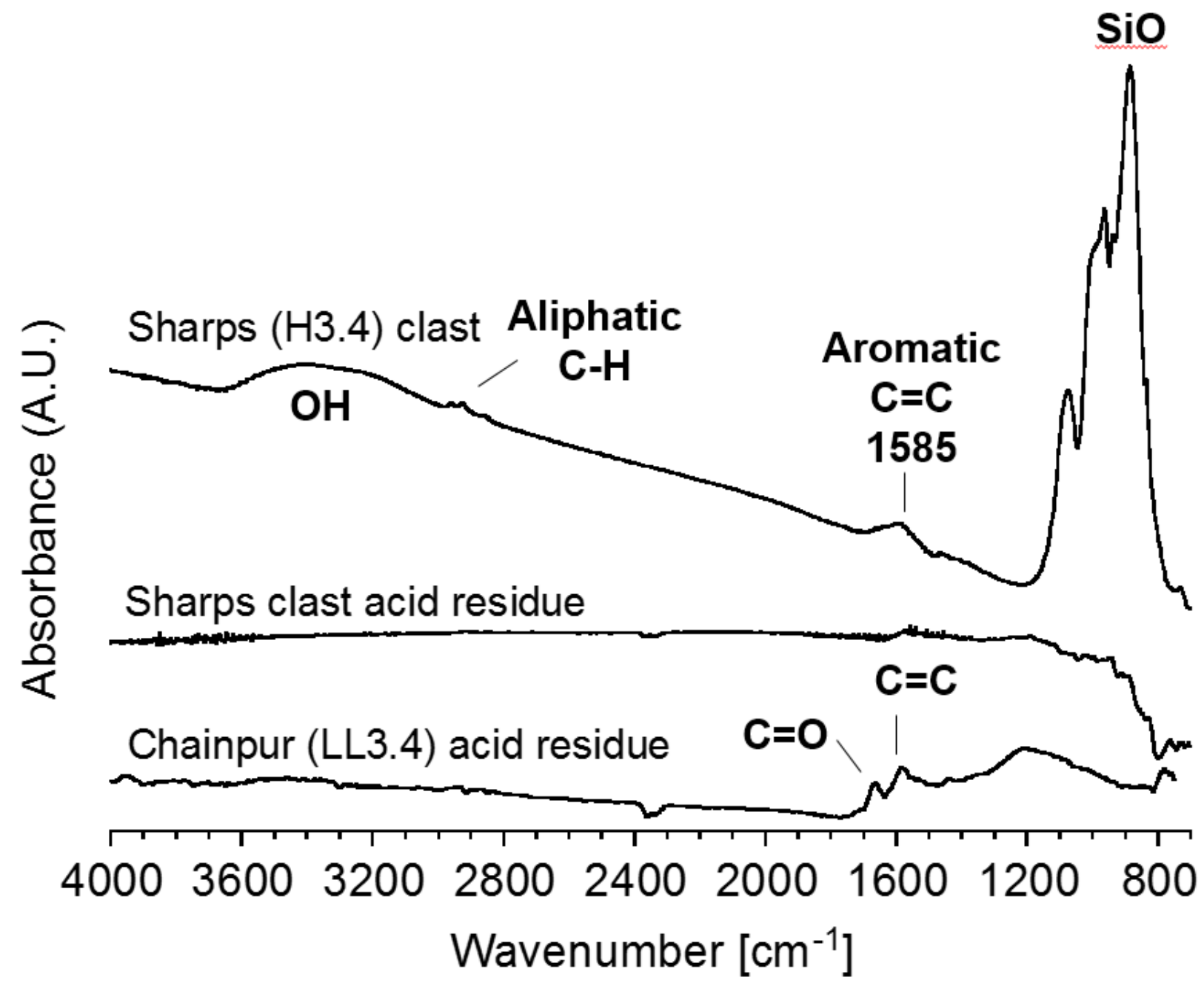

Fig. 3. Fourier transform infrared (FTIR) spectra of the Sharps clast and its acid residue.

The Chainpur (LL3.4) acid residue spectrum taken from Kebukawa et al. (2011) is shown for comparison. The absorbance is in arbitrary units (A.U.). For comparison, the spectra have been offset from one another. The broad absorption band in the range $3700-3000 \mathrm{~cm}^{-1}$ corresponds to O-H stretching modes, the triplet peaks at 2960, 2925, and $2860 \mathrm{~cm}^{-1}$ correspond to aliphatic (methyl and methylene) symmetric and asymmetric $\mathrm{C}-\mathrm{H}$ stretching vibrations. The peak at 1700 $\mathrm{cm}^{-1}$ corresponds to carbonyl $\mathrm{C}=\mathrm{O}$ stretching, the peak at $1600 \mathrm{~cm}^{-1}$ corresponds to aromatic 
$\mathrm{C}=\mathrm{C}$ stretching. A broad band at around $1200 \mathrm{~cm}^{-1}$ corresponds to the aromatic skeletal mode and large peaks spanning 1100 to $800 \mathrm{~cm}^{-1}$ correspond to $\mathrm{Si}-\mathrm{O}$ stretching of silicates.

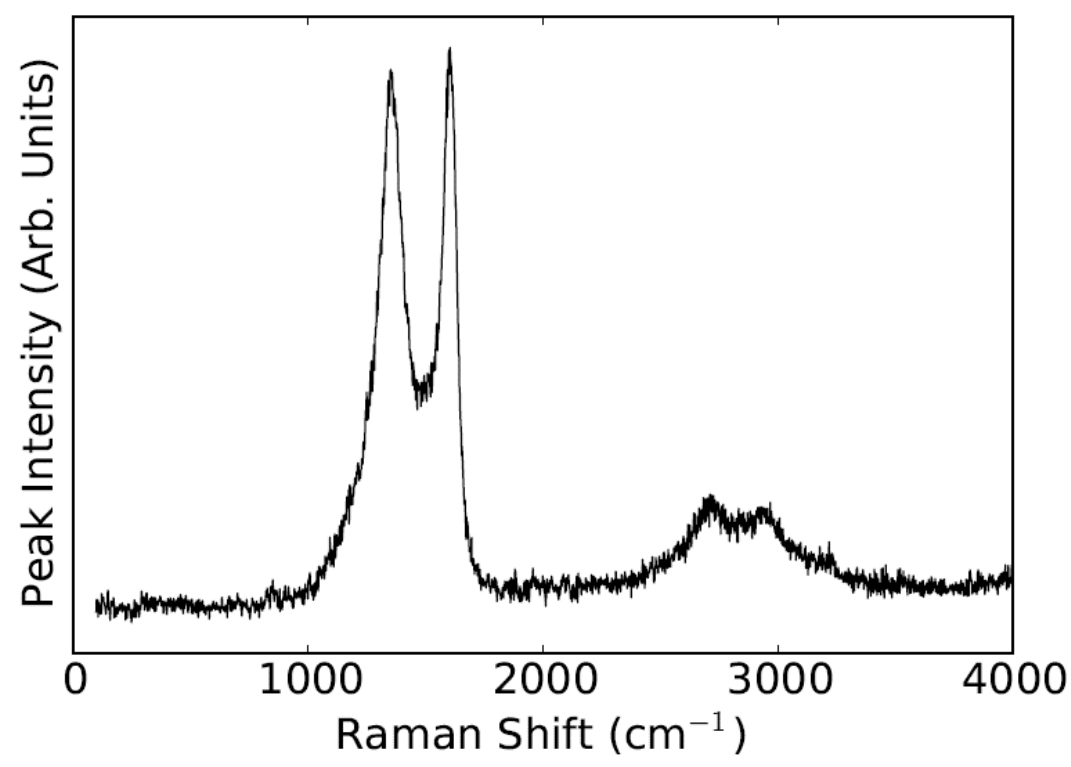

Fig. 4. Representative raw Raman spectrum of the Sharps clast showing both the first(1100 to $1800 \mathrm{~cm}^{-1}$ ) and second-order (2200 to $3400 \mathrm{~cm}^{-1}$ ) regions. 


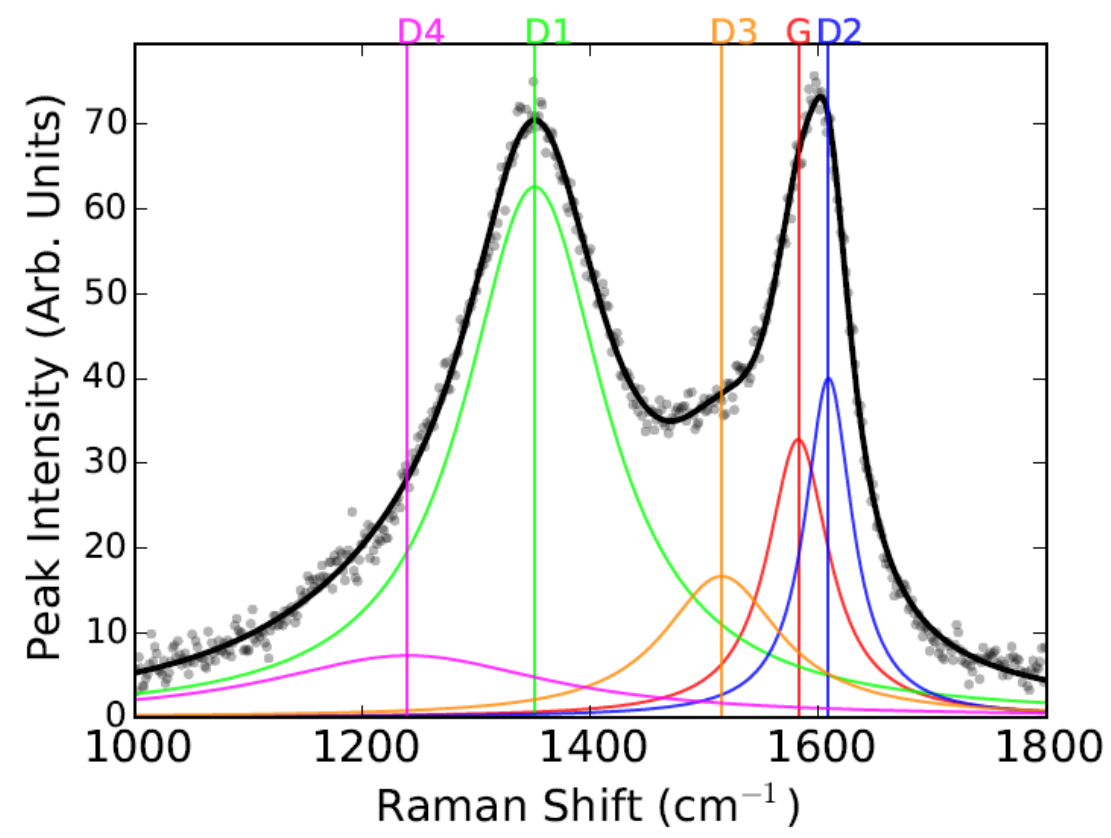

Fig. 5. Deconvolution of peaks in the first-order region of the Raman spectrum for the Sharps clast showing the contributions of the D4, D1, D3, G and D2 bands to the total spectrum.

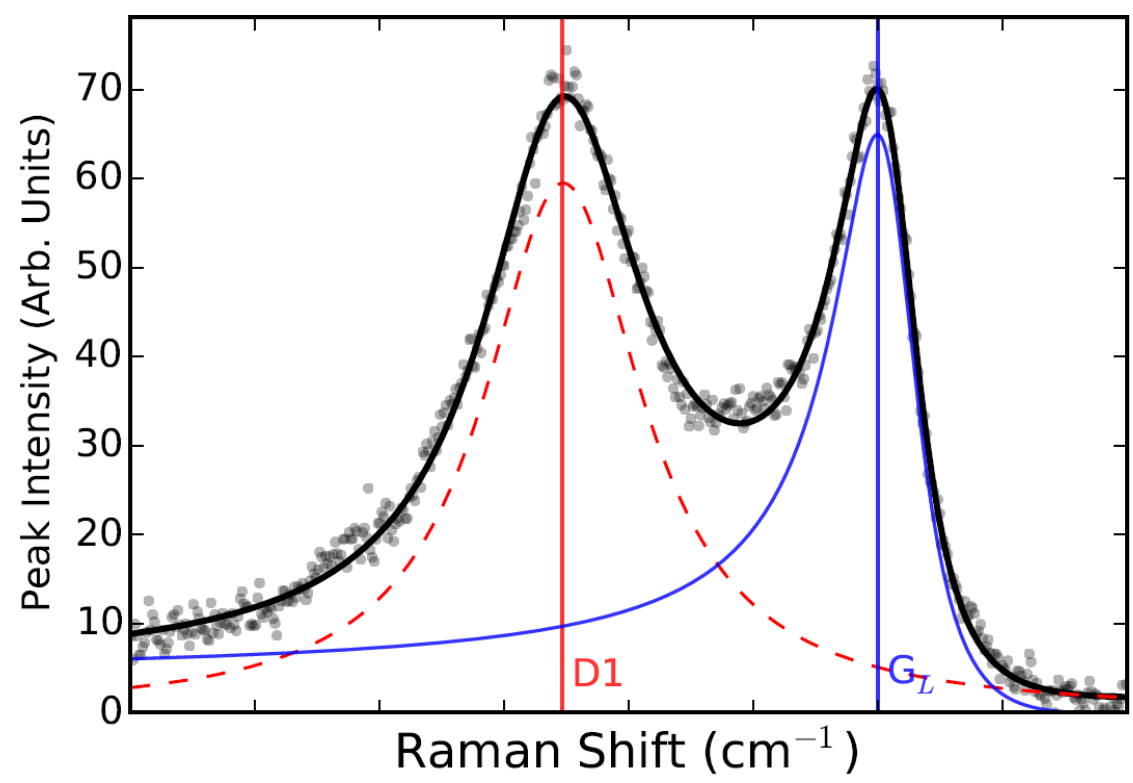

Fig. 6. Deconvolution of peaks in the first-order region of the Sharps clast using the Lorentzian (D1 band) and BWF (Breit-Wigner-Fano, $\mathrm{G}_{\mathrm{L}}$ band) (LBWF) model. 

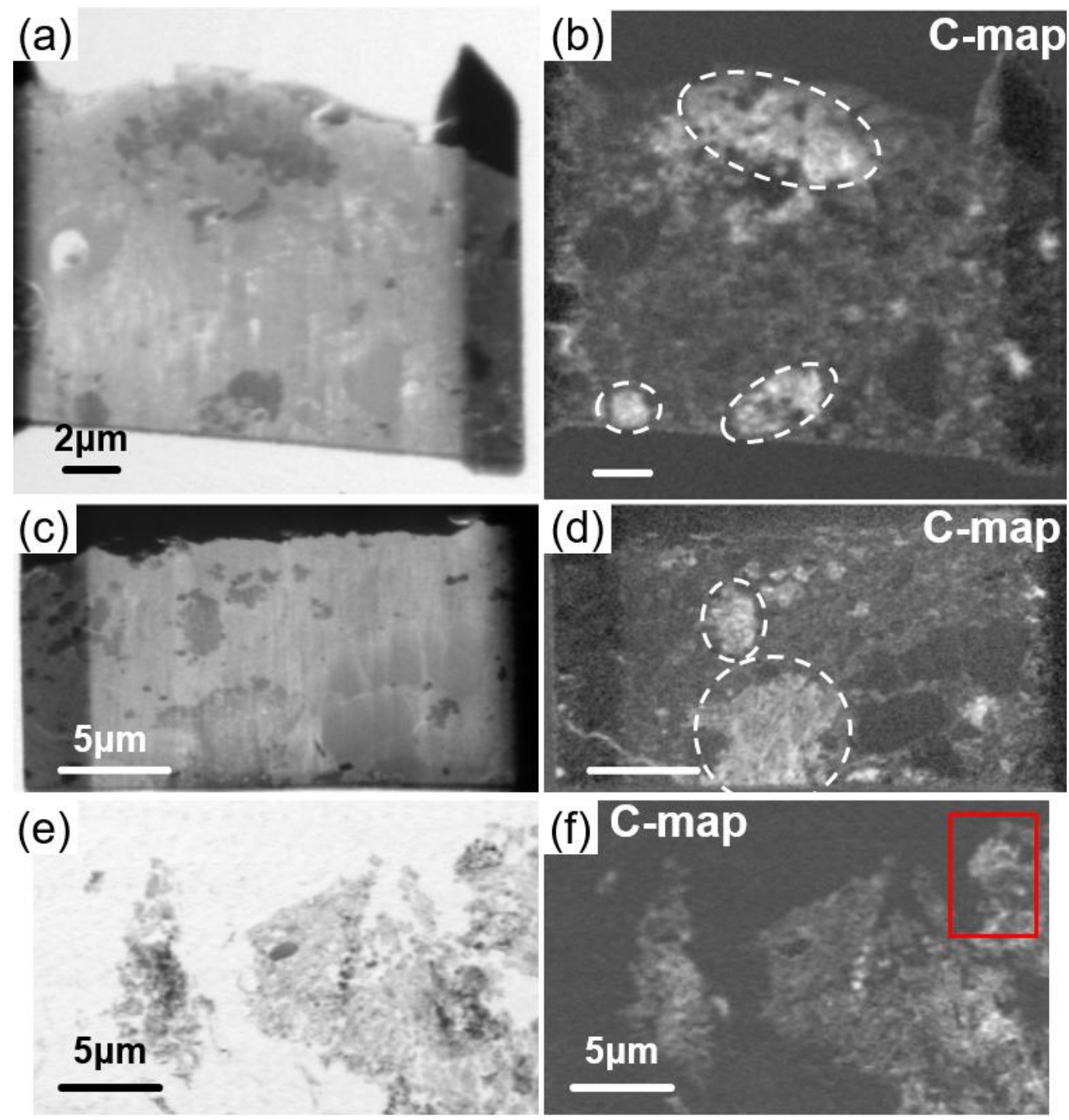

Fig. 7. Scanning transmission X-ray microscope (STXM) images at $390 \mathrm{eV}$ of the Sharps clast focused ion beam (FIB) milled sections and an ultramicrotomed (UMT) thin section, (a) FIB\#1, (c) FIB\#2, and (e) UMT. STXM carbon $K$-edge (289 eV) maps of (b) FIB\#1, (d) FIB\#2, and (f) UMT. Circled areas are C-rich aggregates. The red square indicates the area studied by CXANES. 


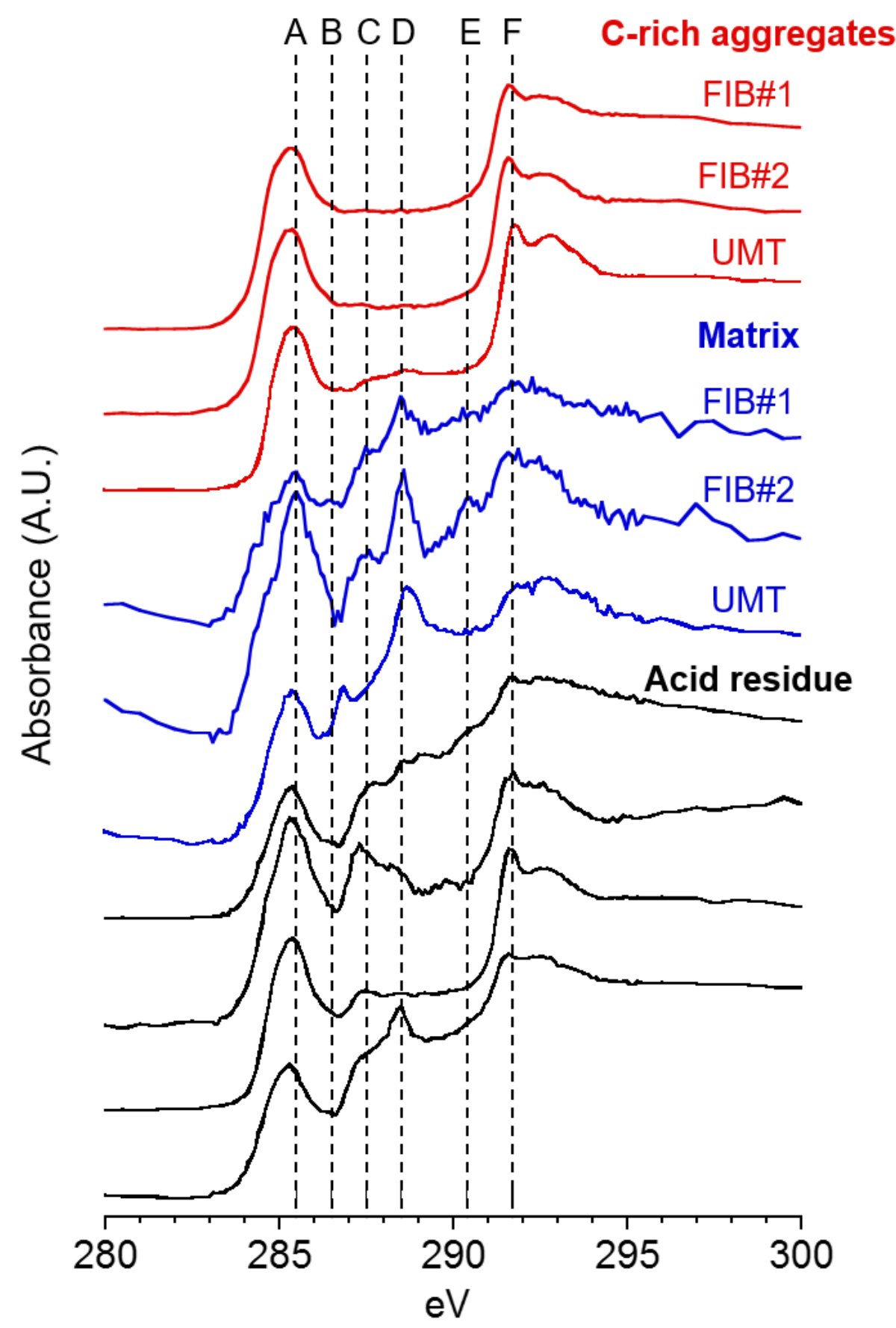

Fig. 8. Carbon X-ray absorption near-edge structure (C-XANES) spectra of C-rich aggregates in one Sharps clast (as measured in the indicated areas in the upper images; Fig. 7b,d,f), matrix, and acid residue of the clast. Table 2 identifies the absorption features (labeled 
A-F). The spectra were normalized to the C-XANES intensity at $296 \mathrm{eV}$. For comparison, the spectra have been offset from one another.

Table 2. Characteristics of carbon X-ray absorption near-edge structure (C-XANES) transitions.

(Table 2 will be arranged next to Fig. 8)

\begin{tabular}{lllll}
\hline & Energy $(\mathrm{eV})$ & Transition & Functional group & \\
\hline A & 285.5 & $1 \mathrm{~s}-\pi *$ & Aromatic/olefinic & $\mathrm{C}=\mathrm{C}$ \\
B & 286.5 & $1 \mathrm{~s}-\pi *$ & Aryl, vinyl-ketone & $\mathrm{C}=\mathrm{C}-\mathrm{C}=\mathrm{O}$ \\
C & 287.5 & $1 \mathrm{~s}-3 \mathrm{p} / \mathrm{s}$ & Aliphatics & $\mathrm{CH}_{\mathrm{x}}$ \\
D & 288.5 & $1 \mathrm{~s}-\pi *$ & Carboxyl & $\mathrm{O}-\mathrm{C}=\mathrm{O}$ \\
E & 290.5 & $1 \mathrm{~s}-\pi *$ & Carbonate & $\mathrm{CO}_{3}$ \\
F & 291.7 & $1 \mathrm{~s}-\sigma *$ & Exciton & Graphene \\
\hline
\end{tabular}

These assignments are derived from Cody et al. (2008a,b).

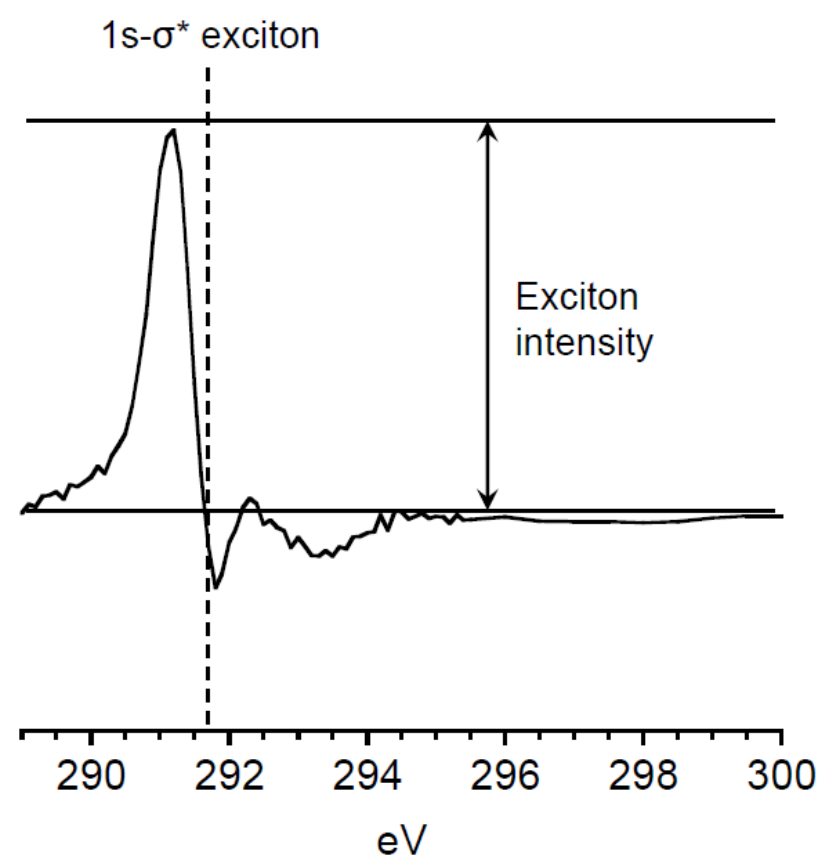


Fig. 9. The first derivative of the C-XANES spectra (from 289 to $300 \mathrm{eV}$ ) highlighting the progressive development of the sharp $1 \mathrm{~s}^{-} \sigma^{*}$ exciton peak at $291.7 \mathrm{eV}$ of $\mathrm{C}$-rich aggregates from FIB\#1. The exciton intensities are obtained by following the method of Cody et al. (2008b).

Table 3. Graphene $1 \mathrm{~s}^{-} \sigma^{*}$ exciton intensities and estimated effective temperatures.

\begin{tabular}{|c|c|c|c|}
\hline & & $\begin{array}{l}\text { Exciton intensity, } \\
E(\%)\end{array}$ & $\begin{array}{l}\text { Effective temperature, } \\
T_{E F F}\left({ }^{\circ} \mathrm{C}\right)\end{array}$ \\
\hline \multicolumn{4}{|l|}{ C-rich aggregates } \\
\hline & FIB\#1 $* 1$ & $47 \pm 3$ & $742 \pm 30$ \\
\hline & $\mathrm{FIB \# 2} *^{2}$ & $58 \pm 2$ & $852 \pm 20$ \\
\hline & $\mathrm{UMT} *^{3}$ & $52 \pm 9$ & $792 \pm 90$ \\
\hline \multicolumn{4}{|l|}{ Matrix } \\
\hline & FIB\#1 $*^{4}$ & $10.5-11.0$ & $322-329$ \\
\hline & FIB\#2 $* 4$ & $24.2-25.3$ & $497-509$ \\
\hline & $\mathrm{UMT} *^{3}$ & $16 \pm 6$ & $403^{+74}-86$ \\
\hline Acid residue $*^{5}$ & & $30 \pm 15$ & $566^{+156}-177$ \\
\hline
\end{tabular}




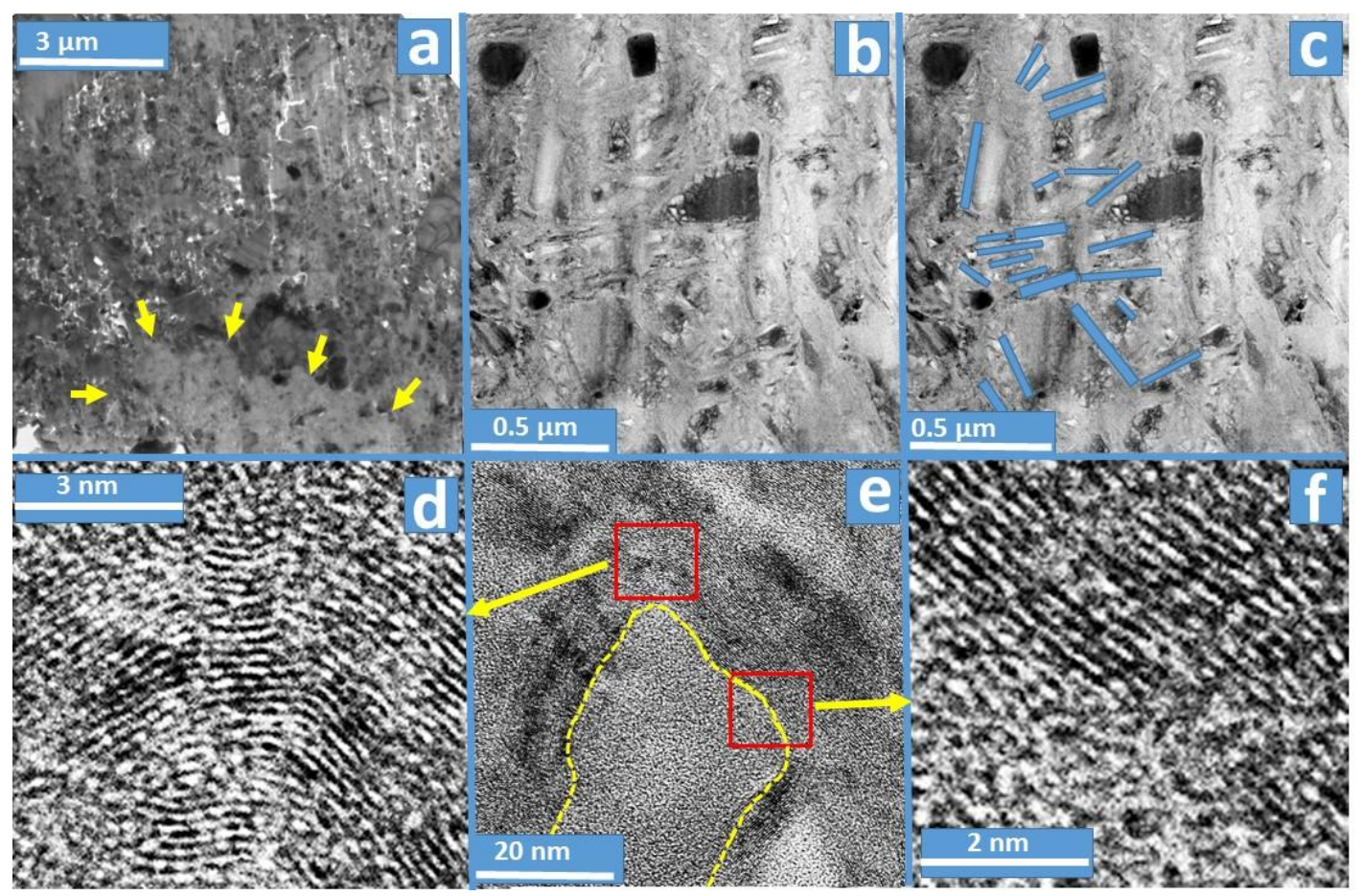

Fig. 10. HRTEM bright field images of carbon-rich masses in a Sharps clast. (a) Low magnification images of a FIB section of a Sharps clast sample, with one carbon mass indicated by the arrows. (b) Close-up views of a portion of the carbon mass in (a). Black grains are mainly Fe-Ni metal and Fe-Ni carbides. Everything else in the field of view is carbon. (c) Same image as (b), with the positions of some graphite "books" indicated by rectangles. (d) Image of more well-ordered carbon (still not properly graphitized) - a close-up of the left side of (e). Carbon (002) lattice fringes measure $0.35 \mathrm{~nm}$. (e) Image of an area of poorly-organized carbon (center outlined) surrounded on both sides and at the top by more well-ordered carbon. (f) Image of more well-ordered carbon (still not properly graphitized) - a close-up from the right side of (e). Carbon (002) lattice fringes measure 0.34 to $0.35 \mathrm{~nm}$. 


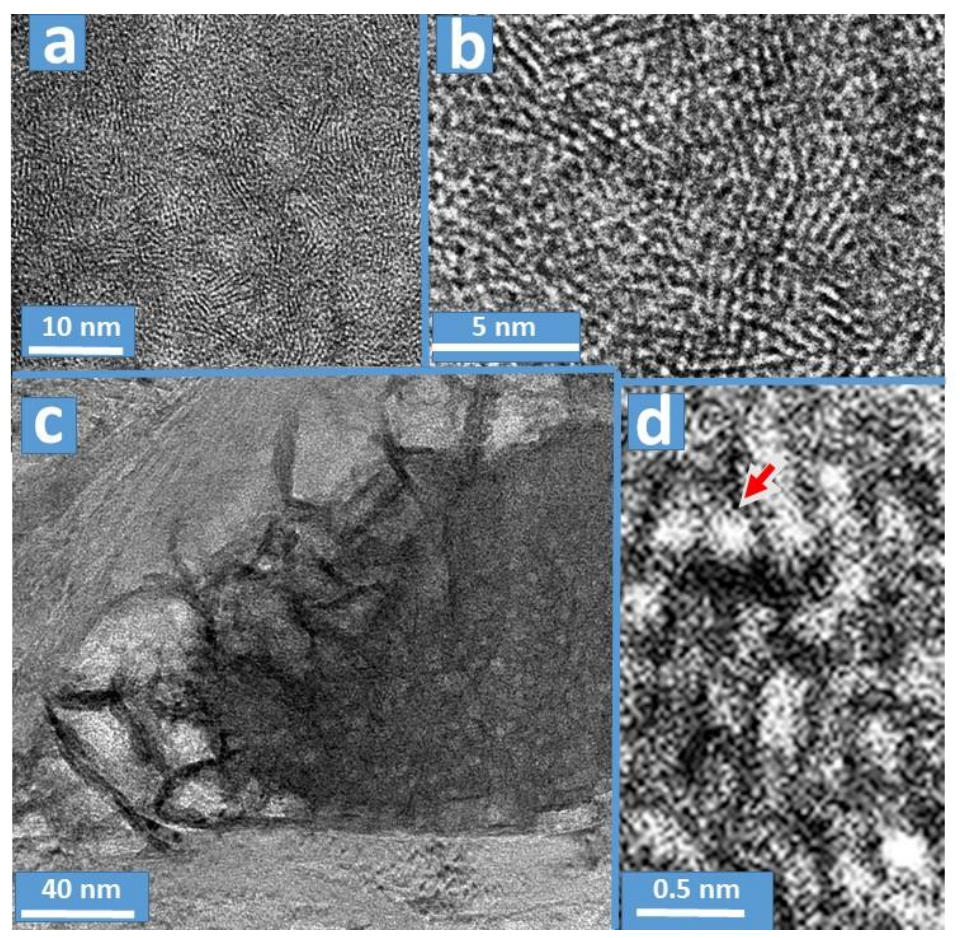

Fig. 11. HRTEM bright field images from the same carbon mass as shown in Fig. 10. (a) A site with more well-ordered graphitic carbon, but only in very small randomly oriented domains. (b) Close-up of (a), more clearly showing the domain size and lattice fringes of the graphitic carbon. The well-crystalline domains achieve a maximum size of between 5 and $10 \mathrm{~nm}$. (c) Graphitic carbon flakes growing on the surface of a Fe-Ni grain; the graphitic carbon presumably nucleated on the metal surface. (d) Close-up of discontinuous carbon sheets (discontinuous 002 lattice fringes) - one truncated carbon sheet is indicated by the arrow. 


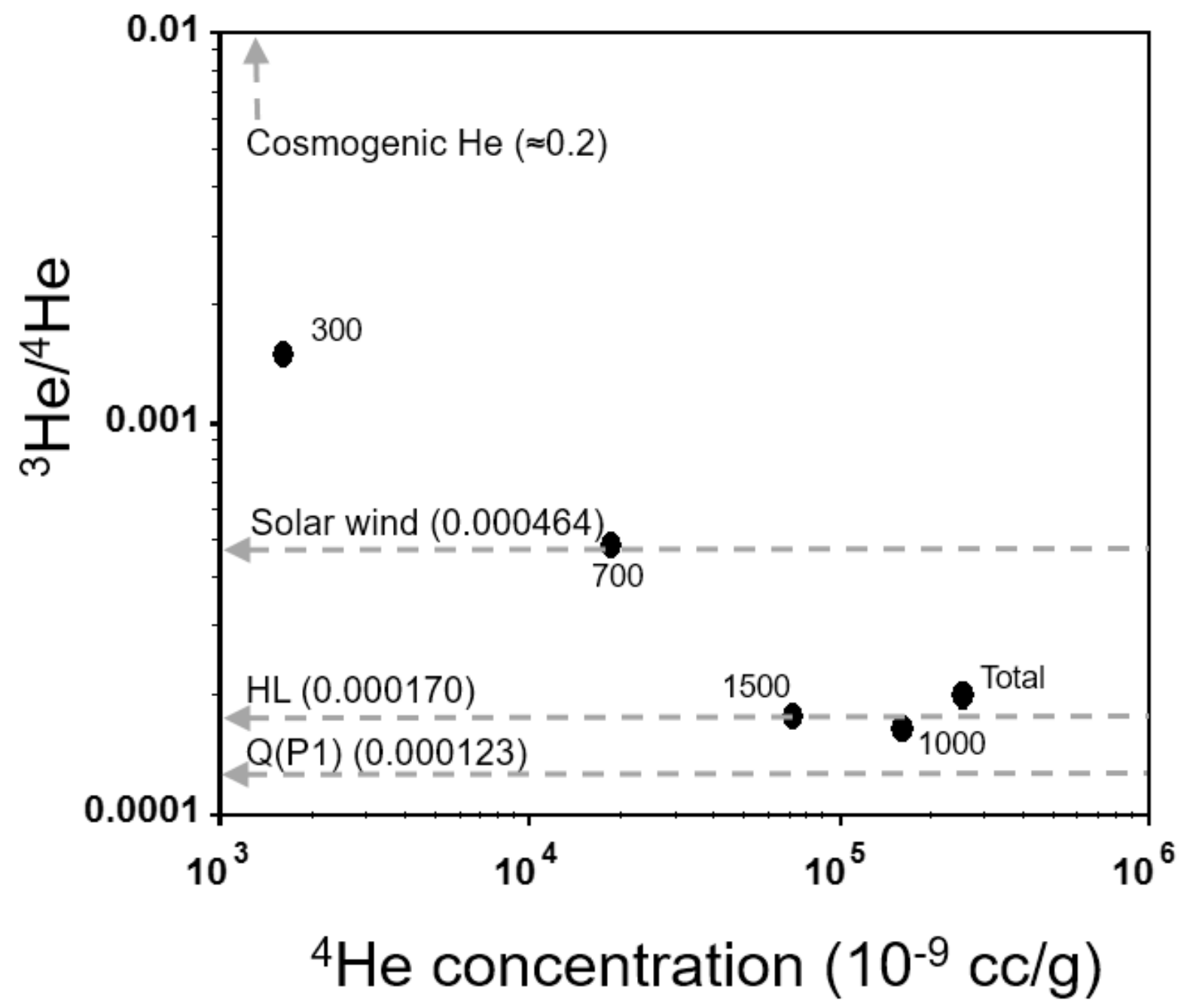

Fig. 12. Plot of ${ }^{3} \mathrm{He} /{ }^{4} \mathrm{He}$ versus ${ }^{4} \mathrm{He}$ concentration. Numbers adjacent to solid black data points indicate heating temperatures in ${ }^{\circ} \mathrm{C}$. Data sources: Solar wind (Heber et al., 2009), HL (Huss and Lewis, 1994), Q (Busemann et al., 2000). 

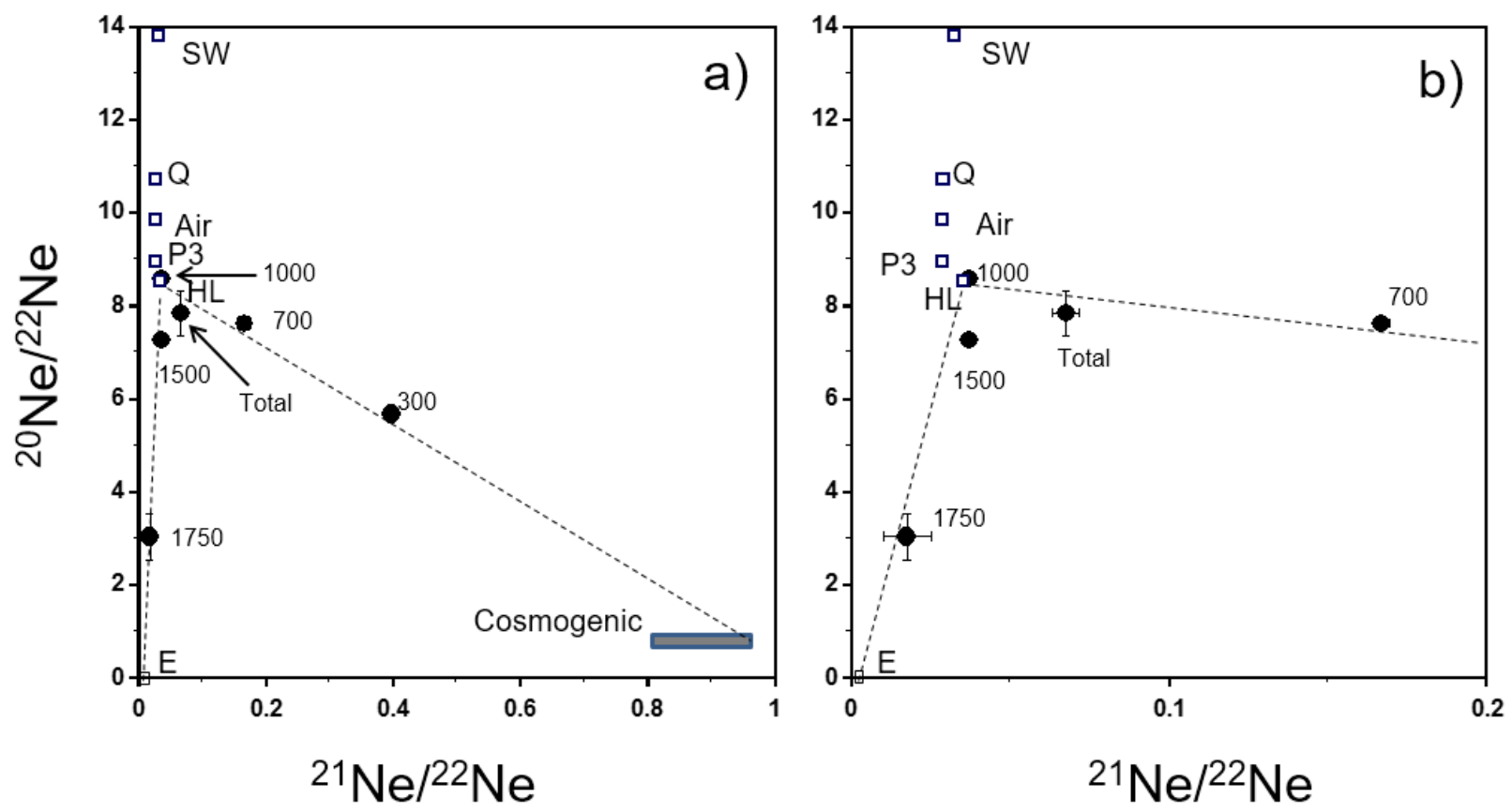

Fig. 13. a) and b): Neon three-isotope plot. Numbers adjacent to solid black data points indicate heating temperatures in ${ }^{\circ} \mathrm{C}$. Data sources: (Ott, 2002), Solar wind (SW) (Heber et al., 2009), Air (Eberhardt et al., 1965), E (Lewis et al., 1994), HL and P3 (Huss and Lewis, 1994), Q (Busemann et al., 2000). 


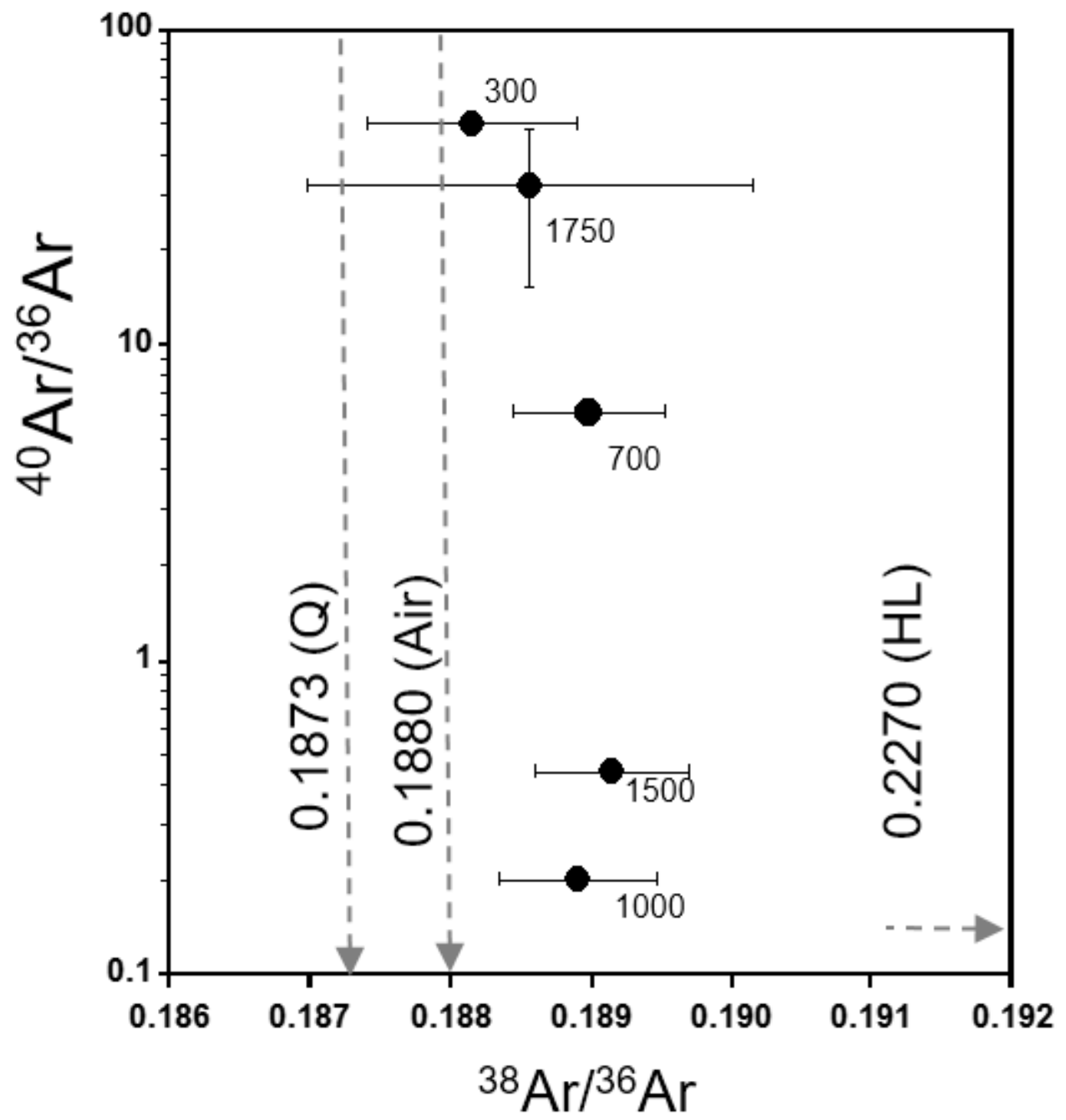

Fig. 14. Plot of ${ }^{40} \mathrm{Ar} /{ }^{36} \mathrm{Ar}$ versus ${ }^{38} \mathrm{Ar} /{ }^{36} \mathrm{Ar}$. Numbers adjacent to solid black data points indicate heating temperatures in ${ }^{\circ} \mathrm{C}$. Data sources: Air (Nier, 1950), HL (Huss and Lewis, 1994), Q (Busemann et al., 2000). 

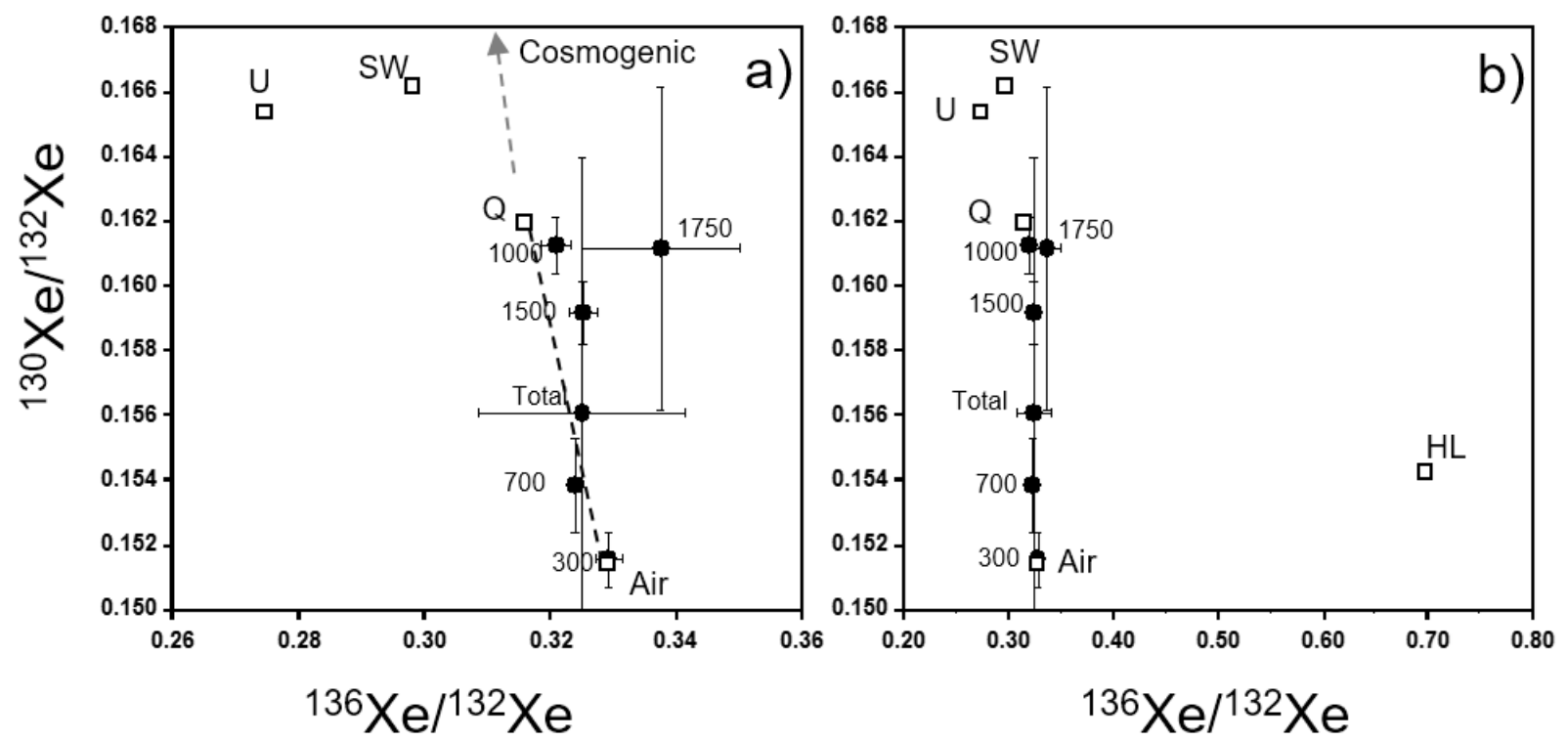

Fig. 15. a) and b): Plot of ${ }^{130} \mathrm{Xe} /{ }^{132} \mathrm{Xe}$ versus ${ }^{136} \mathrm{Xe} /{ }^{132} \mathrm{Xe}$. b) shows wider range including Xe-HL. Numbers adjacent to solid black data points indicate heating temperatures in ${ }^{\circ} \mathrm{C}$. Data sources: Huss and Lewis (1994), Ott (2002), Ozima and Podosek (2002).
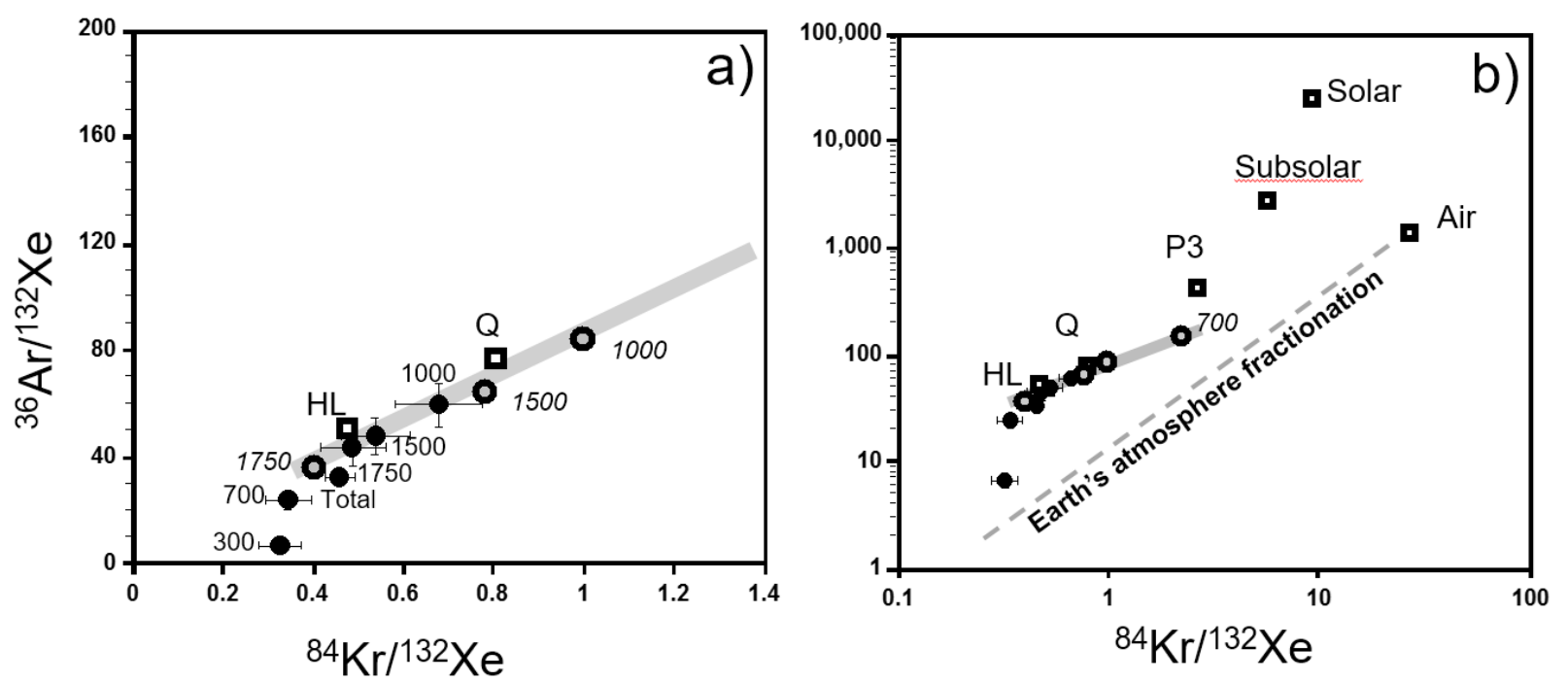

Fig. 16. a) and b): Plot of ${ }^{36} \mathrm{Ar} /{ }^{132} \mathrm{Xe}$ versus ${ }^{84} \mathrm{Kr} /{ }^{132} \mathrm{Xe}$. Filled circles represent measured ratios including Q, HL and air contamination, whereas gray filled circles show those of the Q component listed in Table 4. Numbers adjacent to data points indicate heating temperatures in ${ }^{\circ} \mathrm{C}$. 
Data sources: Ott (2002) for endmembers, Nagao (1994) for terrestrial atmosphere fractionation trend.

Table 4. Concentrations of cosmogenic, HL, E, Q and atmospheric components in the Sharps clast acid residue.

\begin{tabular}{|c|c|c|c|c|c|c|c|c|c|c|c|c|c|c|c|}
\hline Temp. & {$\left[{ }^{3} \mathrm{He}\right]_{\operatorname{cosm}}$} & {$\left[{ }^{4} \mathrm{He}\right]_{\mathrm{HL}}$} & {$\left[{ }^{4} \mathrm{He}\right]_{Q}$} & {$\left[{ }^{20} \mathrm{Ne}\right]_{\mathrm{HL}}$} & {$\left[{ }^{20} \mathrm{Ne}\right]_{Q}$} & $\left.{ }^{21} \mathrm{Ne}\right]_{\text {coss }}$ & {$\left[{ }^{22} \mathrm{Ne}\right]_{\mathrm{E}}$} & {$\left[{ }^{36} \mathrm{Ar}\right]_{\mathrm{HL}}$} & {$\left[{ }^{36} \mathrm{Ar}\right]_{\mathrm{Q}}$} & {$\left[{ }^{84} \mathrm{Kr}\right]_{\mathrm{HL}}{ }^{1)}$} & {$\left[{ }^{84} \mathrm{Kr}\right]_{\mathrm{Q}}$} & {$\left[{ }^{84} \mathrm{Kr}\right]_{\text {Air }}$} & {$\left[{ }^{132} \mathrm{Xe}\right]_{\mathrm{HL}}{ }^{1)}$} & {$\left[{ }^{132} \mathrm{Xe}\right]_{Q}$} & {$\left[{ }^{132} \mathrm{Xe}\right]_{\text {Air }}$} \\
\hline${ }^{\circ} \mathrm{C}$ & \multicolumn{15}{|c|}{$10^{-9} \mathrm{~cm}^{3} \mathrm{STP} / \mathrm{g}$} \\
\hline 300 & 2.15 & 1600 & ND & 52 & ND & 3.72 & ND & 11 & 506 & ND & 12 & 14 & ND & ND & 80 \\
\hline 700 & 5.92 & 18600 & ND & 141 & ND & 2.56 & ND & 76 & 1685 & ND & 26 & ND & ND & 11 & 64 \\
\hline 1000 & ND & 164000 & ND & 841 & ND & 0.10 & ND & 172 & 4011 & ND & 48 & ND & ND & 48 & 23 \\
\hline 1500 & 0.93 & 72400 & ND & 494 & ND & 0.47 & 9.65 & 105 & 2124 & ND & 26 & ND & 0.6 & 33.2 & 13.2 \\
\hline 1750 & ND & 230 & ND & 5 & ND & 0.01 & 0.96 & 3 & 79 & ND & 1 & ND & ND & 2 & ND \\
\hline Total & 9.00 & 257000 & ND & 1533 & ND & 6.86 & 10.61 & 366 & 8404 & ND & 113 & 14 & ND & 95 & 180 \\
\hline \multicolumn{2}{|c|}{$\overline{\mathrm{HL}}\left(\text { estimate from }\left[{ }^{36} \mathrm{Ar}\right]_{\mathrm{HL}}\right)^{2)}$} & 2200000 & & 3550 & & & & $=366$ & & 4 & & & 7 & & \\
\hline \multicolumn{2}{|c|}{$\mathrm{Q}\left(\text { estimate from }\left[{ }^{36} \mathrm{Ar}\right]_{\mathrm{Q}}\right)^{3)}$} & & 41300 & & 354 & & & & $=8404$ & & 90 & & & 111 & \\
\hline
\end{tabular}

ND: Could not be determined because of low concentrations.

1) $\left[{ }^{84} \mathrm{Kr}\right]_{\mathrm{HL}}$ and $\left[{ }^{132} \mathrm{Xe}\right]_{\mathrm{HL}}$ could not be determined except a trace $\mathrm{Xe}$ at $1500{ }^{\circ} \mathrm{C}$.

2) ${ }^{4} \mathrm{He}:{ }^{20} \mathrm{Ne}:{ }^{36} \mathrm{Ar}:{ }^{84} \mathrm{Kr}:{ }^{132} \mathrm{Xe}=6000: 9.7:=1: 0.0096: 0.02$ (for HL; Ott, 2002)

${ }^{3)}{ }^{4} \mathrm{He}:{ }^{20} \mathrm{Ne}:{ }^{36} \mathrm{Ar}:{ }^{84} \mathrm{Kr}:{ }^{132} \mathrm{Xe}=4.92: 0.0421:=1: 0.0107: 0.0132$ (for Q; Ott, 2002)

Following ratios for endmembers are used: ${ }^{3} \mathrm{He}:{ }^{4} \mathrm{He}=0.2: 1$ (cosmogenic) and $0.00017: 1$ (HL); ${ }^{20} \mathrm{Ne}:{ }^{21} \mathrm{Ne}:{ }^{22} \mathrm{Ne}=0.85: 0.90: 1$ (cosmogenic), $0: 0: 1$ (Ne-E) and $8.5: 0.036: 1$ (HL); ${ }^{36} \mathrm{Ar}:{ }^{38} \mathrm{Ar}=1: 0.1873(\mathrm{Q})$ and $1: 0.2268(\mathrm{HL}) ;{ }^{78} \mathrm{Kr}:{ }^{84} \mathrm{Kr}:{ }^{86} \mathrm{Kr}=0.0060: 1: 0.3095(\mathrm{Q})$, $0.0042: 1: 0.3623$ (HL), and $0.0061: 1: 0.3052$ (air) $;{ }^{124} \mathrm{Xe}:{ }^{132} \mathrm{Xe}:{ }^{136} \mathrm{Xe}=0.0046: 1: 0.3164$ (Q), $0.0084: 1: 0.6991$ (HL) and $0.0035: 1: 0.3294$ (air).

Data sources: Nier (1950), Ott (2002), Lewis et al. (1994), Huss and Lewis (1994), Busemann et al. (2000), Ozima and Podosek (2002). 


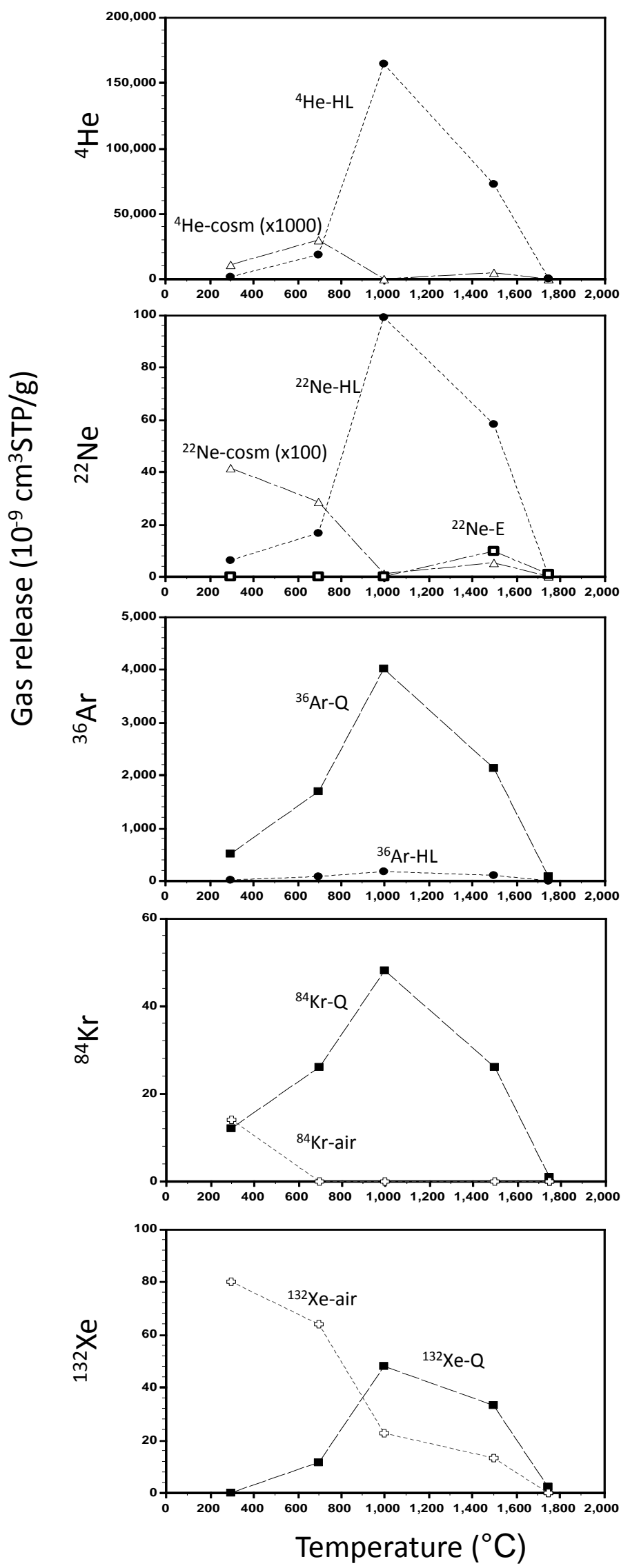


Fig. 17. Release profiles of noble gas isotopes of different components, i.e., cosmogenic, HL, E, Q and air contamination presented in Table 4.

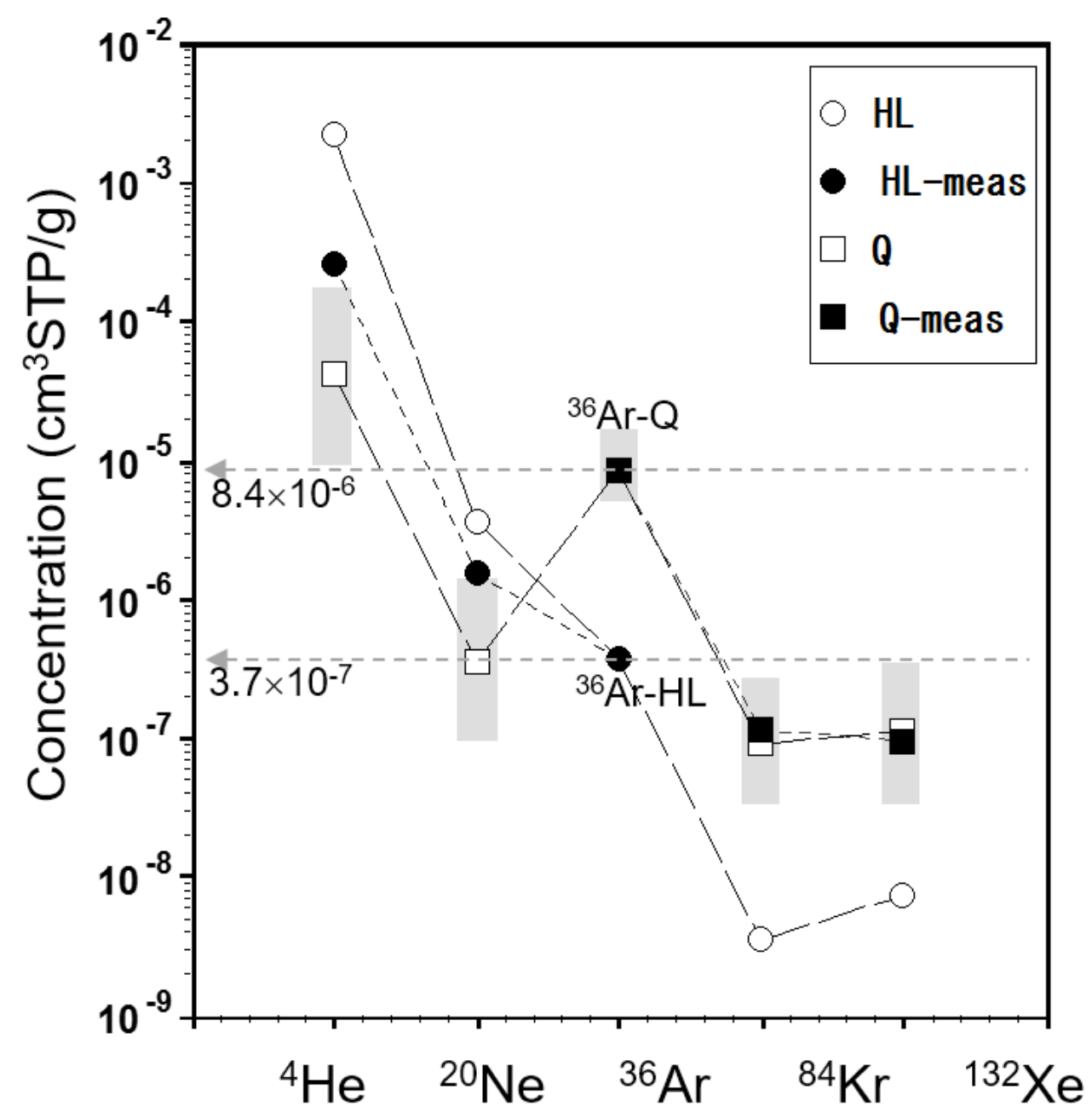

Fig. 18. Measured concentrations of ${ }^{4} \mathrm{He},{ }^{20} \mathrm{Ne},{ }^{36} \mathrm{Ar},{ }^{84} \mathrm{Kr}$ and ${ }^{132} \mathrm{Xe}$ compared with the concentrations for HL and Q components from the literature. Elemental ratios of HL and Q in the literature are normalized to the measured ${ }^{36} \mathrm{Ar}$ concentrations of $\mathrm{Q}\left(8.4 \times 10^{-6} \mathrm{~cm}^{3} \mathrm{STP} / \mathrm{g}\right)$ and $\mathrm{HL}$ $\left(3.7 \times 10^{-7} \mathrm{~cm}^{3} \mathrm{STP} / \mathrm{g}\right)$ in the sample (see text). Gray rectangles show concentration ranges of Qgas reported for $\mathrm{HF} / \mathrm{HCl}$ etched residues (Busemann et al., 2000). Elemental ratios of HL and Q are shown in the caption of Table 4 . 

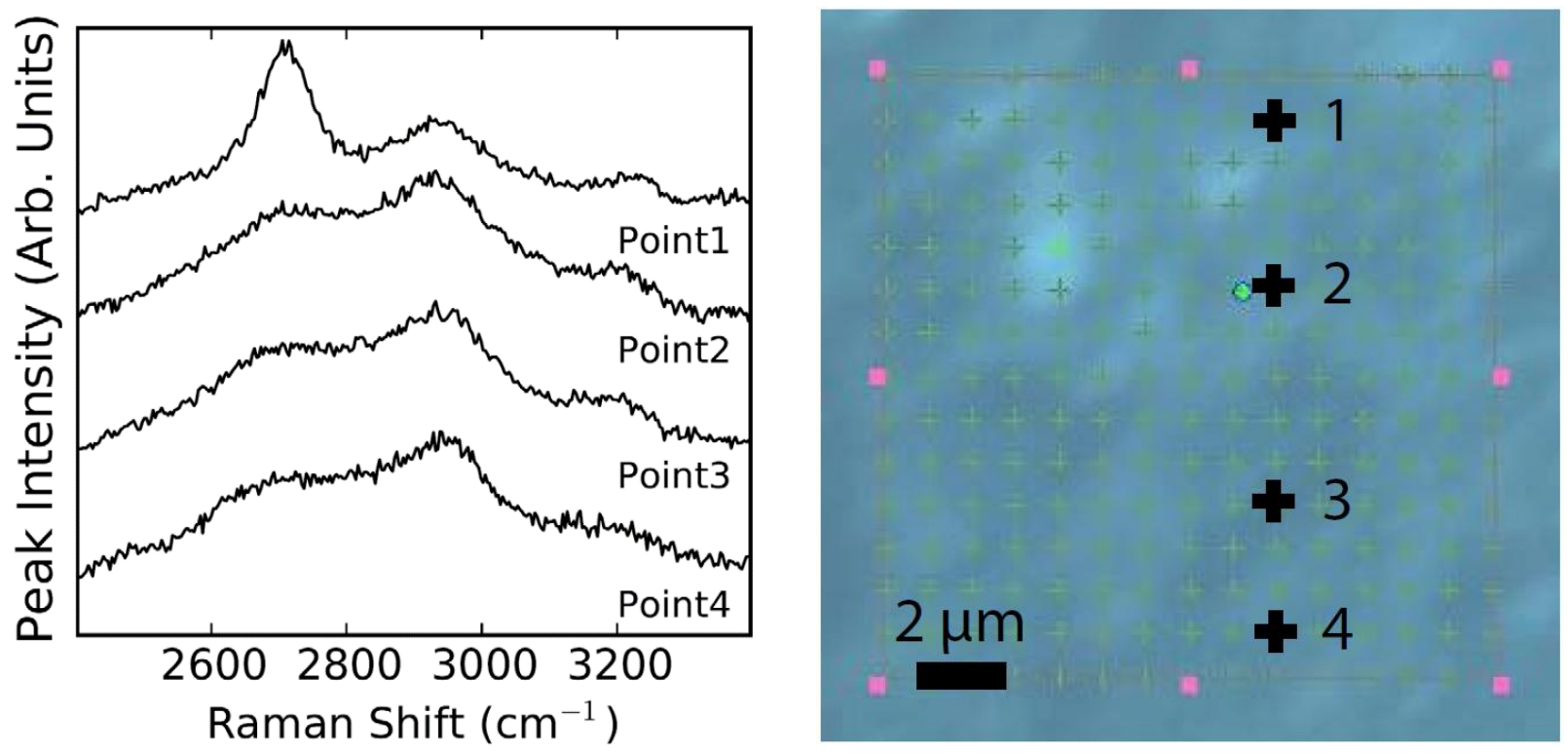

Fig. 19. Raman spectra of the Sharps clast in the second-order region showing the S1 and S2 bands at $2700 \mathrm{~cm}^{-1}$ and $2900 \mathrm{~cm}^{-1}$, respectively. In some places (e.g., Point 1) the $\mathrm{S} 1$ intensity is notably higher than S2, reflecting a higher metamorphic grade than the majority of the clast IOM. 